\title{
Performance Based Road Asset Management System, with a case study: Abu Dhabi
}

by

\author{
Abdulla Salem Al-Kathairi
}

A thesis submitted to the Faculty of Graduate and Postdoctoral Affairs in partial fulfillment of the requirements for the degree of

Doctor of Philosophy

in

Transportation Engineering

Carleton University

Ottawa, Ontario

(C) 2014

Abdulla Salem Al-Kathairi 


\section{Abstract}

It is common for road authorities to adopt the traditional method of road maintenance contracts that include a typical arrangement of relationships between the Client, the Contractor and the Consultant. The traditional method of road maintenance contracts has been found ineffective and expensive which caused difficulties in controlling road quality, time to finish, and cost of construction.. Escalation of cost and delays in completion of maintenance projects coupled with, lack of proper training in the public sector are the main problems associated with traditional method of contracting.

The Performance Based Contracts (PBC) has been recognized as an efficient method of contracts addressing the limitations of the traditional contracting methods. Unlike the traditional method of contracting, in $\mathrm{PBC}$ the contractor is generally free to make the decisions of "what to do", "when" and "how" as long as the specified performance measures are achieved. This will lead to assign the responsibility of completing the contract with its risk of failure totally to the contractors. It has been a challenge for contractors to successfully manage the entire risk of projects particularly with limited resources, limited understanding of PBC, lack of skillful staff, and poor management. In addition, unavailability of accurate pavement condition prediction models to understand and predict pavement performance results in a higher risk to the contractor in PBC.

This thesis identifies the main problems and challenges for successfully adopting PBC are discussed and analyzed. In order to assist contractors as well as road managers a methodological framework is developed and examined in this thesis. The developed framework necessitates the identification of many cornerstones to effectively manage 
pavement conditions in the Emirate of Abu Dhabi. The main components of the developed framework include 1) developing a robust database of detailed knowledge of the road network, 2) developing practical models to predict the present and future conditions of the pavement, and 3) developing robust models to optimize maintenance strategies. The developed framework was applied on a case study using data from the City of Abu Dhabi. 


\section{Acknowledgements}

I would like to thank my thesis supervisor Professor Abd El Halim Omar Abd El Halim for his patience and continued support throughout this research. I have learned a lot through his leadership and wisdom. His valuable guidance, generous support, motivation, and inspirational attitude are vital to achieving this degree. A special thanking is due to Carleton University for providing me with the opportunity to complete my Ph.D., and achieve my dream.

Also, I would like to thank my examination committee members including Professor Dr. Ing. Ibrahim A. Al-Dimeery, Professor Roshdy Hafez, Professor Mohammad Rayhani, and Professor Michael C. Ircha for their valuable comments and suggestions which added value and improvement to my thesis. Also, I am thankful for my fellow students at Carleton University for their encouragement and support during my years at Carleton.

I am also grateful to the Chairman of the Federal Transport Authority - Land \& Maritime, United Arab Emirates for supporting to make this research possible; also grateful for the continuous support from the Government of Abu Dhabi throughout my studies at Carleton University. Many thanks to Abu Dhabi Municipality for providing the data required for this research.

I am deeply indebted to the late, His Highness Sheikh Zayed bin Sultan Al Nahyan (May Allah bless him and rest his soul in peace), founder of the UAE who created ample of opportunities to educate and train his people. I would like to quote his saying...... "Unless wealth is used in conjunction with knowledge to plan for its use, and unless there are enlightened intellects to direct it, its fate is to diminish and to disappear. The greatest 
use that can be made of wealth is to invest it in creating generations of educated and trained people."

Last but not least, I owe an eternal debt of gratitude and appreciation to my family for their unconditional love, support, encouragement and patience. It would have been a challenge to complete this research without continuous support from my family. I really place a high value to unlimited supply of prayers from my mother, my wife and my friends. My family has always been supportive of me, and I am truly grateful. A special love and thanks to my son Salem who sacrificed to allow me to pursue my goals.

I would like to thank everyone who directly or indirectly contributed in shaping up this dissertation work. 


\section{Dedication}

I dedicate this thesis to my father, may Almighty Allah bless him and rest his soul in peace. 


\section{Table of Contents}

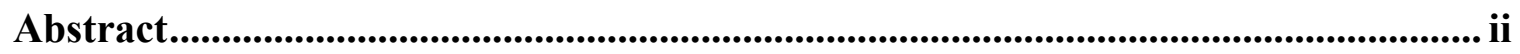

Acknowledgements .................................................................................................. iv

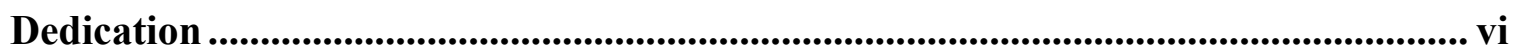

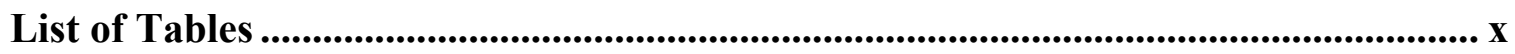

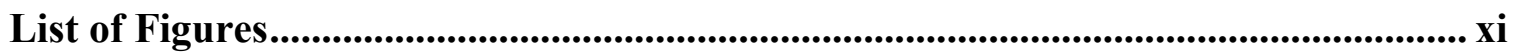

List of Appendices .......................................................................................................... xiii

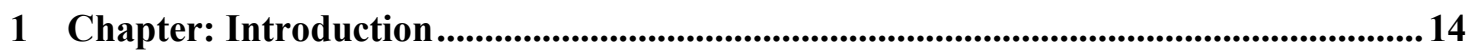

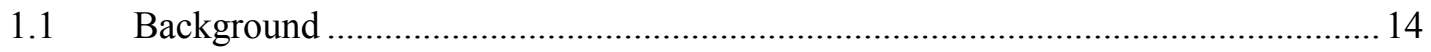

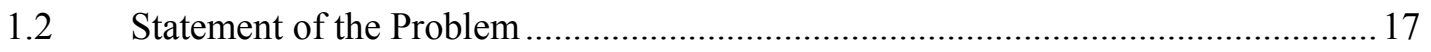

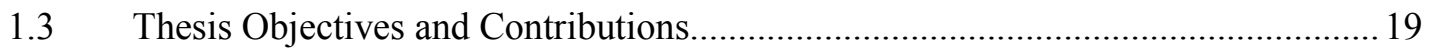

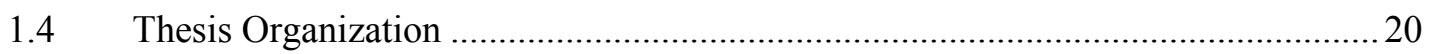

2 Chapter: Literature Review …...................................................................................................22

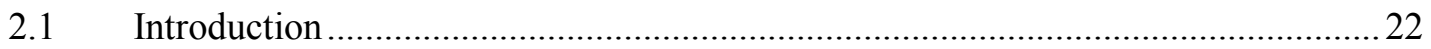

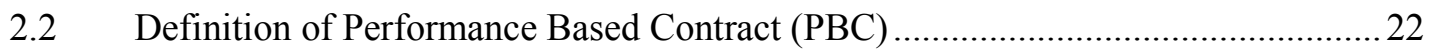

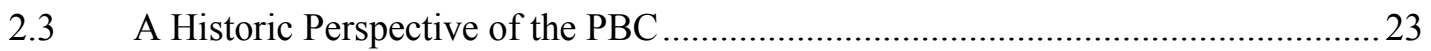

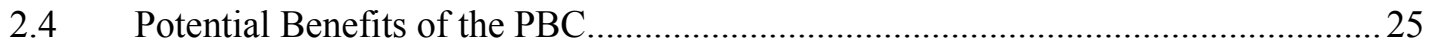

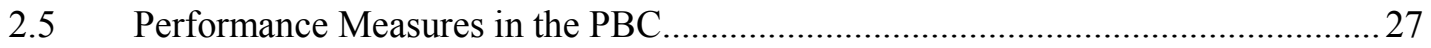

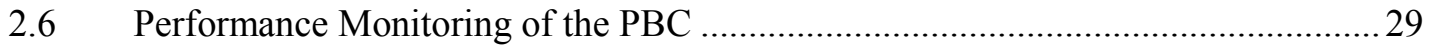

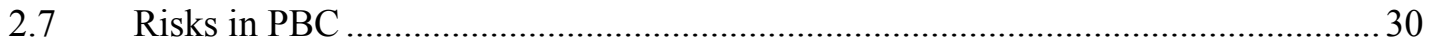

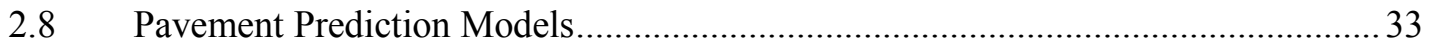

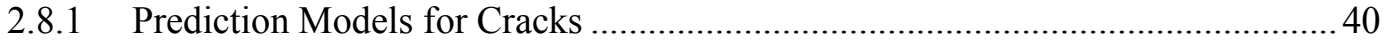

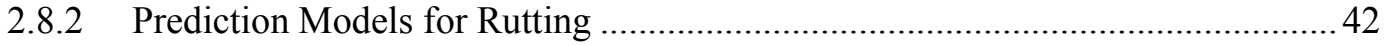

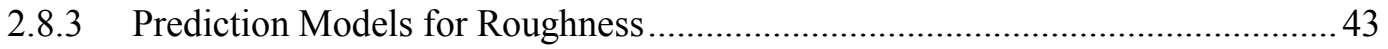

2.9 Optimization of Pavement Maintenance Strategies ............................................. 46

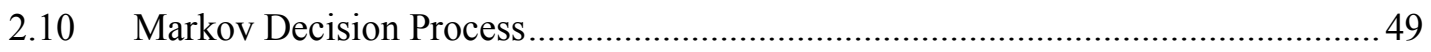


2.11 Summary of the Literature Review

3 Chapter: Data of Pavement Condition and Maintenance Treatment in Abu Dhabi .. 54

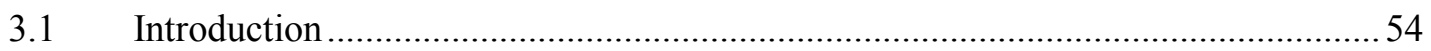

3.2 Pavement Data Collection Equipment and Methodology ......................................... 54

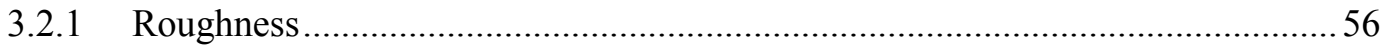

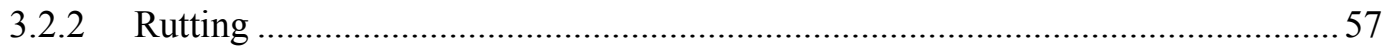

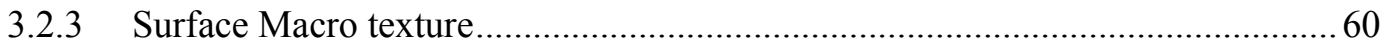

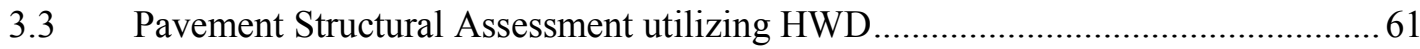

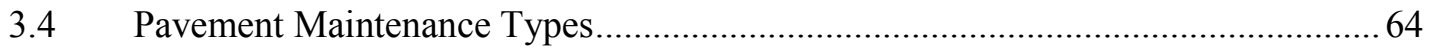

4 Chapter: Development of Pavement Condition Prediction Model ................................68

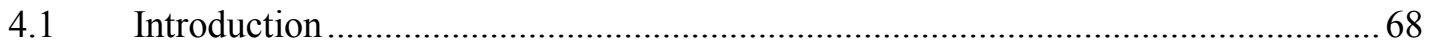

4.2 Comparison between Markov Chain and Regression Modeling ............................... 70

4.3 Data Used to Develop Pavement Prediction Models for Abu Dhabi ........................ 71

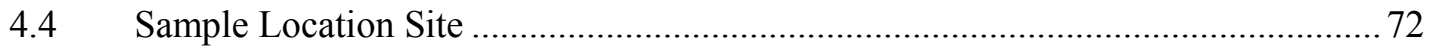

4.5 Pavement Prediction Models for Abu Dhabi .......................................................... 75

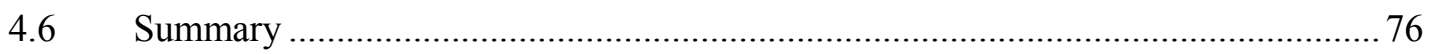

5 Chapter: Optimization Model .................................................................................................. 77

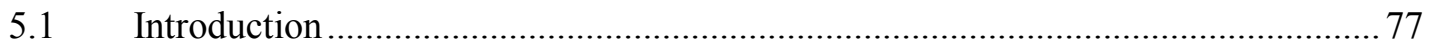

5.2 Development of an Optimization Model ............................................................ 78

5.2.1 Identifying Road Network Information ......................................................... 79

5.2.2 Evaluation of Current Needs/Performance Targets …....................................... 82

5.2.3 Identification of Maintenance Treatments ....................................................... 83

5.2.4 Prediction of Future Road Conditions ……....................................................... 84

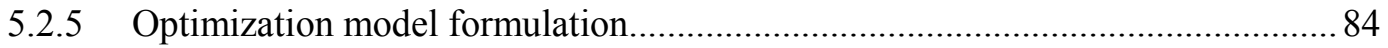

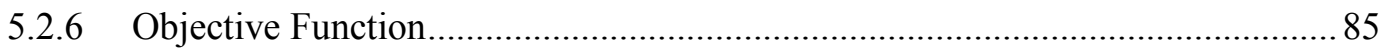

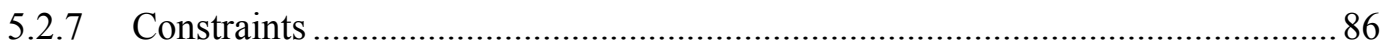




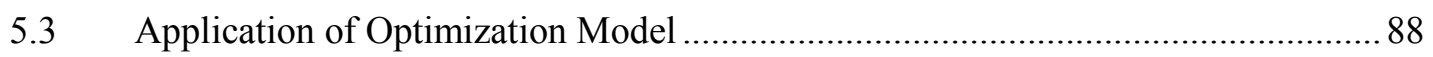

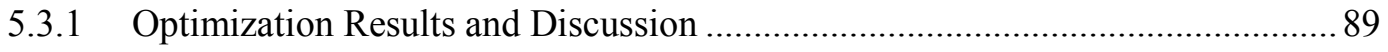

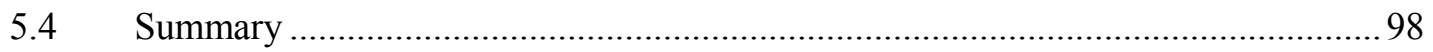

6 Chapter: Performance Based Road Asset Management Framework for Abu Dhabi.99

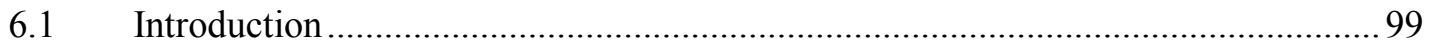

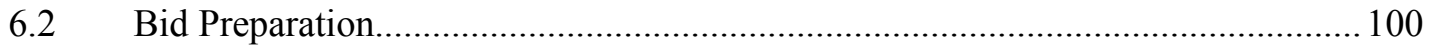

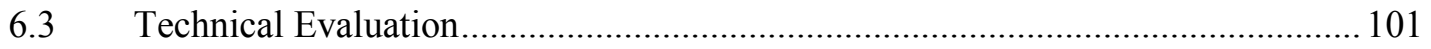

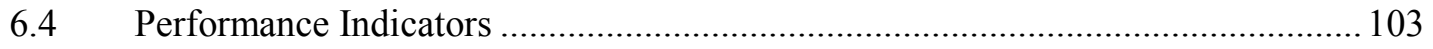

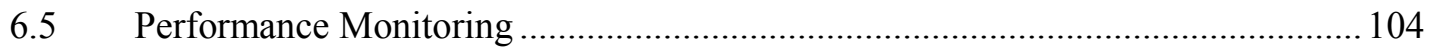

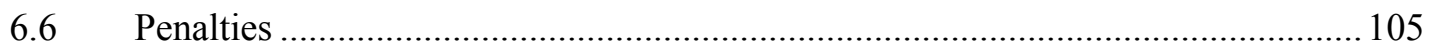

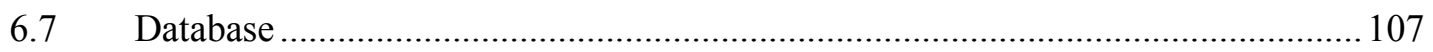

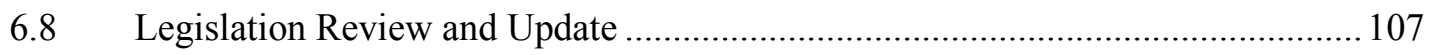

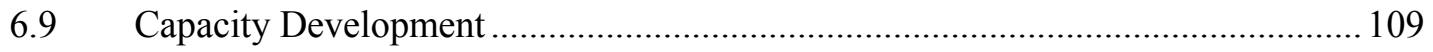

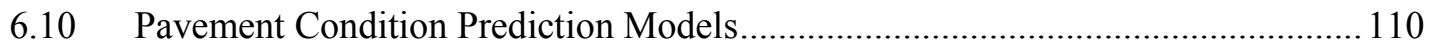

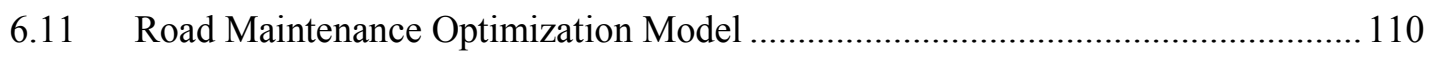

7 Chapter: Conclusions and Recommendations ................................................................. 111

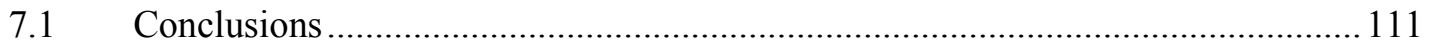

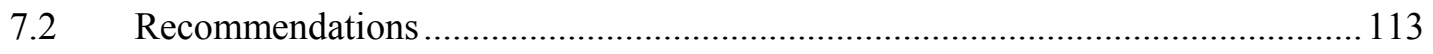

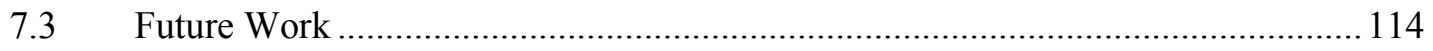

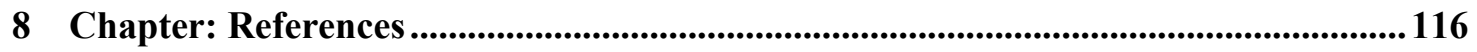

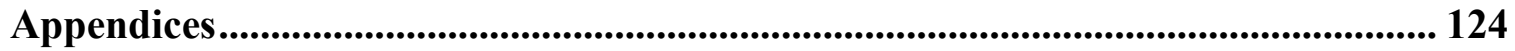




\section{List of Tables}

Table 2.1 Cost Savings by Country for Using PBC (World Bank 2005) ..................... 26

Table 2.2 An example of Performance Measures for a project in British Columbia........ 29

Table 2.3 An example of Performance Measures for projects in Latin American ........... 29

Table 2.4 Deterioration Modeling Approaches ............................................................ 36

Table 2.5 Types of Performance Models Deterministic Models .................................. 36

Table 2.6 Advantages and Disadvantages of different Models ................................... 38

Table 4.1 Chainage for Westbound Carriageway ..................................................... 74

Table 4.2 Chainage for Eastbound Carriageway …................................................. 74

Table 4.3 Influence Factors Classes Used in Default Prediction Models........................ 75

Table 4.4 Pavement Condition Index Prediction Models ............................................. 76

Table 5.1 Pavement Areas in Emirate of Abu Dhabi.................................................... 81

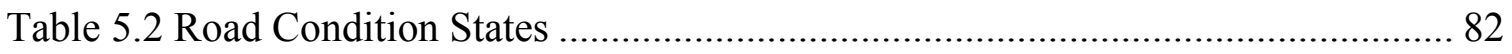

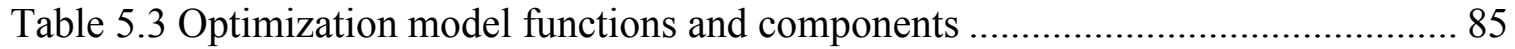

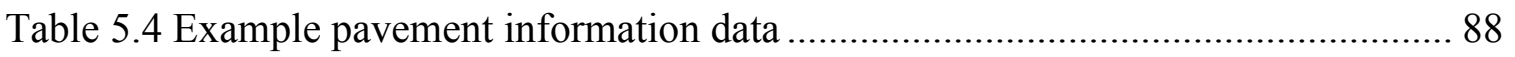

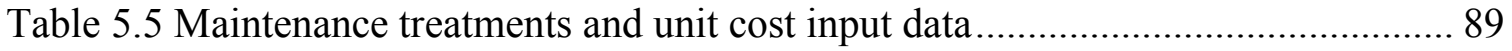

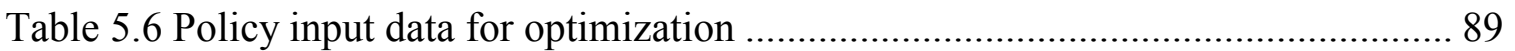

Table 5.7 Results of optimization model for pavement section 1 ............................... 91

Table 5.8 Results of optimization model for pavement section $2 \ldots \ldots \ldots \ldots \ldots \ldots \ldots \ldots \ldots \ldots \ldots . . . . . \ldots 2$

Table 5.9 Results of optimization model for pavement section 3 .............................. 93

Table 6.1 Proposed evaluation criteria to award PBC in Abu Dhabi ............................ 102

Table 6.2 Proposed Performance Indicators for PBC for Abu Dhabi........................... 103

Table 6.3 Proposed penalties for failure to meet the performance criteria .................... 106 


\section{List of Figures}

Figure 1.1 Map showing three zones of road network of the Emirate of Abu Dhabi....... 14

Figure 1.2 Illustration of the traditional method of maintenance contracts ..................... 16

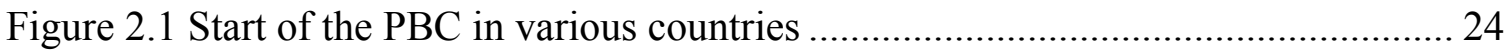

Figure 2.2 PBC implemented Worldwide............................................................. 25

Figure 2.3 Distribution of Risks with Different Approaches.................................... 31

Figure 2.4 Deterioration Modeling and Impact of Maintenance ................................... 34

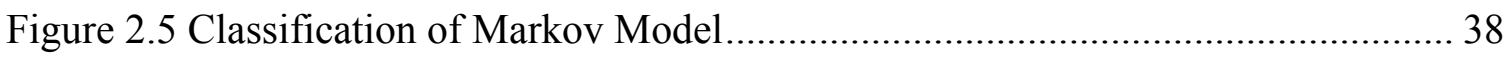

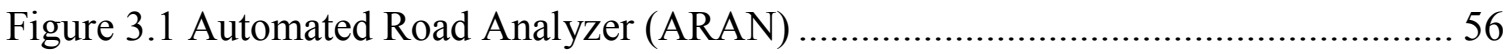

Figure 3.2 Rut profile as a result of densification................................................... 58

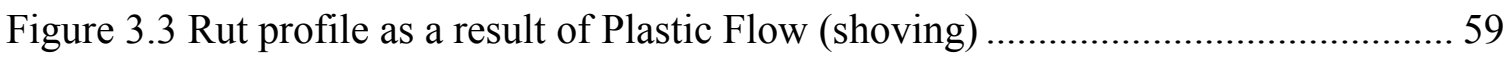

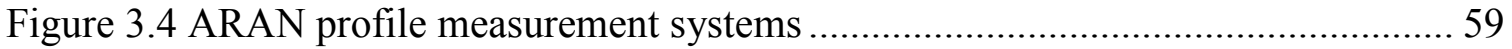

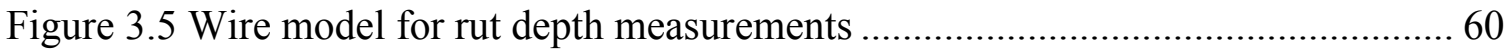

Figure 3.6 Mean Profile Depth (MPD) .................................................................. 61

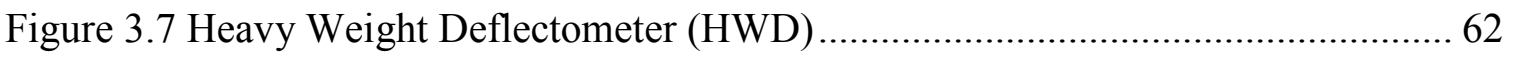

Figure 3.8 Vehicle used for Geocoded video logging ........................................... 63

Figure 3.9 Types of pavement maintenance as per time and pavement condition .......... 65

Figure 3.10 Typical Variation in Pavement Conditions as function of Time .................. 67

Figure 3.11 Deterioration curves with and without preventive maintenance .................. 67

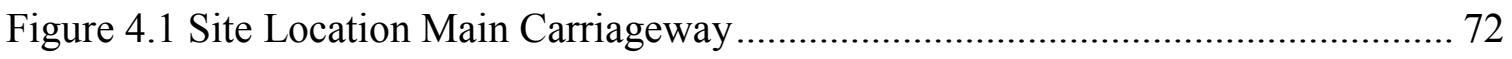

Figure 4.2 Lane Designation for Main Carriageway Data Collection ............................ 73

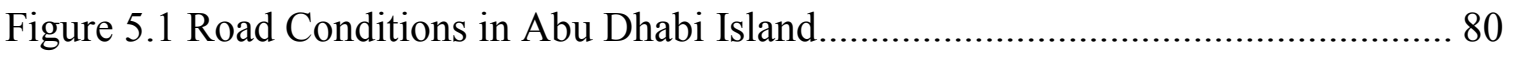

Figure 5.2 Road Conditions in Abu Dhabi Mainland .............................................. 81 
Figure 5.3 Pavement condition states and maintenance activities .............................. 83

Figure 5.4 Pavement Condition Index (PCI) for pavement section 1 (Class 3) .............. 94

Figure 5.5 Estimated Maintenance cost for pavement section 1 (Class 3) ..................... 95

Figure 5.6 Pavement Condition Index (PCI) for pavement section 2 (Class 2) .............. 95

Figure 5.7 Estimated Maintenance cost for pavement section 2 (Class 2) .................... 96

Figure 5.8 Pavement Condition Index (PCI) for pavement section 3 (Class 1) .............. 96

Figure 5.9 Estimated Maintenance cost for pavement section 3 (Class 1) .................... 97

Figure 5.10 Total Estimated Maintenance cost for all three sections ........................... 97

Figure 6.1 Proposed framework for implementing PBC ........................................ 99 


\section{List of Appendices}

Appendix A: Detail Results of Regression Analysis.............................124

Appendix B: Code of the Optimization Model.................................. 136 


\section{Chapter: Introduction}

\subsection{Background}

The Emirate of Abu Dhabi is one of the seven emirates or states of the United Arab Emirates (UAE). The Abu Dhabi Emirate is located in the western and southwestern part of the UAE along the southern cost of the Arabian Gulf. The total area of the Abu Dhabi Emirate is 59,402 square $\mathrm{km}$ which represents about $87 \%$ of the total area of the UAE (SCAD, 2011). The Emirate of Abu Dhabi has over 35,000 km of roads with the highways composing of $10,363 \mathrm{~km}$, and local and internal roads $25,000 \mathrm{~km}$. The roads in the Emirate of Abu Dhabi are divided into these three regions or zones. Figure 1.1. Zone 1 includes the roads in Abu Dhabi city and suburban areas, Zone 2 is the Eastern Region that includes roads in Al Ain city and areas around Al Ain while Zone 3 is the Western Region or Al Ghrabia that includes roads to the West of Abu Dhabi.

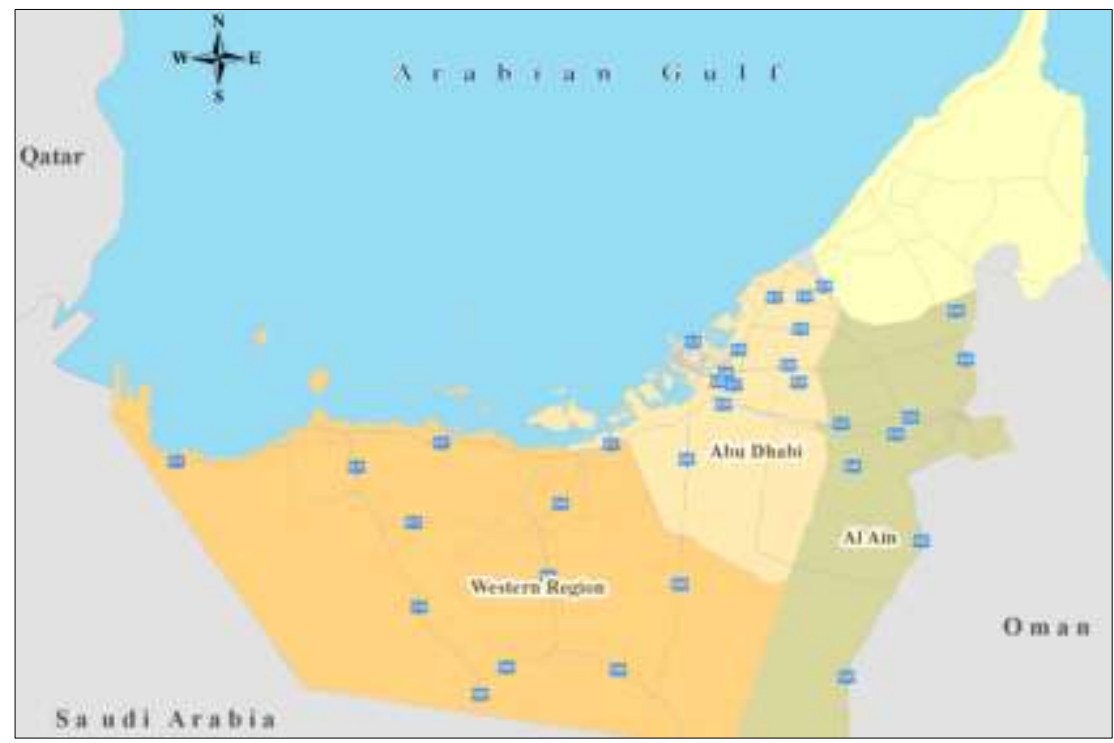

Figure 1.1 Map showing three zones of road network of the Emirate of Abu Dhabi Source: Department of Transport Abu Dhabi, 2014 
The population of the Abu Dhabi Emirate has been growing rapidly, about 7 percent annual growth over the last five years. According to the Statistical Center of Abu Dhabi (SCAD), in 2012 the estimated population of the Abu Dhabi Emirate was over 2.4 million. There has been an unprecedented increase in the traffic volume over recent years. The number of motor vehicles registered in the Abu Dhabi Emirate has reached 878,897 vehicles in 2013, about 4 vehicles per 10 habitants.

Currently, the road network in the Emirate of Abu Dhabi is the only option to serve the growing needs of the transportation from the public and private sectors. Other modes, such as rail are in the process of development. Therefore, maintaining roads in the Emirate of Abu Dhabi at a high level of service is greatly needed.

The road authorities (Department of Transport and Municipalities) are responsible for road maintenance in the Emirate of Abu Dhabi. It is very common for these authorities to adopt the traditional method of maintenance contracts illustrated in Figure 1.2. As shown in this figure, in traditional contracting method mostly two types of mechanisms are adopted. In the first type, Client, Contractor, and Consultant (Client Representative) work together. The Client refers to the road authorities and Consultants are hired to represent the Client. Consultants supervise the Contractors on the behalf of Client, however, Client can also instruct to the Contractors. In the second type of the traditional contracting method as shown in Figure 1.2 Client, Contractor, Consultant (Client Representative), and Consultant (Contractor Representative) work together. In this type Contractor hires a Consultant to representative them and interact with the Client and representative of the Client. 

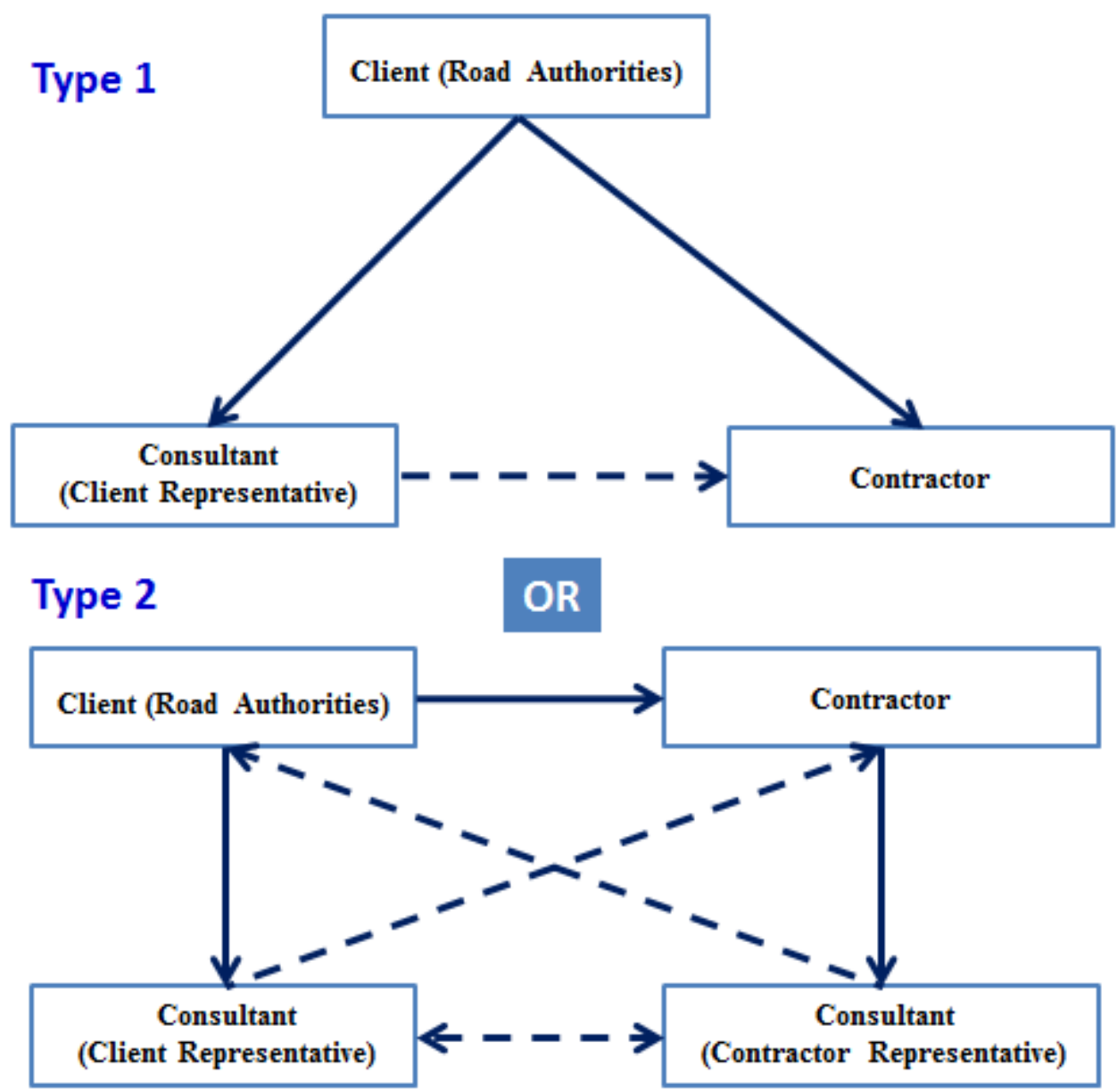

Figure 1.2 Illustration of the traditional method of maintenance contracts

The traditional method of maintenance contracts has been widely recognized as ineffective and expensive as the client (the road authority) has to supervise and pay both Consultant and Contractor (Piñero and Jesus 2004, Gupta et al., 2011). Sultana, et al., (2013) highlighted problems associated with traditional method, for instance, escalation of cost and time, poor quality of work and inadequate motivation of contractors, no clear risk sharing between the owner and the contractor, and delay in project completion.

Over the last two decades, road authorities in many countries have adopted Performance Based Contracts (PBCs). These are also called outcome based procurement, in reference to the competitive procurement processes that result in relationship where 
payments are made for measured outputs instead of the traditional way where the measurement and payment reflect the quantity of input (Giglio, J M., Ankner, W. D. 1998; Juan Carlos Piñero 2003; Manion and Tighe 2007; Queiroz 1999; World Bank 2005, and Gupta et al., 2011).

In traditional contracts, the client specifies techniques, materials, methods, quantities, along with the time period for the contract. In contrast, in $\mathrm{PBC}$, the client agency specifies minimum performance measures to be met or exceeded within the contract period. PBC is a type of contract in which payments are explicitly linked to the contractor successfully meeting or exceeding certain clearly defined minimum performance indicators (World Bank 2005).

One of the objectives of the $\mathrm{PBC}$ is to encourage contractor innovation and improve quality by applying value engineering and improved efficiency (Segal et al. 2003, Gupta et al., 2011). PBC approach has been successfully used in several highway maintenance and rehabilitation projects in many countries around the world, for example, Canada, UK, Australia, New Zealand, Brazil, and Argentina.

\subsection{Statement of the Problem}

The road authorities in the Emirate of Abu Dhabi are confronted with the challenge of maintaining the road network at its highest level of service while investing the minimum amount of money. To achieve this requires searching for and adopting efficient and cost effective road maintenance approaches. One such approach is the PBC to help to enhance the innovation and technologies related to road maintenance methods, 
reduction in cost, and substantial shift of risk from client to contractor, and increased overall satisfaction of the road users.

However, there are a number of challenges that could hinder the success of a PBC. For example, these challenges include selecting an appropriate contractor, existing legislation, technical capacity (skills and expertise) of the road authorities staff to define and monitor the performance standards, means or methodology to measure and report on performance standards, proper evaluation of the existing conditions of assets to establish baseline and performance and payment security, warranties, and penalties. Moreover, there is a lack of pavement condition prediction models to understand and predict pavement condition. As pavement deterioration follows a stochastic behavior (i.e. unpredictable and without a stable pattern or order). The deterioration process and the improvements due to maintenance and rehabilitation varies based on many factors such as the environment, loading, and data used for the modeling all of which result in a higher risk to the contractor in $\mathrm{PBC}$.

The risk of failure in PBC could be the result of contractor error in (i) predicting deterioration of contracted assets; (ii) determining appropriate design, specifications and materials; (iii) planning needed maintenance interventions; and (iv) estimating quantities. Therefore, there is a great need to develop a comprehensive framework to facilitate the selection of an effective maintenance and rehabilitation program that takes into account possible measures to address the potential challenges. 


\subsection{Thesis Objectives and Contributions}

The main objectives of this thesis are to identify the weaknesses of traditional contracting methods, study the PBC method, development of a framework suitable for Abu Dhabi conditions and perform a case study verifying its application. The achievement of these objectives led to several important contributions. The first contribution of this thesis is the development of a viable "framework for PBC" suitable for the special conditions of the United Arab Emirates. At present, there are no frameworks or models available to road authorities as well as contractors in Abu Dhabi, which provide methodologies to assist in the adoption of PBC. In order to assist the contractors as well as the road authorities in Abu Dhabi to provide a scientific approach to implement PBC for road maintenance, a methodological framework is proposed in this thesis. The developed methodological framework will greatly assist the contractors as well as the road authorities to model the pavement performance, and above all to optimize road maintenance strategies for effective utilization of resources to manage road maintenance contracts in Abu Dhabi.

The second contribution of the thesis is the formulation and verification of robust prediction and optimization models for pavement deterioration and rehabilitation costs and schedule. The success of letting long term maintenance work on a performance basis largely depends on the use of robust models such as the one presented in this thesis is a major achievement. The pavement condition prediction model and optimization model are developed using historical data provided by road authorities in Abu Dhabi. These models could assist in customizing the Highway Development and Management Model (HDM) for Abu Dhabi. 
The proposed framework necessitates the identification of many of the cornerstones to effectively manage the pavement condition in the Emirate of Abu Dhabi. The proposed framework was developed based on a thorough examination and assessment of the current traditional pavement management system implemented in Abu Dhabi in reference to the performance-based road maintenance contracts implemented in various countries around the world.

It should be noted that, while the entire thesis is focused on data and conditions obtained from the Emirate of Abu Dhabi for road pavement, the final developed framework can be used in other countries in the Gulf region. However, other assets, such as traffic signs, street lights, pavement marking, and barriers are important but were not considered explicitly in this study. In the development of the framework, the unit cost in Arab Emirates Dirham (AED) per km is considered in the optimization model included the pavement maintenance cost, the cost of roadside infrastructure, and road furniture costs. The proposed framework and modelling methodologies can be applied to other road assets. In addition, it can be utilized anywhere with proper modifications and careful selection of the parameters. Furthermore, the pavement prediction models developed in this thesis are limited to asphalt surfaced pavements. However, the optimization model and framework proposed in this research is also applicable to other types of the pavement such as reinforced concrete pavement.

\subsection{Thesis Organization}

This thesis consists of seven chapters Chapter One provides an introduction background to the research thesis, the statement of problem, main objectives, and 
contributions of the thesis. Chapter Two provides a literature review highlighting the concept of performance based contracts, different performance modeling background, and maintenance and rehabilitation programing and optimization.

Chapter Three explains the data used in this thesis. Chapter Four presents the pavement prediction models developed using data from the Emirate of Abu Dhabi. Chapter Five describes the optimization model developed to optimize the pavement maintenance strategies. Chapter Six introduces the proposed framework to adopt PBC in the Emirate of Abu Dhabi. Chapter Seven summarizes the main conclusions and recommendations of the thesis. 


\section{Chapter: Literature Review}

\subsection{Introduction}

This chapter presents a review of pertinent literature to understand certain key terms, basic concepts, challenges, and lessons learned from adopting performance based road maintenance contracts. The literature review further investigates how the progression of the body of knowledge that has evolved in the area of performance based contracts led to the proposed framework. In addition, the literature review related to pavement prediction models and optimization models is explained in this chapter.

\subsection{Definition of Performance Based Contract (PBC)}

Performance-based contracting (PBC) is defined as "a type of contract in which payment for the deliverable is explicitly linked to the contractor's successfully meeting or exceeding certain clearly defined performance indicators" (Sultana, et al., 2013). The main aspect of PBC is that contractors are paid based on the end result achieved and not by following any specified method of performing the work. Therefore, contractors are paid based on how well they meet the specified performance goals. Payments to contractors are made in installments, usually monthly. Incentives and penalties can be introduced and consist of increases or decreases of a payment due to their exceeding or not meeting the specified performance goal (NCHRP 2009, Ozbek et al., 2010, Gupta et al., 2011). Consequently, the PBC define success in terms of how well the contractor meets the set performance goals. The intent of $\mathrm{PBC}$ is to encourage contractor innovation and improve quality by encouraging value engineering and improved efficiency (Segal et 
al. 2003, Gupta et al., 2011). As in case of PBC the long term planning provides the contractor with enough time horizon to deploy new technologies.

PBC involves a significant shift away from more traditional approaches to the delivery and maintenance of road infrastructure and associated services by a shift from the situation where the client has responsibility for the design and supervision of construction and maintenance activities to a focus on the key outcomes that the client wishes to achieve and incentivizing the achievement of those outcomes.

There are many names for PBC used around the world and within certain states or provinces (NCHRP 2009, Gupta et al., 2011). These various names are:

- Performance-Based Maintenance Contract (United States)

- Performance Contract (Western Australia)

- Total Maintenance Contract (Texas)

- Performance-Specified Maintenance Contract (Australia and New Zealand)

- Asset Management Contract (originally more common abroad, but this term is now used in the United States).

- Contract for Rehabilitation and Maintenance (Argentina)

- Managing Agent Contract (United Kingdom)

- Area Maintenance Contract (Finland and Ontario, Canada)

\subsection{A Historic Perspective of the PBC}

The development of the PBC started in the late 1980s to early 1990's. British Columbia, Canada, was first province to contract a PBC in 1988. As shown in Figure 2.1, 
British Columbia was followed by Argentina, Australia, Uruguay, Brazil, United States of America, and New Zealand, (Zietlow 2005, Gupta et al., 2011, Sultana, et al., 2012).

\section{8 \\ 1996 \\ 1996 \\ 1996 \\ 1995 \\ 1990}

In 1998 New Zealand let its first PBC for the maintenance of 406 kilometers of national roads, later more PBC were introduced.

In the late 1996 Latin America such as Brazil, Chile, and Colombia started same time PBC, others like Ecuador, Guatemala, and Peru followed in starting PBC for

Uruguay and Montevideo both extended PBC in 1996. Ministry of Public Works in Uruguav started a program to introduce PBC for the maintenance of the

In the United States of America, the State of Virginia pioneered a Performance Contract called "Asset Management and Maintenance Contract" for the maintenance of 402 kilometers of Interstate Highways in 1996. Four years later

Australia started its first PBC in 1995 covering 459 kilometers of urban roads in Svdnev. Since then several new contracts have been implemented in New South

In the mid 1990's Argentina started PBC for a road of $1000 \mathrm{Km}$, using end result performance specifications for the maintenance services and a penalty system for not meeting the response times for rectifying deficiencies.

1988

First PBC was implemented in British Columbia in Canada, However, performance standards in this contract were more oriented towards work

Figure 2.1 Start of the PBC in various countries

Over the last decade adoption of PBC increased in many countries.

Figure 2.2 shows countries where $\mathrm{PBC}$ has been successfully implemented. It is quite apparent from figure 2.2 that there is an increasing trend in the adoption of $\mathrm{PBC}$ 
worldwide, with various degrees of adoption from countries that are preparing to adopt PBC to countries that are already established in their adoption of PBC. This trend highlights that $\mathrm{PBC}$ is an increasingly important maintenance delivery contractual format.

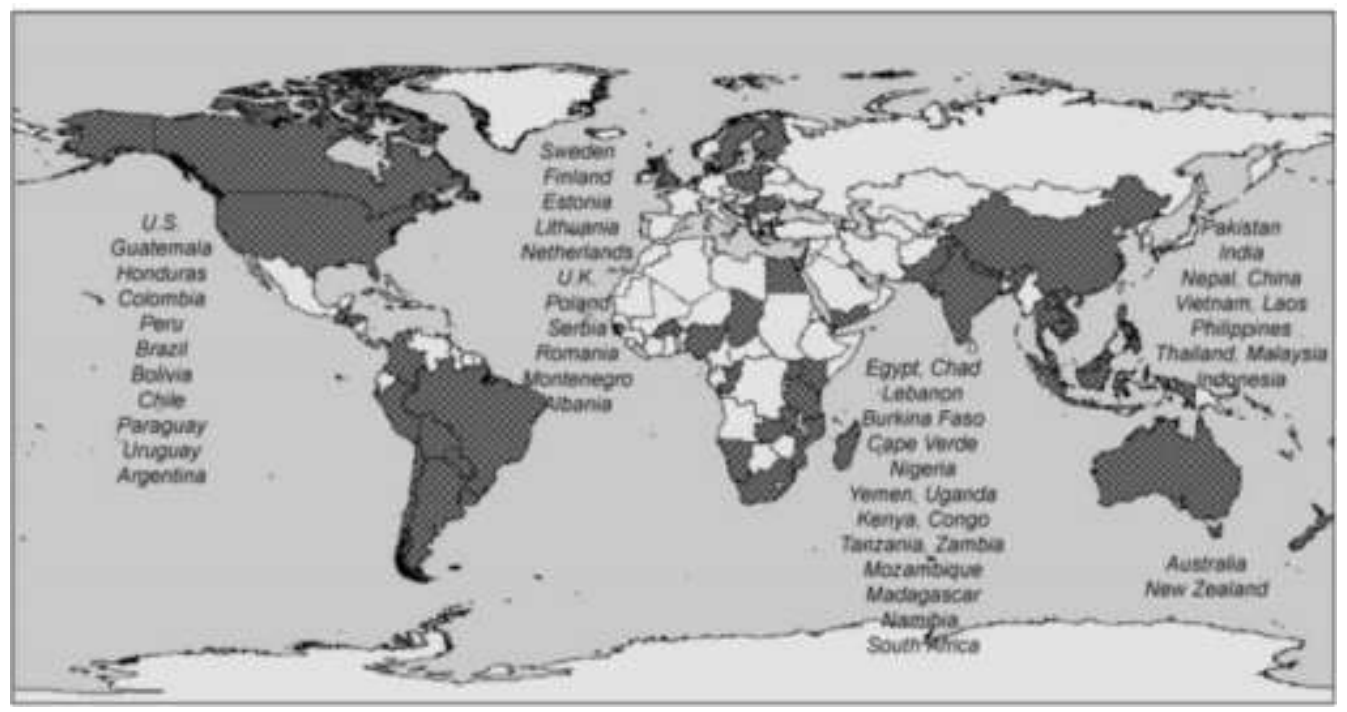

Figure 2.2 PBC implemented Worldwide

Source: Anastasopoulos et al., 2010

\subsection{Potential Benefits of the PBC}

PBC offers several benefits over traditional approaches. For example researchers (Ozbek et al., 2010, Gupta et al., 2011, Sultana, et al., 2012) have identified a list of benefits given below. For this list, the first three benefits including cost saving, innovation and higher productivity, and transfer of risk to contractor are the most important benefits.

1. Cost savings in managing and maintaining road assets (10\% up to $40 \%$ cost savings, see Table 2.1).

2. Incentives to the private sector for innovation and higher productivity.

3. The risk for cost overruns is transferred to the contractor and the road agency faces fewer unpredictable costs. 
4. Greater expenditure certainty for road agencies.

5. Better customer satisfaction with road service and conditions.

6. Reduction in administrative expenses and road agency overheads, requiring fewer agency personnel to manage the road network.

7. Significantly greater flexibility in the private sector (than in the public sector) to reward performance and react quickly against non-performers.

8. The PBC helps insure that variation orders are minimized and that the contractor is generally paid in equal monthly installments throughout the contract period.

9. A PBC approach can help ensure stable financing for the maintenance program over a longer-term when compared with traditional method-based contracts. A PBC typically covers a period of several years. It therefore obliges the government treasury to make a multi-year funding commitment for road maintenance.

Table 2.1 Cost Savings by Country for Using PBC (World Bank 2005)

\begin{tabular}{|l|l|}
\hline \multicolumn{1}{|c|}{ Country } & \multicolumn{1}{c|}{ Cost Savings } \\
\hline Norway & About $20 \%-40 \%$ \\
\hline Sweden & About $30 \%$ \\
\hline Finland & About $30 \%-35 \%$ \\
\hline Holland & About $30 \%-40 \%$ \\
\hline Estonia & $20 \%-40 \%$ \\
\hline England & $10 \%$ minimum \\
\hline Australia & $10 \%-40 \%$ \\
\hline New Zealand & About $20 \%-30 \%$ \\
\hline United States & $10 \%-15 \%$ \\
\hline Ontario, Canada & About $10 \%$ \\
\hline Alberta, Canada & About $20 \%$ \\
\hline British Columbia, Canada & About $10 \%$ \\
\hline
\end{tabular}

Source: World Bank, 2009 


\subsection{Performance Measures in the PBC}

The basis of a $\mathrm{PBC}$ is to define performance measures or standards that are expected to be achieved by the contractor. Performance measures are the most critical element of performance contracting (FHWA 2002). The performance measures have to be clearly defined and objectively measurable in order to avoid ambiguity and risk disputes (Zietlow 2005, Gupta et al., 2011). Moreover, experts support the use of a few key performance measures instead of many because of the associated simplicity and manageability of those performance measures (NCHRP 2009). It is therefore important that the owner agency properly identify which physical attributes on performance measures of the road network are required and the associated level of service to be achieved (Manion and Tighe 2007).

Performance measures are a set of defined outcome-based conditions (for example roughness) that an agency uses to evaluate the success of the contractor. Performance goals are the minimum acceptable levels to be achieved for each performance measure (for example an IRI of $2 \mathrm{~m} / \mathrm{km}$ ) (SAIC 2006).

Lichiello and Turnock (2002) in their Guidebook for Performance Measurement defined performance measurement as "the specific representation of a capacity, process, or outcome deemed relevant to the assessment of performance. A performance measure is quantifiable and can be documented." For a performance measure to be effective, the following questions should be considered (SAIC 2006):

- Is the performance measure specific?

- Is the performance measure measurable?

- Is the performance measure achievable?

- Is the performance measure results- oriented?

- Is the performance measure timely?

- Does the measurement meet with the agency's objectives and desires? 
- Has the performance been measured before?

- Dose the measurement conflict with the agency's standard specifications?

- Does the measurement aim to improve performance?

A study commissioned by Land Transport New Zealand (Kadar and Henning 2007) identified that the effectiveness key performance measures should meet the following essential requirements and/or assumptions:

- The performance requirements are consistent with the policies and objectives of the community and with those of the owner.

- Policies can be expressed with the help of measurable parameters, i.e. qualitative policies can be translated into quantitative measures or parameters.

- The relationship between quantitative measures and future performance can be modeled reliably. Deterioration models for local conditions are available and are satisfactorily calibrated.

- The input parameters for the performance models can be measured satisfactorily and accurately at a cost commensurate with the asset value.

- The funding level of the asset management activities is consistent with the desired outcome and asset value.

Different agencies have different performance measures and performance goals. Under its International Technology Exchange Program, the United States Federal Highway Administration (FHWA, 2002) conducted a study of the European practice of PBC. The study presented a summary of the performance measures used in Europe as well as some of the US states. 
Table 2.2 presents an example of the performance measures and goals for a project in British Columbia (NCHRP 2009). Another example is shown in Table 2.3 for the performance measures and goals specified by some Latin American Countries (Zietlow 2005).

Table 2.2 An example of Performance Measures for a project in British Columbia

\begin{tabular}{|l|l|}
\hline \multicolumn{1}{|c|}{ Performance Measures } & \multicolumn{1}{c|}{ Performance LOS } \\
\hline Roughness (Index) & IRI of 2.28 \\
\hline Rutting (mm) & Rut depth $20 \mathrm{~mm}$ \\
\hline Surface Distress SDI Index Potholes & $\begin{array}{l}\text { SDI of 7.9 } \\
\text { Repaired within 48 hours }\end{array}$ \\
\hline
\end{tabular}

Source: NCHRP,2009

Table 2.3 An example of Performance Measures for projects in Latin American

\begin{tabular}{|l|l|}
\hline \multicolumn{1}{|c|}{ Performance Measures } & \multicolumn{1}{c|}{ Performance LOS } \\
\hline Potholes & No potholes \\
\hline Roughness (asphalt) & IRI $<2.0$ (Argentina), IRI $<2.8$ (Uruguay) \\
\hline Rutting mm & $<12 \mathrm{~mm}$ (Argentina), $<10 \mathrm{~mm}$ (Uruguay, \\
\hline Cracks & Sealed \\
\hline
\end{tabular}

Source: Zietlow, 2005

\subsection{Performance Monitoring of the PBC}

Monitoring the performance measures is a major factor in the success of $\mathrm{PBC}$ model (Segal et al. 2003). There are different approaches to monitor and evaluate the contract performance measures. One approach is that the public agency be responsible for monitoring the measures the performance standards periodically. The agency may wish to use a random, unannounced inspection of performance measures (NCHRP 2009, Sultana, et al., 2012). Another approach would have the monitoring performed by the contractor. 
In this case, the public agency requires the contractor to present periodic (monthly, annually etc.) reports of the performance measure. The agency also may assure that the monitoring and evaluation of performance is done properly by joining the contractor during data collection as well as scheduling random quality assurance evaluations. The monitoring could also be performed by an independent third party, which may result in added cost (NCHRP 2009).

\subsection{Risks in PBC}

In traditional contracting, the public agencies prescribe the specifications, materials, and construction methods that reduce risk of the contractor and the public agency assumes the risk of any failure in the specifications, plans, designs, unexpected or additional work, etc. (Moynihan et al. 2009, Ozbek et al., 2010, Sultana, et al., 2012).

In PBC the contractor is generally free to make the decisions of "what to do", "when" and "how" as long as the specified performance measures are achieved. This means that the contractor bares the entire risk of any failure or shortcomings of its decisions (World Bank 2005). Therefore, the risk is shifted to the contractor who generally controls the project to achieve the performance standards. Figure 2.3 depicts the distribution of risk with different contract approaches. As shown in this figure, as the highway agencies move from traditional contracting to different forms of contracting, its risk decreases while the contractor's risk increases (Queiroz 1999). 


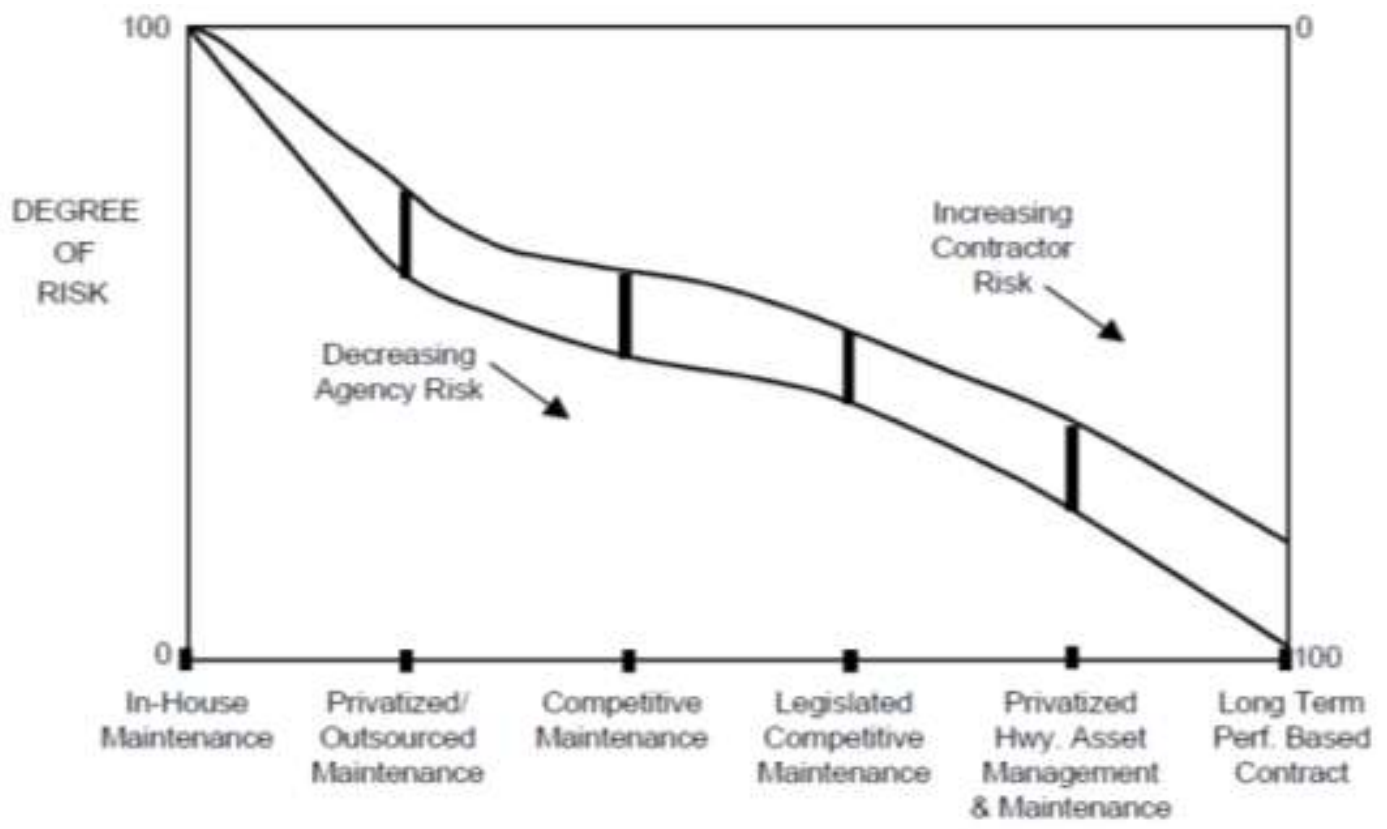

Figure 2.3 Distribution of Risks with Different Approaches

Source: Hass et al., 2001

In PBC a contractor could be exposed to various risks, Owen (2000) lists examples of such risks given as follows, however, the first three including extended maintenance periods, condition of the base layer and poor quality control are the most important risk factors.

1. Extended maintenance periods.

2. Condition of the base layer of the road.

3. Poor quality control producing variable results.

4. Unrealistic or too tight tolerances.

5. Unproven confidence limits on specified performance values.

6. Use of unproven/untried materials.

7. Communication between parties and clear understanding of the philosophy and principles of a performance specification.

8. Method of measurement, variability between testing agencies.

9. Assessment of failure and resultant proportional payment. 
However, it is worth noting that the allocation of risks in $\mathrm{PBC}$ varies from country to country (Segal et al. 2003). The following are some examples:

- In Virginia, USA, the contractor assumes the risk for unpredictable costs, including inflation, escalating material prices, accidents, etc.

- In Argentina PBCs allow for reimbursement of cost overruns in certain circumstances, such as those beyond the control of the contractor (earthquakes, hurricanes and pavement material shortages). The government uses the contractor's schedule of input prices submitted in the bid as a baseline for overruns estimates. The risk of excessive cost overruns is contained by a $25 \%$ cushion on these prices.

- In British Columbia, Canada, and Estonia, PBC include an annual price adjustment process that takes into consideration changes in price indices for labor and fuel.

In understanding the potential risks in the performance-based pavement maintenance contracts it is essential to identify and understand the factors that affect pavement performance and service life. This is because extra costs associated with unforeseen maintenance and rehabilitation of pavement projects comes from inaccuracies in estimating of the service life of the pavement. If for some reason one of the critical variables impacting pavement deterioration rate is not considered in estimating the pavement service life, the consequence would be that the pavement would deteriorate at a higher rate than what was designed and expected by the contractor. Ultimately the contractor has to absorb the cost of maintaining the prematurely deteriorated pavement because of the lack of foresightedness in identifying the risk variable. Therefore, the risk 
of failure could be a result of the contractor error in (i) predicting deterioration of contracted assets; (ii) determining appropriate design, specifications and materials; (iii) planning needed maintenance interventions; and (iv) estimating quantities.

It is important to identify all the risk variables impacting pavement performance, it is also very important to understand the key performance measures that are required by the highway agencies. Pavement performance modeling plays a critical role in understating and estimating potential risk in $\mathrm{PBC}$, however, it is a risky area if the modeling predictions are not right (Keir \& Blerk, 2006). One of the high risk areas in the PBC is performance modeling (Panthi 2009). Performance modeling is crucial in terms of establishing the appropriate maintenance activity, and the appropriate time of application to maintain the level of service specified for different performance measures.

\subsection{Pavement Prediction Models}

It has been recognized in research studies that the best way of managing the risk associated with long term maintenance contracts is to be able to measure the present and predict the future condition state of the asset. The main purpose of pavement prediction models is to predict the future condition state when its present condition state is known. Various types of distresses, such as roughness, rutting, cracks, etc., or indices based on combinations of such distresses, can be used as input for these models.

Figure 2.4 illustrates how performance modeling is used to predict future deterioration of pavement, expected improvements due to application of maintenance or rehabilitation activity and determining the "need year" of application. In addition, it illustrates the application of the deterioration model to rehabilitation alternatives applied 
in the needs year. Performance modeling helps in predicting performance and deterioration of pavements as a function of time, and therefore, predicts pavement life. The different types of distress, such as roughness, rutting, cracking, etc., or indexes based on combinations of such distresses, can be used as input for these models (FHWA 2002a).

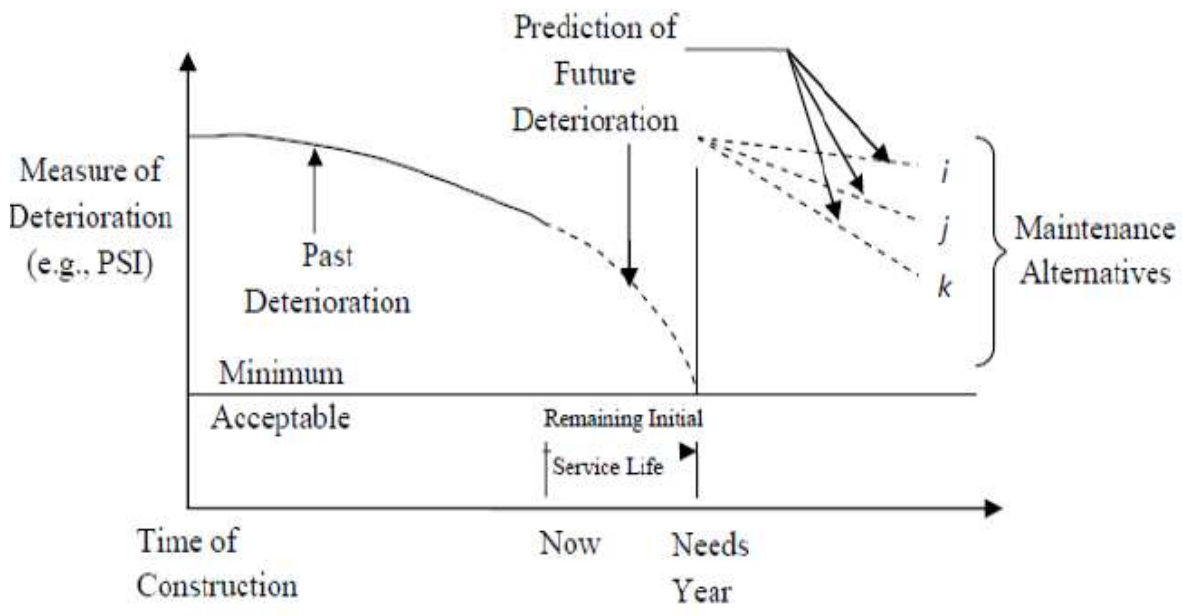

Figure 2.4 Deterioration Modeling and Impact of Maintenance Source: FHWA, 2002

A classification of prediction models has been suggested by Mahoney (1990), based on earlier work by Lytton (1987). Later pavement deterioration models were generally classified into two groups including: deterministic and probabilistic. (FHWA 2002a; Haas et al. 1994; Li 1997; Li 2005; Mahoney 1990; Morcous 2002; Moynihan et al. 2009).

Deterministic models predict average values of pavement performance measures. For the deterministic models, a condition is predicted as a precise value on the basis of mathematical function of observed conditions (Robinson and McDonald, 1991) and the future condition of a pavement section is predicted as the exact serviceability value or pavement condition index with the past information of the pavement (Durango, 2002). In 
other words a deterministic model predicts a single value (Lytton, R.L 1987) of the dependent variable; e.g., level of distress, condition of pavement, life of pavement, etc.

In contrast, probabilistic models can predict averages as well as distributions of these measures. For instance a probabilistic model predicts the performance of a pavement by giving the probability with which the pavement would fall into a particular condition state (Durango, 2002).

Based on modeling approach, performance modeling is classified into four groups (Haas et al. 1994; TAC 1997): mechanistic, empirical, mechanistic-empirical, and subjective. Table 2.4 summarizes the four types. Most deterministic models are mechanistic or empirical. They include primary response, structural performance, functional performance, and damage models (FHWA, 2002; Mbwana, 1996; Mahoney, 1990). Examples of stochastic models include survival curves and Markov process models. There are various deterioration models proposed in the literature. Examples of the probabilistic models include survival curves and Markov process models shown in Table 2.5. 
Table 2.4 Deterioration Modeling Approaches

\begin{tabular}{|l|l|}
\hline Modeling Approach & \multicolumn{1}{|c|}{ Description } \\
\hline Mechanistic & $\begin{array}{l}\text { Based on some primary response behavior such as stress, strain, } \\
\text { etc. }\end{array}$ \\
\hline Empirical & $\begin{array}{l}\text { Using regression, where the dependent variable of observed or } \\
\text { measured structural or functional deterioration is related to one } \\
\text { or more independent variables like subgrade strength, axle load } \\
\text { applications, pavement layer thicknesses and properties, } \\
\text { environmental factors, and their interaction. }\end{array}$ \\
\hline Mechanistic- & $\begin{array}{l}\text { Where measured structural or functional deterioration, such as } \\
\text { distress or roughness, is related to a response parameter through } \\
\text { a transfer function or regression equations }\end{array}$ \\
\hline Subjective & $\begin{array}{l}\text { Or probabilistic, where experience is "captured" in a formalized } \\
\text { or structure way, using semi-Monrovian transition process } \\
\text { models, or Bayesian, for example, to develop deterioration } \\
\text { prediction models. }\end{array}$ \\
\hline
\end{tabular}

Source: Adopted from TAC, 1997

Table 2.5 Types of Performance Models Deterministic Models

\begin{tabular}{|c|c|c|c|c|c|c|}
\hline \multicolumn{4}{|c|}{ Deterministic Models } & \multicolumn{3}{|c|}{ Probabilistic Models } \\
\hline $\begin{array}{l}\text { Primary } \\
\text { Response }\end{array}$ & Structural & Functional & Damage & & $\begin{array}{r}\text { Transiti } \\
\mathrm{M}\end{array}$ & $\begin{array}{l}\text { Process } \\
\text { lels }\end{array}$ \\
\hline $\begin{array}{l}\text { - Deflection } \\
\text { - Stress } \\
\text { - Strain }\end{array}$ & $\begin{array}{l}\text { - Distress } \\
\text { - Pavement } \\
\text { Condition }\end{array}$ & $\begin{array}{l}\text { - PSI } \\
\text { - Safety }\end{array}$ & $\begin{array}{l}\text { - Load } \\
\text { Equivalent }\end{array}$ & $\begin{array}{l}\text { Survivor } \\
\text { Curve }\end{array}$ & Markov & $\begin{array}{l}\text { No } \\
\text { Markov }\end{array}$ \\
\hline
\end{tabular}

Source: FHWA, 2002

Deterministic models are developed using regression, empirical, and combined mechanistic-empirical methods. The selection of the mathematical form to be used for pavement performance models must fit the observed data and the regression-statistical analysis (Li 1997). A common feature among different types of deterministic models is 
that they are based on a large number of long term observed field data and processed through regression analysis (Li 1997).

On the other hand, most probabilistic models are developed to characterize the uncertain behavior of pavement deterioration processes (Li 2005; Panthi 2009). The Markov model has proved to be an effective performance modeling tool by various researchers (Butt et al. 1987; Haas et al. 1994; Li 1997; Madanat et al. 1995, Weijde, 2013). The Markov model is commonly used due to its ability to capture the probabilistic behavior of pavement and the time dependent uncertainty deterioration process as well as for different maintenance and rehabilitation activities (Panthi 2009). The model is based on the change of a pavement from a given state to another over a period of time. The fundamental assumption of the Markov model is that the future of the process depends only on the current state. Therefore, when we observe the state of the road at time " $t$ " we can study the probabilities that the road will deteriorate to different conditions based only on the condition at that time. The Markov model is classified, according to different assumptions, as homogeneous and non-homogeneous. A homogenous Markov model assumes that variables (such as load, traffic, environment, etc.) are constant throughout the analysis period ( $\mathrm{Li}$ 1997). On the other hand, non-homogenous Markov model considers the rate of change incurred at each different stage. Markov chain models are developed using time-based (estimate the probability of time needed to transition from one state to another) or state-based models (estimate the probability of transition from one state to another in a predetermined period of time). Figure 2.5 illustrates the classification of the Markov model. 


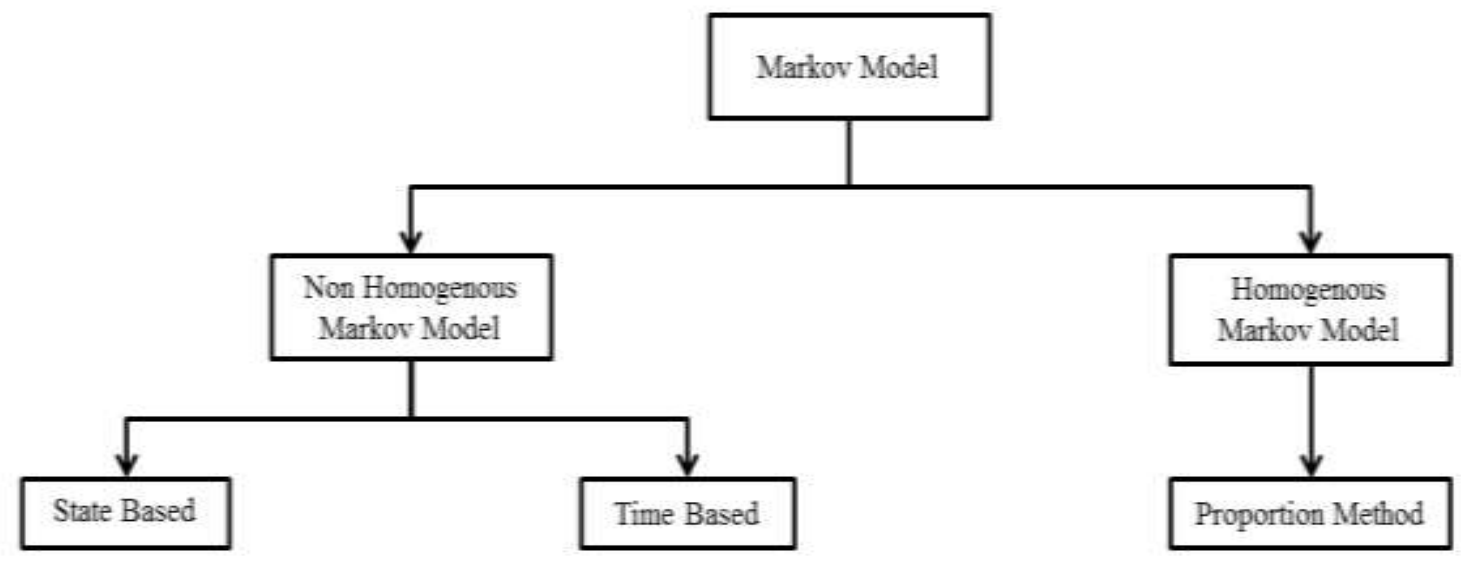

Figure 2.5 Classification of Markov Model

Source: Li, Z, 2005

The different types of models along with advantages and disadvantages are presented in Table 2.6. The regression models can easily capture the variation in data to reflect a robust relationship to predict the future condition of pavement.

Table 2.6 Advantages and Disadvantages of different Models

\begin{tabular}{|l|l|l|}
\hline \multicolumn{1}{|c|}{ Model } & \multicolumn{1}{|c|}{ Advantages } & \multicolumn{1}{c|}{ Disadvantages } \\
\hline Regression & $\begin{array}{l}\text { Microcomputer software packages } \\
\text { are now widely available for } \\
\text { analysis which makes modeling } \\
\text { easy and less time consuming } \\
\text { These models can be easily } \\
\text { installed in a PMS } \\
\text { Models take less time and storage } \\
\text { to run }\end{array}$ & $\begin{array}{l}\text { Needs large database for a better } \\
\text { model. } \\
\text { Works only within the range of } \\
\text { input data } \\
\text { Faulty data sometimes get mixed } \\
\text { up and induces poor prediction. } \\
\text { Needs data censorship } \\
\text { Selection of proper form is difficult } \\
\text { and time taking }\end{array}$ \\
\hline $\begin{array}{l}\text { Survivor } \\
\text { Curve }\end{array}$ & $\begin{array}{l}\text { Comparatively easy to develop } \\
\text { It is simpler as it gives only the } \\
\text { probability of failure } \\
\text { corresponding to pavement age }\end{array}$ & $\begin{array}{l}\text { Considerable error may be expected } \\
\text { if small group of units are used }\end{array}$ \\
\hline
\end{tabular}




\begin{tabular}{|c|c|c|}
\hline Model & Advantages & Disadvantages \\
\hline Markov & $\begin{array}{l}\text { Provides a convenient way to } \\
\text { incorporate data feedback } \\
\text { reflects performance trends } \\
\text { regardless of non- trends }\end{array}$ & $\begin{array}{l}\text { No readymade software is available } \\
\text { Past performance has no influence } \\
\text { It does not provide guidance on } \\
\text { physical factors which contribute to } \\
\text { change } \\
\text { Needs large computer storage and } \\
\text { time }\end{array}$ \\
\hline $\begin{array}{l}\text { Semi } \\
\text { Markov }\end{array}$ & $\begin{array}{l}\text { Can be developed solely on } \\
\text { subjective inputs } \\
\text { Needs much less field data } \\
\text { Provides a convenient way to } \\
\text { incorporate data feedback } \\
\text { Past performance can be used }\end{array}$ & $\begin{array}{l}\text { No readymade software is available } \\
\text { Needs large computer storage }\end{array}$ \\
\hline Mechanistic & $\begin{array}{l}\text { Prediction is based on cause and- } \\
\text { effect relationship, hence gives the } \\
\text { best result }\end{array}$ & $\begin{array}{l}\text { Needs maximum computer power, } \\
\text { storage and time } \\
\text { Uses large number of variables } \\
\text { (e.g. material properties, } \\
\text { environment conditions, geometric } \\
\text { elements, loading characteristics } \\
\text { etc.) } \\
\text { Predicts only basic material } \\
\text { responses }\end{array}$ \\
\hline $\begin{array}{l}\text { Mechanistic } \\
\text { Empirical }\end{array}$ & $\begin{array}{l}\text { Primarily based on cause- and- } \\
\text { effect relationship, hence its } \\
\text { prediction is better } \\
\text { Easy to work with the final } \\
\text { empirical model } \\
\text { Needs less computer power and } \\
\text { time }\end{array}$ & $\begin{array}{l}\text { Depends on field data for the } \\
\text { development of empirical model } \\
\text { Does not lend itself to subjective } \\
\text { inputs } \\
\text { Works within a fixed domain of } \\
\text { independent variable } \\
\text { Generally works with large number } \\
\text { of input variables (material } \\
\text { properties, environment conditions, } \\
\text { geometric elements, etc.) which are } \\
\text { often not available in a PMS }\end{array}$ \\
\hline Bayesian & $\begin{array}{l}\text { - Can be developed from past } \\
\text { experience and limited field data } \\
\text { - Simpler than Markov and } \\
\text { - Semi-Markov models } \\
\text { - Can be suitably enhanced using } \\
\text { feedback data }\end{array}$ & $\begin{array}{l}\text { - May not consider mechanistic } \\
\text { behavior } \\
\text { - Improper judgment can lead to } \\
\text { erroneous model }\end{array}$ \\
\hline
\end{tabular}

Source: Panthi,2009 


\subsubsection{Prediction Models for Cracks}

The prediction models for cracks predict initiation of cracking, progression of cracking, or score for percent area of cracking. A model developed by UNDP (Queiroz and Hudson 1982) predicts the number of equivalent single axles of $80 \mathrm{kN}$ (18-kip) for the initiation of 1-mm-widecracks.

$\log 10 \mathrm{Nc}=1.205+5.96 \log 10 \mathrm{MSN} \quad \mathrm{R} 2=0.52$

where, $\mathrm{N}_{\mathrm{c}}=$ the number of ESALs to first crack; and MSN = modified structural number.

The calculation of the modified structural number (MSN) requires explanation.

Structural number is defined as an index number derived from an analysis of traffic, roadbed soil conditions, and a regional factor that may be converted to thickness of various flexible pavement layers through the use of suitable layer coefficients related to the type of material being used in each layer of the pavement structure (AASHTO 1993). It is expressed as,

$\mathrm{SN}=\mathrm{a} 1 \mathrm{D} 1+\mathrm{a} 2 \mathrm{D} 2 \mathrm{~m} 2+\mathrm{a} 3 \mathrm{D} 3 \mathrm{~m} 3$

where, $a_{i}=i^{\text {th }}$ layer coefficient, $m_{i}=i^{\text {th }}$ drainage coefficient, and $D_{i}=$ depth of the $i^{\text {th }}$ layer.

The contribution of subgrade to pavement load carrying capacity is considered by defining a pseudo structural number for the subgrade.

SNsg $=3.51^{*} \log 10 \mathrm{CBR}-0.85(\log 10 \mathrm{CBR}) 2-1.43$

where, $\mathrm{CBR}=$ California Bearing Ratio, $\%$. 
The modified structural number is determined as follows,

$\mathrm{MSN}=\mathrm{SN}+\mathrm{Ssg}$

The progression of cracking is expressed in percentage of the area as follows,

$\mathrm{CR}=-18.53+0.0458^{*} \mathrm{~B}^{*} \mathrm{LN}+0.000501^{*} \mathrm{~B}^{*} \mathrm{AGE} \mathrm{E}^{*} \mathrm{LN} \quad \mathrm{R} 2=0.64$

where, $\mathrm{CR}=$ amount of cracking, in percentage of the area, $\mathrm{AGE}=$ age of the pavement, years, $\mathrm{B}=$ mean surface deflection by Benkelman beam, $\mathrm{mm}$, and $\mathrm{LN}=$ logarithm to base 10 of the number of cumulative equivalent axles. The UNDP study was extended and data from other studies were combined to develop the World Bank Model (Paterson 1987). The model was developed from a comprehensive designed database of in-service pavements. The cracking model developed for asphalt concrete pavement is as follows:

TyCR2 $=4.21 \exp (0.139 \mathrm{MSN}-17.1 \mathrm{YE} 4 / \mathrm{MSN} 2)$

TECR2 $=0.0342$ EHM-2.86 e $-0.198 \mathrm{EY}$

where, $\mathrm{Ty}_{\mathrm{CR} 2}=$ expected (mean) age of surfacing at initiation of narrow cracking, years and $\mathrm{TE}_{\mathrm{CR} 2}=$ expected (mean) cumulative traffic at initiation of narrow cracking, million ESALs, MSN $=$ modified structural number, $\mathrm{YE}_{4}=$ annual traffic loading, million ESALs/lane/year, EHM = maximum tensile strain in surfacing, $10^{-3}$, and $\mathrm{EY}=1 /\left(\mathrm{EHM}^{4}\right.$ $1000 \mathrm{YE}_{4}$ ), provided that $\mathrm{EY}<=6$.

Transportation and Road Research Laboratory (TRRL) (Paterson 1987) developed a model to predict combined cracking and patching as follows: 


$$
(\mathrm{C}+\mathrm{P})=21600 \text { NES MSN-MSN } \quad \text { For MSN }<4.0, \mathrm{C}+\mathrm{P}>=0
$$

Where, $(\mathrm{C}+\mathrm{P})=$ sum of areas of cracking and patching $(\mathrm{m} 2 / \mathrm{km} / \mathrm{lane})$,

MSN $=$ modified structural number, and $\quad$ NEs $=$ cumulative traffic loadings since latest resurfacing (million ESALs).

In summary, the important explanatory variables for cracking employed in these studies are cumulative ESAL, age, subgrade characteristics and structural number.

\subsubsection{Prediction Models for Rutting}

Rutting is mainly caused by the repeated application of traffic loading that results the permanent deformation of all the pavement layers. Stresses induced by traffic loading cause shear displacements within the materials that results deformation in pavement layers. Stresses that exceed the shear strengths of the materials can cause plastic flow resulting in depressions under the repeated load. Repeated loadings at lesser load and tire pressure levels cause smaller deformations which accumulate over time and manifest as a rut if the loadings are channelized into wheel-paths. In modern pavement construction, rutting due to densification and deformation in the lower layers under traffic loading is usually minor because it is taken into account in the structural design methods, but can become significant when the pavement is weakened by water ingress (Paterson 1987). Indeed, rutting develops by plastic flow in bituminous surface layers if the bituminous materials are soft under high temperatures. Various models for the prediction of rutting are developed based on mechanistic responses, strength of pavement, age, cumulative traffic, etc. A model based (Monismith, 1975) on permanent strain is as follows: 
$\log \varepsilon \mathrm{P}=\mathrm{a}+\mathrm{b} \log \mathrm{N}$ or $\varepsilon \mathrm{P}=\mathrm{ANb}$

where, $\varepsilon_{\mathrm{P}}=$ permanent strain, $\mathrm{N}=$ number of load repetitions, $\mathrm{a} \& \mathrm{~b}=$ experimentally determined factors, and $\mathrm{A}=$ antilog of $\mathrm{a}$.

Peterson (Paterson 1987) developed a model to predict mean rut depth as a function of age of pavement, modified structural number, traffic, compaction index, deflection, rehabilitation state, monthly precipitation, and index cracking as follows.

$\mathrm{RDM}=\mathrm{t} 0.166 \mathrm{MSN}-0.502$ COMP-2.30 NE4ERM $\quad \mathrm{R} 2=0.42$

Where, $\mathrm{ERM}=0.0902+0.0384 \mathrm{DEF}-0.009 \mathrm{RH}+0.00158 \mathrm{MMP}$ Acrx

$\mathrm{RDM}=$ mean rut depth in both wheel paths $(\mathrm{mm}), \mathrm{t}=$ age of pavement since rehabilitation or construction (year), $\mathrm{MSN}=$ modified structural number, $\mathrm{COMP}=$ compaction index of flexible pavements (fraction), $\mathrm{NE}_{4}(\mathrm{t})=$ cumulative traffic loading at time $\mathrm{t}$ (million ESAL), DEF = mean peak Benkelman beam deflection under $80 \mathrm{kN}$ standard axle load of both wheel paths $(\mathrm{mm}), \mathrm{RH}=$ rehabilitation state $(=1$ if pavement overlay, $=0$ otherwise), $\mathrm{MMP}=$ mean monthly precipitation $\left(\mathrm{mm}\right.$ per month), and $\mathrm{A}_{\mathrm{crx}}=$ area of indexed cracking (percent of total surfacing area).

It is evident from the above models that traffic, structural number, deflection, and subgrade characteristics predominantly affect rutting.

\subsubsection{Prediction Models for Roughness}

Roughness has an important bearing on the performance of a pavement. Most of the roughness prediction models developed are for flexible pavements, with some of 
them for unpaved roads. The AASHO Road Test (AASHO 1962) quantified the effects of pavement strength and traffic loading on road roughness. Roughness models from the Transportation and Road Research Laboratory (TRRL) study also show strong effects of pavement strength and traffic loading (FHA 1991). TRRL roughness prediction model is described as follows,

$\mathrm{Rt}=\mathrm{R} 0+\mathrm{s}(\mathrm{S}) \mathrm{Nt}$

where, $\mathrm{s}(\mathrm{S})=$ function of modified structural number, $\mathrm{R}_{0}, \mathrm{R}_{\mathrm{t}}=$ roughness at time $\mathrm{t}=0$, and at $\mathrm{t}$, respectively, and $\mathrm{N}_{\mathrm{t}}=$ cumulative number of equivalent $80 \mathrm{kN}$ standard axle loads to time t.

Arizona State roughness prediction model is described as follows (Zaniewski et al. 1990),

$\mathrm{R}_{\mathrm{i}}=\mathrm{C}_{0}+\mathrm{C}_{1}+\mathrm{C}_{2} \mathrm{~T}^{2}$

where, $\mathrm{Ri}=$ roughness for homogeneous section $(\mathrm{in} / \mathrm{mile}), \mathrm{T}=$ years since the treatment, and $\mathrm{C}_{0}, \mathrm{C}_{1}$ and $\mathrm{C}_{2}=$ regression coefficients.

UNDP (Queiroz and Hudson 1982) developed an empirical model for the prediction of pavement roughness in terms of Quarter Car Index (QI),

$\mathrm{QI}=12.63-5.16 \mathrm{RH}+3.31 \mathrm{ST}+0.393 \mathrm{AGE}+8.66(\mathrm{LN} / \mathrm{MSN})+7.17 * 10-5\left(\mathrm{~B}^{*} \mathrm{LN}\right) 2$

Where, $\mathrm{RH}=$ state of rehabilitation, dummy variable: $=0$ as constructed, $=1$ overlaid, $\mathrm{ST}=$ surface type dummy variable, $=0$ asphaltic concrete $=1$ surface treatment, 
$\mathrm{AGE}=$ number of years since construction or overlay,

$\mathrm{LN}=\log 10$ of cumulative equivalent axles,

MSN = modified structural number, and

$\mathrm{B}=$ Benkelman beam deflection, $(0.01 \mathrm{~mm})$

Another model for the prediction of Alberta Riding Comfort Index, a roughness measure determined by the Portland Cement Association road meter, was developed in which several explanatory variables were considered including traffic, climatic zone, subgrade soil type, and others. Only pavement age (AGE) and $\mathrm{RCI}_{\mathrm{B}}$ (previous riding comfort index) were found to be statistically significant. The developed model is described as follows:

$\mathrm{RCI}=-5.998+6.870^{*} \mathrm{LOG}(\mathrm{RCIB})-0.162 * \mathrm{LOG}(\mathrm{AGE} 2+1)+0.185^{*} \mathrm{AGE}-$

0.084*AGE*LOG (RCIB) $-0.093 *$ AGE $\quad$ R2 $=0.84$

Where, $\mathrm{RCI}_{\mathrm{B}}=$ previous $\mathrm{RCI}$, and $\mathrm{AGE}=$ age in years .

The above models indicate that the most important variables employed in estimating roughness are age, and traffic (cumulative ESALs).

The mathematical equations and models mentioned above are the models developed in different parts of the world which provide information about important variables and performance measures that should be considered in pavement performance modeling. The presented models are composed of various variables which were not readily available for calibration purposes. 


\subsection{Optimization of Pavement Maintenance Strategies}

It is important to find optimal maintenance strategies to make sure roads are well maintained with economical spending. Maintenance strategy means the best schedule to perform maintenance and the best kind of maintenance at every stage of the road life cycle. For example, consider a single road, newly constructed at time " 0 " and choose a fixed period of time (say every year) to evaluate the status of the road and decide what kind of treatment (if any) you should apply to it. At time "1", the road would have deteriorated to a certain state. This deterioration is probabilistic and is affected by many factors. If we continue to observe the road every year and decide on a different treatment (with different cost), we will have a growing tree of decision sequences, each sequence of decisions will have a different cost. The optimization process is to predict at time " 0 " what would be the best sequence (in a probabilistic sense) that will maintain the road at the minimum required condition with minimum cost. Finding optimal strategies can be a challenge. An optimization model could assist in finding optimal strategies. The objective of an optimization model is to find the optimal strategies, and therefore optimized Life Cycle Cost (LCC). Invariably most of optimization models have single performance criterion (aggregate measures) which is maximized against the total or annual maintenance expenditure (Lamptey et al., 2005). This performance criterion is usually the pavement condition index (PCI) or other forms of indices such as the international roughness index (IRI). An advantage of using a single composite performance criterion (over multiple distress indicators) lies in their economy: there is no need to carry out separate field monitoring of each indicator of pavement distress. 
However, one disadvantage is that aggregate measures only give an indication of overall pavement condition and fail to provide the distribution of various distresses. For the purpose of performance-based contracts, there usually are more than one pavement performance criteria that the contractor has to fulfill.

Many agencies use life-cycle cost analysis (LCCA) as a means of evaluating the long-term economic viability of pavement designs. As such, it is important for each agency to conduct a realistic assessment of pavement economics in order to provide objective input into the life-cycle cost analysis. LCCA has been highly recommended for finding optimal pavement designs in order to take account of a long-term pavement performance (AASHTO, 1986; AASHTO, 2002; Haas et al., 1994). In an effective pavement design process based on LCCA, not only initial construction cost but also maintenance and user costs subsequently incurred during a predefined analysis period need to be included (Haas et al. 1994).

Sanchez-Silva et al. (2005) employed a probabilistic model for determining optimal design of flexible pavement that considers subsequent rehabilitation cost but not explicitly the physical effects of rehabilitations. Deshpande et al. (2008) proposed a reliability-based model that takes account of rehabilitation effects for yielding optimal pavement design and rehabilitation strategies. These authors used indices of fatigue damage for representing pavement performance without relating them to user costs. This shortcoming was addressed by Abaza (2002) and Abaza et al. (2003) who proposed a life-cycle model of flexible pavements that considers road user cost in the optimization of maintenance strategy. Mamlouk et al. (2000) developed a project-level pavement management system for analyzing optimal pavement design and maintenance strategies 
(PDMSs). These models, however, are based on engineering criteria such as remaining life of pavement and overlay, terminal serviceability and alike, which are difficult to relate with standard economic evaluation criteria. Another approach widely used for the LCC of pavement is Option Evaluation System (OES) such as HDM-III (Watanatada, Tsunokawa et al. 1987), RTIM (Cundill, 1993), HERS (FHWA, 1998a) and HDM-4 (PIARC, 2002). Given a PDMS, OESs simulate the history of pavement performance during a defined analysis period as a function of traffic loading, environmental effects and maintenance impacts, and compute maintenance costs and road user costs as a function of the predicted pavement conditions. The LCCA of a given PDMS is then obtained as the sum of these costs and the cost of initial construction, all of which are discounted to obtain the net present value of LCCA. Several researchers have used HDM4 and its predecessor, HDM-III, to investigate optimal PDMS in various situations (e.g., Riley et al. 1994; Tsunokawa et al. 2002; Tsunokawa and U1- Islam, 2003; Jain et al. 2006). These systems are based on coherent framework of economic evaluation and built on a set of relationships obtained through extensive research undertaken during the last four decades (see for example, Moavenzadeh et al., 1971; Abaynayaka et al., 1977; CRRI, 1982; Geipot, 1982; Hide, 1982; Paterson, 1987; Watanatada, Tsunokawa et al., 1987; Djarf, 1995; NDLI, 1995; Bennett, 1996; Odoki and Kerali, 2002; Morosiuk et al. 2004; and Bennett and Greenwood, 2004). Tsunokawa and Ul-Islam (2003) showed that the optimal pavement design strengths obtained by the LCCA with HDM-4 were in good agreement with the strengths determined by two standard pavement design guidelines (e.g. AASHTO, 1993; TRL, 1993). OESs, however, require alternative PDMSs for comparison to be specified by analysts. Since it is impossible to exhaust all possible 
PDMSs options, it is inevitable for OESs to lead to sub-optimal options. To overcome this deficiency, Tsunokawa, Hiep et al. (2006) presented a methodology named Gradient Search with Option Evaluation Systems (GSOE) where only maintenance strategies are considered for a given pavement.

There are two commonly applied approaches to formulate optimization model (Golabi, Kulkarni, and Way, 1982). The first uses a model that gives least cost maintenance policies under the condition that the road is maintained at minimum standards, and the second is to develop a model that gives the best possible road conditions under budget constraints. In either case the road deteriorates over time and this needs to be predicted. Both models can be based on formulating the problem as a constrained Markov decision process, and linear programming can be used to find the optimal solution (Dekker, Nicolai, and Kallenberg, 2007). In the next section Markov Decision Process is discussed.

\subsection{Markov Decision Process}

A detailed explanation regarding Markov Decision Processes (MDP's) is given in a research paper by Dekker, Nicolai and Kallenberg, 2007. The main assumption of a Markov chain is that the present state includes all the information needed for future predictions, meaning that information from previous situations is not required. Because of this the transition probabilities $P_{i j}$ can be defined as follows:

$$
P_{i j}=P\left(X_{t+1}=j I X_{0}=i_{0}, X_{1}=i_{1}, \ldots, X_{t}=i\right)=P\left(X_{t+1}=j I X_{t}=i\right)
$$


If the transition probabilities do not depend on $t$, then the Markov chain is stationary, but according to Plasmeijer (1999) most of the road deterioration process is not stationary over time. To model road deterioration as a Markov chain one has to take into account that this will most likely result in a non-stationary process.

The Markov Decision Chain is a Markov chain that can be altered by actions, and where the optimal actions can be found. The chain is defined by $E, A, P$, and $r$, where $E$ denotes the state space, $A(i)$ the action set in state $i \in E, P(i, j), I, j \in E$ the transition probabilities and $r_{i}(a), i \in E, a \in A(i)$, the immediate costs in state $i$ when choosing action $a$.

By a policy $\beta$ we mean a sequence of decision rules $\left(\beta_{i}(a), a \in A(i), i \in E\right)$ where $\beta_{i}$ (a) can be interpreted as the probability that action $a \epsilon A(i)$, is chosen when in state $i \epsilon$ $E$. A policy is deterministic if all the decision rules are nonrandomized.

A criterion to find the best action $a$ can be done by either optimizing the long-run expected average rewards or by finding the lowest expected total discounted cost by solving a set of equations.

$$
\begin{aligned}
& g_{i}(R)=\lim _{n \rightarrow \infty} \inf \left(\frac{1}{N+1}\right) \sum_{k=0}^{N} \sum_{j \varepsilon E} P_{i j}^{k}(R) r_{j}\left(\pi^{k+1}\right) \\
& v^{\alpha}(R)=\sum_{k=0}^{\infty} \alpha^{k} p^{k}(R) r\left(\pi^{k+1}\right)
\end{aligned}
$$

Here $\pi$ is a decision rule, $P(\pi)$ the matrix with $P_{i j}(\pi(i))$ as the $i^{\text {th }}$ element, $\mathrm{r}(\pi)$ vector with $\mathrm{r}_{\mathrm{i}}\left(\pi(\mathrm{i})\right.$ as $i^{\text {th }}$ element. $P^{k}(\mathrm{R})=P\left(\pi^{\mathrm{k}}\right) \ldots . P\left(\pi^{1}\right)$ and $P^{0}(R)=I$, the identity matrix. If for equation 1 the state-space is finite then there is an average optimal policy, and in the 
case of equation 2 their exists a unique solution if $\alpha<1$. A detailed procedure on how to optimize can be found Dekker, Nicolai and Kallenberg, 2007.

There are three solution methods for finding optimal policy: policy improvement, value iteration and linear programming. The idea of policy improvement is to start with an initial policy and find with each step for each state an improving action. Value iteration repeatedly evaluates the optimality equation in order to find the solution. This algorithm is considered to be faster than the policy improvement method when the transition matrix is sparse and only few transitions are possible.

Linear programming requires that you formulate a LP for the optimal criterion. The advantage of this method is that standard LP solver can be used and one can easily set restrictions on the limiting probabilities of certain states.

An example of a practical use of Markov decision models is done in Golabi, Kulkarni, and Way (1982). They developed a Network Optimization System (NOS) for the State of Arizona, that finds optimal maintenance policies considering minimal road quality conditions, via linear programming. This NOS exists of a long term optimization model, minimizing the yearly long run average maintenance cost and a short term model that minimizes the total expected maintenance cost of a period of years. They considered four variables important for evaluating pavement performance: raveling, present cracking, last-year change in cracking, and index to the first crack. They claimed that in the first year 14 million dollars were saved and forecasted another 101 million in savings for the next four years. However Wang, and Zaniewski, (1996) reported that the steady state condition was never reached due to fluctuation in budgeting, pavement behavior and transition probabilities. 


\subsection{Summary of the Literature Review}

The PBC differ significantly from the traditional method-based contracts. The main aspect of the PBC is that contractors are paid based on the end result achieved not on following the specified method of performing the work. Therefore, the contractor is paid based on how well they meet the specified performance measures. Because of that, PBC encourages contractor innovation and quality which in turn creates opportunities for value engineering and improved efficiencies, and improved workmanship. Agencies that have implemented performance based contracts claim cost saving between $10-40 \%$.

However, there are many risks inherent in PBCs. The risk of failure in a PBC could be a result of the contractor error in (i) predicting deterioration of contracted assets; (ii) determining appropriate design, specifications and materials; (iii) planning needed maintenance interventions; and (iv) estimating quantities. Risks in PBC arise because of the uncertainty in accurately estimating the service life of the pavement. Predictions of service life get even more complex when a contractor maintaining the pavement has to meet multiple performance requirements throughout the contract period. The best way of managing risk associated with long term pavement maintenance contract is to be able to measure the present and future condition state of the pavement. One way of doing so is by modeling to predict future condition state of the pavement when it's past condition data are available. Probabilistic models, such as the one proposed in this research, are preferred over the deterministic models when there are many uncertainties in the input of the model. An inherent difficulty of using asset management models that are widely available is that these models invariably optimize maintenance cost using single 
(aggregate) performance criteria as opposed to multiple performance criteria that are usually present in the long-term performance-based maintenance contracts.

Performance indicators based on multiple distress indicators are found in many countries, and can easily be obtained for analysis. In this scenario, formulation of maintenance strategies based on multiple performance criteria is recommended and is deemed appropriate.

In the $\mathrm{PBC}$, performance modeling is an important and a challenging task. Moreover, pavement deterioration follows a stochastic behavior, and the deterioration process and the improvement due to maintenance and rehabilitation activities varies based on many factors such as environment, loading, and data used for the modeling, which result in a risk to the contractor in such a contract model. An integrated framework to facilitate the selection of effective maintenance and rehabilitation strategies that takes into account possible causes of risk is well needed. 


\section{Chapter: Data of Pavement Condition and Maintenance Treatment in Abu Dhabi}

\subsection{Introduction}

This chapter discusses the details of the data concerning pavement condition and various road maintenance treatments applied in the Emirate of Abu Dhabi. The road authorities Municipalities and Department of Transport regularly collect the pavement data with the help of third party consultants. The Abu Dhabi Municipality Road Network (ADMRN) data is used as a case study in this thesis. ADMRN includes in excess of 12,000 km of greater Abu Dhabi city's roads. The approximate asset value of ADMRN would be over AED 26 Billion, making it among the most valuable assets owned by Abu Dhabi Municipality (ADM). The residents of Abu Dhabi including workers and visitors use the ADMRN, whether as pedestrians; on bicycles or motorcycles; in buses, taxies, or cars; or as truck drivers. The mobility and safety of over 1.6 million people residents of Abu Dhabi depend on proper maintenance and rehabilitation of the ADMRN.

This chapter includes two sections; first section presents information about the pavement data collection equipment and methodology, and the second section provides information about various types of pavement maintenance applied in Abu Dhabi.

\subsection{Pavement Data Collection Equipment and Methodology}

The pavement condition data is an important component in developing effective maintenance and rehabilitation strategies for many reasons. First, identifying appropriate maintenance and rehabilitation alternatives rely on pavement information such as 
thickness, current condition, traffic, climate conditions, etc. The pavement data includes many factors, for example, pavement current condition, pavement historical performance, pavement materials, pavement thicknesses, traffic information, pavement geometry, and environmental data.

In the Emirate of Abu Dhabi state of the art equipment including Automated Road Analyser (ARAN), Heavy Weight Deflectometer (HWD) and Weigh in Motion traffic equipment are used to assess the structural and functional conditions of the pavement. From the ARAN testing: roughness (ride), rut depth, surface macro texture and surface distress results were collected. From the HWD testing: layer modulus and remaining structural life were calculated and reported. From the Weigh in Motion study the current axle loading was determined for evaluating remaining life.

The ARAN car shown in Figure 3.1 was used to carry out the surface profiling and imaging. The ARAN car is designed to provide advanced, automated and high quality pavement profile measurements and imagery for use by engineers and construction managers. The ARAN is capable of capturing real time continuous highwayspeed data acquisition of longitudinal profile parameters and International Roughness Index (IRI) with differential GPS Data and Digital Photo Logging. 


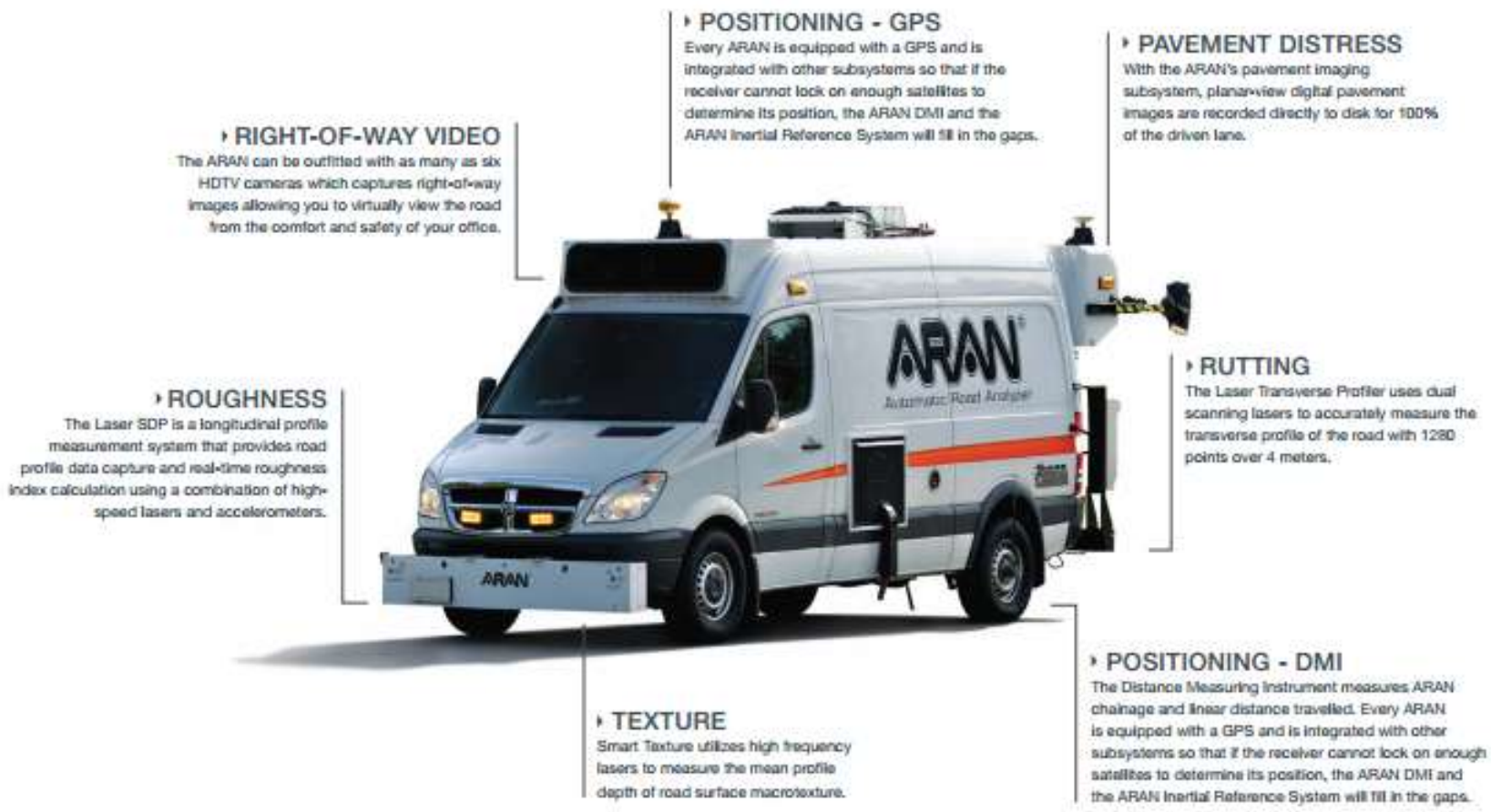

Figure 3.1 Automated Road Analyzer (ARAN)

Source: Fugro Roadware Inc, Vehicles used for ADM Data collection, 2012

The Automated Road Analyzer can measure road conditions for example:

- Roughness

- Rutting

- Surface Macro texture

\subsubsection{Roughness}

The roughness of pavement is generally defined as an expression of irregularities in the pavement surface that adversely affect the ride quality of a vehicle (and thus the user). Roughness is an important pavement characteristic because it affects not only ride quality but also vehicle delay costs, fuel consumption and maintenance costs. The World Bank found road roughness to be a primary factor in the analyses and trade-offs involving 
road quality vs. user cost (UMTRI, 1998). Roughness is also referred to as "smoothness" although both terms refer to the same pavement qualities

As per ASTM E1926 standard the roughness is reported in terms of International Roughness Index (IRI). The IRI is considered the most universal and recognized index by agencies to express the roughness of pavements. IRI is generally expressed in meters/kilometer (or millimeters/meter). As the roughness increases, the riding comfort and sense of safety decrease that implies the need of maintenance.

\subsubsection{Rutting}

A rut is defined as the maximum vertical pavement displacement, in the transverse profile, either across the wheel path (wheel path rut) or across the lane width (lane rut) measured from a reference plane. Traffic-associated permanent deformation (rutting), in particular, result from a rather complex combination of densification and plastic flow mechanisms. Densification, according to Paterson (1987) is the change in the volume of material as a result of the tighter packing of the material particles and sometimes also the degradation of particles into smaller sizes. Rutting due to densification is usually fairly wide and uniform in the longitudinal direction with heaving on the surface seldom occurring, as illustrated in Figure 3.2. 


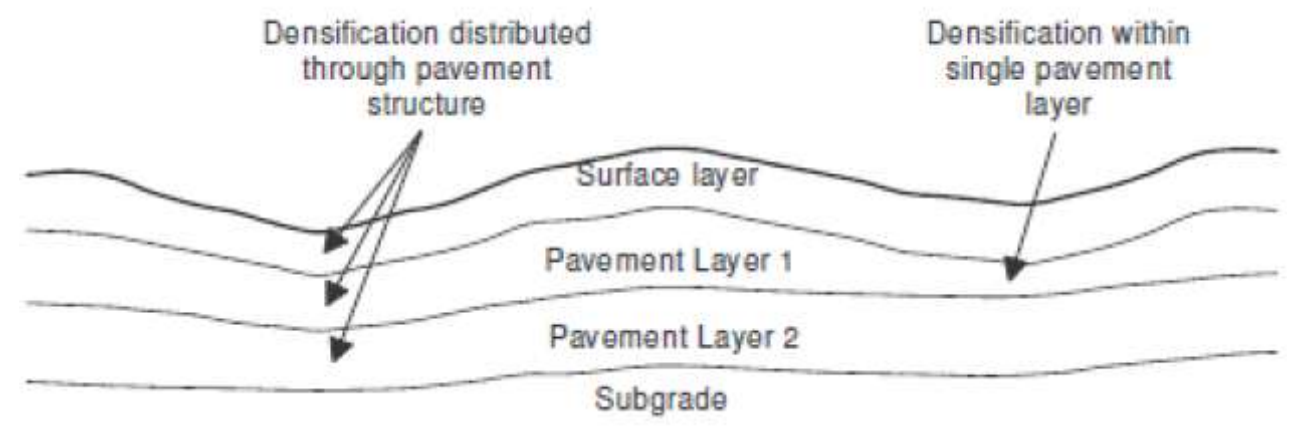

Figure 3.2 Rut profile as a result of densification

Source: Kannemeyer, 2003

The degree of densification is primarily dependent on the compaction practices during construction. The density specification should be selected in accordance with the expected loadings and pavement type. Failure to reach the specified compaction during construction will result in an increase of densification under traffic, most of which occurs early in the life of the pavement. It is important to note that for similar rut depth values, the deformation within the pavement may be located within a single weak layer, or more evenly distributed through the depth of the pavement, as illustrated in Figure 3.3.

Plastic flow is associated with densification and shear displacements in which both depression and heave are usually manifested. Plastic flow occurs when the shear stresses imposed by traffic exceed the inherent strength of the pavement layers. The rutting in this case is usually characterized by heaving on the surface alongside the wheel-paths. Plastic flow is controlled through the structural and material design specifications, which are normally based on a measure of the shear strength of the materials used (for example, the California Bearing Ratio (CBR) for soils, and Marshall Stability for bituminous materials. The best known example of plastic flow is shoving within the asphalt layers, as illustrated in Figure 3.3. 


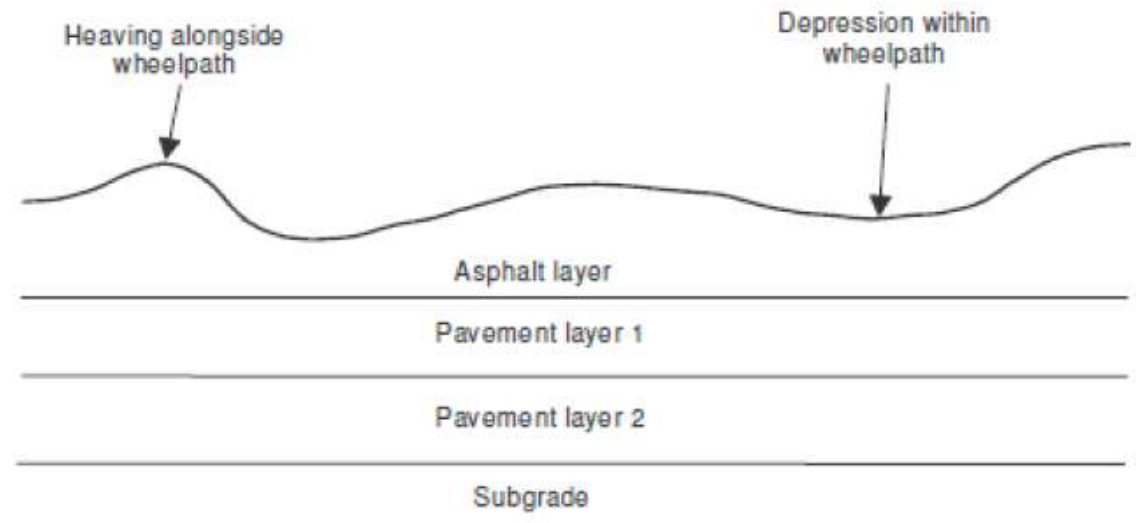

Figure 3.3 Rut profile as a result of Plastic Flow (shoving)

Source: Kannemeyer, 2003

The ARAN is configured with a laser based system that by the triangulation method measures the surface transverse profile to $0.1 \mathrm{~mm}$ resolution at 1280 points across a $4.0 \mathrm{~m}$ width behind the survey vehicle (Figure 3.4).

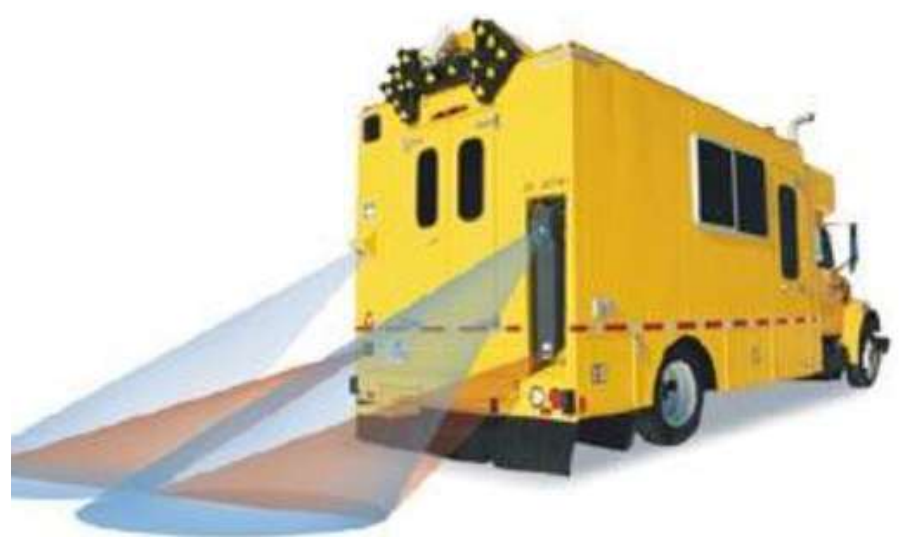

Figure 3.4 ARAN profile measurement systems

Source: Fugro Roadware Inc, 2012

The wire model algorithm with the ARAN connects the high points on the pavement transverse profile and establishes the rut depth under these points, as shown in Figure 3.5. The wire model expresses the rut depth based on a wire stretched over the high points. The distance to the pavement from the wire is calculated and the highest 
values constitute the rut depth. The rut depth is then determined in each wheel-path across that profile from the center of the lane using a reference level.

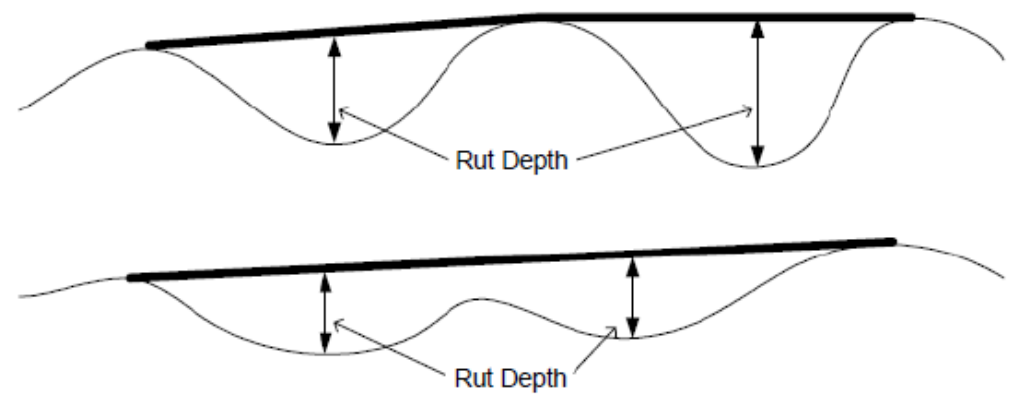

Figure 3.5 Wire model for rut depth measurements

Source: Kannemeyer, 2003

In this survey rutting has been measured for both left and right wheel-path using a 3.0 meter wire model and is expressed in millimeters.

\subsubsection{Surface Macro texture}

The pavement surface macro texture is measured using a $64 \mathrm{kHz}$ laser mounted in the right (outer) wheel-path of the ARAN vehicle. The ARAN system measures and reports surface macro texture in terms of Mean Profile Depth (MPD) in accordance with ASTM E1845 and ISO 13473-1. This is a measure of macro texture based on the height of the highest peaks above the mean depth, calculated over a $100 \mathrm{~mm}$ line as illustrated in Figure 3.6. 


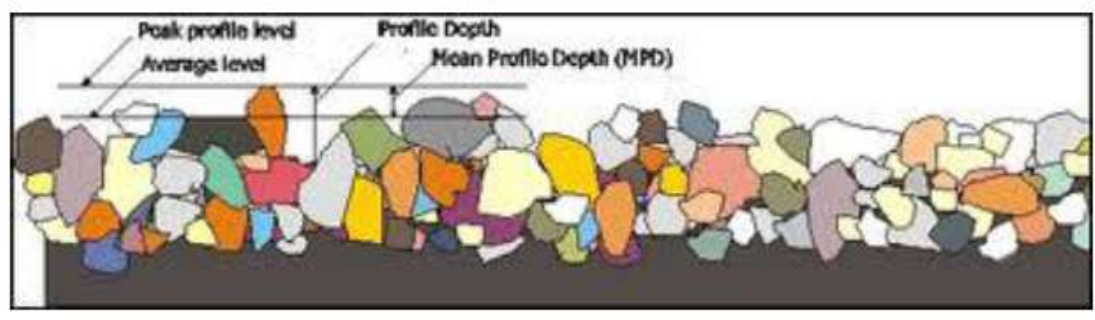

Figure 3.6 Mean Profile Depth (MPD)

Source: Kannemeyer, 2003

The pavement surface skid resistance is a function of the surface textures that include the wavelength ranges described by micro texture, consisting of wavelengths of $1 \mu \mathrm{m}$ to $0.5 \mathrm{~mm}$, and macro texture, with wavelengths of $0.5 \mathrm{~mm}$ to $50 \mathrm{~mm}$. Micro texture is a surface characteristic having wavelength components less than $0.5 \mathrm{~mm}$, formed by the irregularities on the surface particles exposed at surface level, and is normally measured with a friction measurement device such as the ROAR or SCRIM. The micro texture is affected primarily by aggregate characteristics (shape, angularity and texture). Macro texture is a surface characteristic related to potential channels for water drainage between the vehicle tyre and road surface, which has a wavelength range of $0.5 \mathrm{~mm}$ to $50 \mathrm{~mm}$. Macro texture is a function primarily of the mixture gradation and design.

\subsection{Pavement Structural Assessment utilizing HWD}

Heavy Weight Deflectometer (HWD) testing employs a non-destructive device which includes nine geophones, as shown in Figure 3.7, designed for multi-purpose pavement applications, ranging from unpaved roads to airfields. HWD generated data, combined with layer thicknesses, can be confidently used to obtain the resilient elastic moduli of the structural layers within a pavement structure. This information was, in turn, 
used in the structural analysis to determine the bearing capacity, estimated expected life, and to develop a rehabilitation plan.

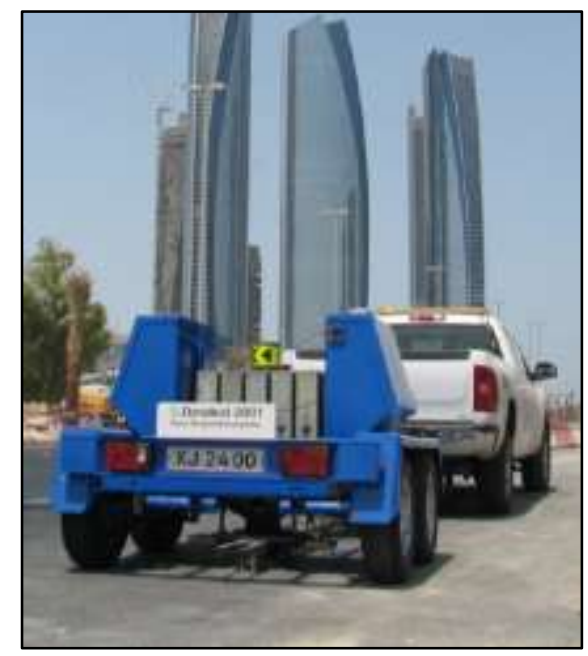

\section{Figure 3.7 Heavy Weight Deflectometer (HWD)}

Source: Abu Dhabi Municipality data collection reports, 2014

The pavement structural evaluation was conducted using the Dynatest Heavy Weight Deflectometer. A minimum of three tests were carried out at each location in accordance with ASTM D4694. The drop loads were $60 \mathrm{kN}, 90 \mathrm{kN}$ and $130 \mathrm{kN}$. At each test point, the peak applied load and peak deflections were recorded from nine geophones at selected offsets ranging from under the center of the load to a distance of $1.8 \mathrm{~m}$ from the load.

The Back-Calculation analysis of the HWD data was carried out using ELMOD 6.0 to report layer resilient elastic modulus. The remaining structural life was determined in terms of tolerable equivalent standard axles load repetitions $(80 \mathrm{kN})$ using the Austroads subgrade deformation and asphalt fatigue criterion.

The following were automatically recorded during the survey:

- Linear Reference (Station)

- GPS Location

- Peak Load 
- Peak Deflection for each of the 9 Geophones

- Surface Temperature

- Air Temperature

- Date and Time of Test

In addition, in some cases a Geocoded video logging vehicle equipped with three cameras was used in which two cameras mounted for collecting the road data related to road furniture within right of way at right and left side of the road while one camera was to capture the pavement condition Figure 3.8 shows a picture of the vehicle used for geocoded video logging.

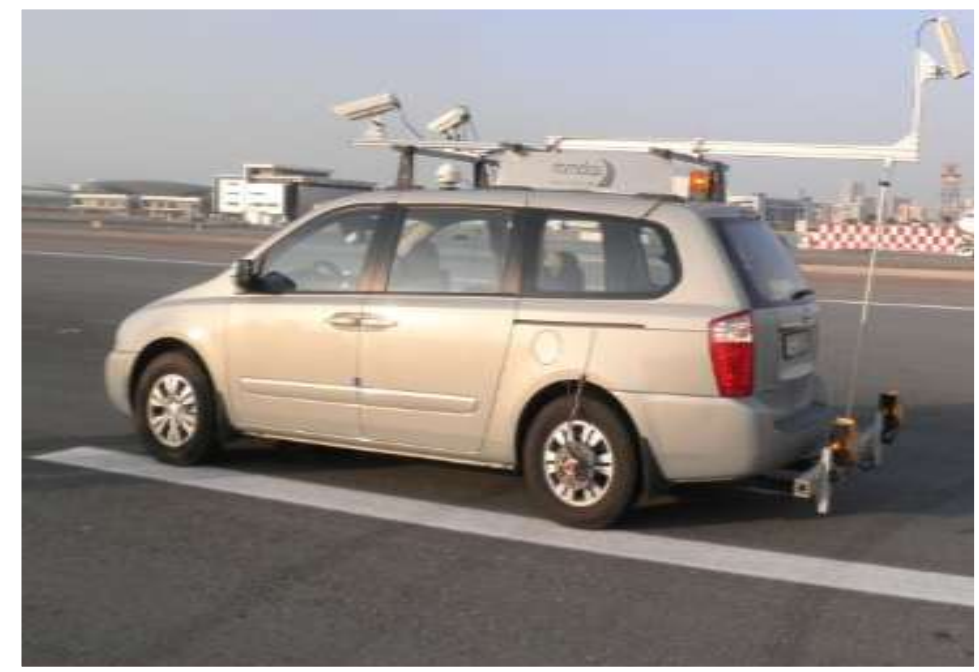

Figure 3.8 Vehicle used for Geocoded video logging

Source: Abu Dhabi Municipality data collection reports 2014

The data collected through Geocoded video logging included a number of factors, for example:

- Road Identification and Classification

- Street Name

- Type of Pavement

- Gullies and Catch Basins

- Street Lights 
- Road Side Cameras

- Control Cabinets

- Traffic Signs

- Gantry Signs

- $\mathrm{Road} /$ Pavement Markings

- Traffic Signals

- Bus Stands

- Fire Hydrants

- Bollards

- Location of Bridges

- Kerb-stone

- Fence

- Parapets

- Barriers

- Guard Rails

- Foot Path / Walkways

- Median

- Roundabouts conditions and Geometric Configuration

- Layby

- Cat Eyes and Studs

- Condition and type of Island

- Humps/Speed Breakers

- Location and Condition of Pedestrian Crossing

\subsection{Pavement Maintenance Types}

Typically three types of pavement maintenance are applied. As show in Figure 3.9 these three maintenance types are Preventive, Corrective, and Emergency. 


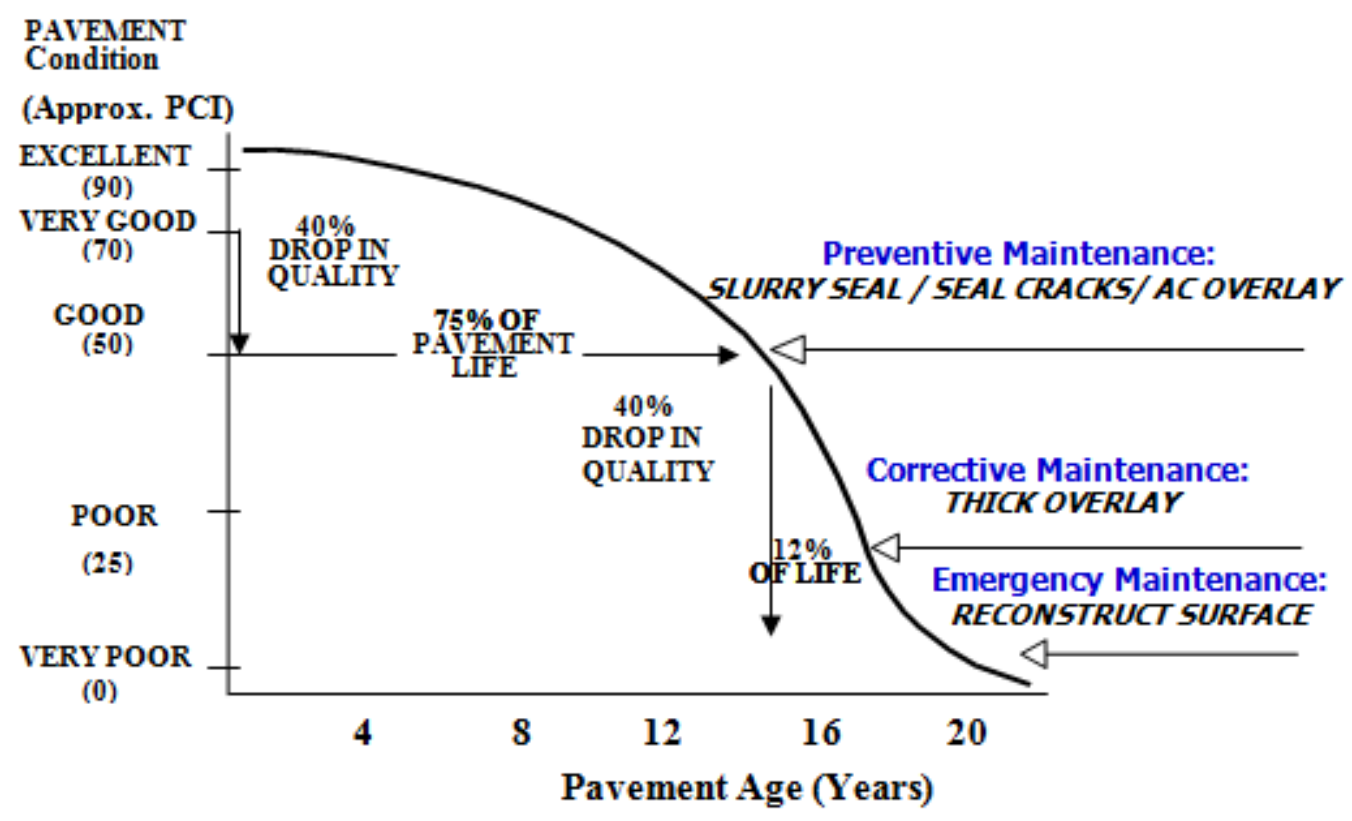

Figure 3.9 Types of pavement maintenance as per time and pavement condition Source: Hicks et al., 2000

Preventive maintenance: is used to correct minor deterioration, retard progressive failures, and reduce the need for corrective maintenance. It is performed before the pavement shows significant distress to provide a more uniform performing pavement system. The preventive maintenance is normally applied under a planned strategy of costeffective treatments to an existing pavement system and its accessories that preserves the system, retards future deterioration, and maintains or improves the functional condition of the system. Preventive maintenance prolongs the life of a particular depreciated asset, either by replacing it with a new one, or by some other intervention (such as Slurry seal, Cracks seal or Thin overlay).

Corrective maintenance: is performed after a deficiency occurs in the pavement; i.e., loss of friction, moderate to severe rutting, or extensive cracking. Corrective maintenance is generally performed after a deficiency occurs in the pavement system, such as moderate to severe heaving, raveling or extensive cracking. Corrective maintenance may 
also be referred to as reactive maintenance which is conducted in response to detection, through periodic safety and service inspections or as reported by members of the public, of flaws or defects that could adversely affect the safety of, or service offered by, the asset. Most reactive maintenance activities are performance-based, meaning that they occur when inspections reveal that the performance of an asset has fallen below the required level of safety or serviceability.

Emergency Maintenance: Performed during an emergency situation, such as flooding, sand storm or a severe pothole or trip hazard that needs repair immediately. This could also include temporary treatments that hold the surface together until a more permanent treatment can be performed. There are no clear boundaries between when a treatment is preventive versus corrective, or corrective versus emergency. All types of maintenance are needed in a complete pavement system preservation program. However, emphasizing preventive maintenance may prevent or prolong the need for corrective maintenance.

Although each type of maintenance is needed in a comprehensive pavement preservation program, the emphasis should be placed on preventing a pavement from reaching the condition where corrective maintenance is required, since the cost associated with this approach can be substantial O'Brien (1987). This situation is often depicted as shown in Figure 3.10, which compares different treatments at different times. The challenge is to determine the cost effectiveness of the preventive maintenance approach compared with standard practices of rehabilitation when the pavement wears out, such challenge is depicted in Figure 3.11. 


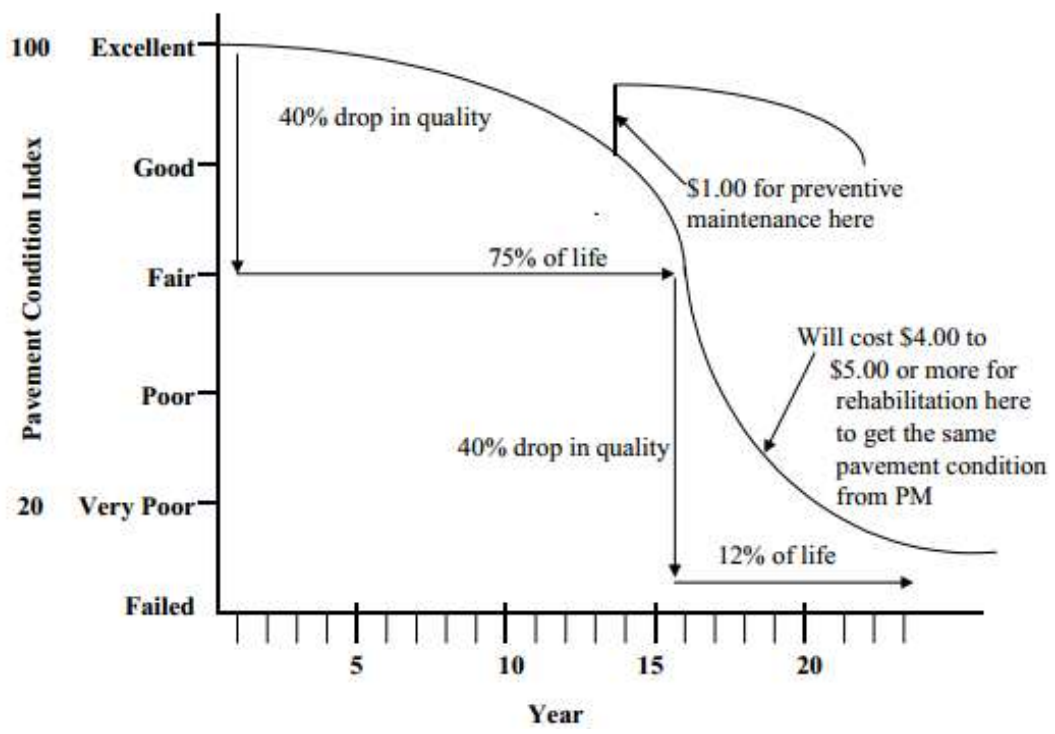

Figure 3.10 Typical Variation in Pavement Conditions as function of Time Source: O’Brien, 1987

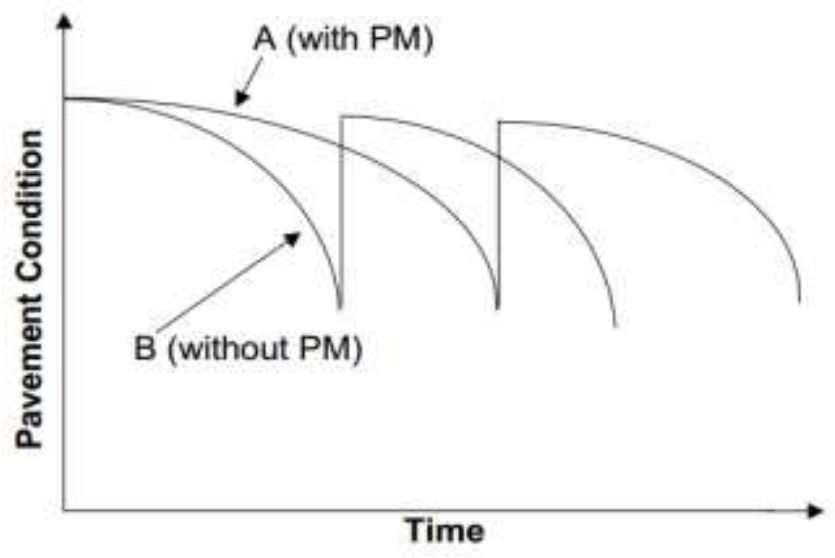

Figure 3.11 Deterioration curves with and without preventive maintenance Source: O’Brien, 1987 


\section{Chapter: Development of Pavement Condition Prediction Model}

\subsection{Introduction}

This chapter describes the pavement prediction models developed for Abu Dhabi. The background information required for the development of pavement condition models is also discussed in this chapter.

In general, the pavement prediction models described in the literature review chapter predict the pavement performance as a function of many explanatory variables. For this research, the regression modeling approach is adopted for the development of performance models. The alternate approach was to use Markov chain process to predict the condition of pavement. The reasons to select the regression approach are as follows:

- The regression model provides a continuous age-PCI curve, while Markov assumes few discrete states (e.g. excellent, very good, good, fair and poor).

- Markov would require a large volume of data to reflect very fine degradation values, like a small drop of the PCI.

The regression models are simpler to model and use in the Pavement Management Systems. This research is limited to asphalt-surfaced pavements for which the key performance measures that could be considered for performance modeling are as follows:

- Rutting (mm)

- Roughness, IRI (m/km)

- Area of alligator cracks of medium and high severity (percent)

- Area of 'other cracks' (combination of low severity alligator, block, edge, longitudinal, transverse, and reflection cracks) (percent) 
The performance prediction models express the future state of performance measures as a function of explanatory variables. A partial list of explanatory variables includes pavement structure, age, traffic loads, and environmental variables. Numerous performance prediction models can be found elsewhere in the literature (Lukanen and C. Han 1994, Darter et al. 1985, Jackson and Mahoney 1990, Lytton, R.L 1987).

The prime variables affecting the pavement performance include age, traffic, rehabilitation type, and pavement strength in terms of structural number. As mentioned previously, the developed models could also be classified as homogenous and nonhomogenous models. In homogenous models, some variables such as pavement structure and traffic could be assumed as constant. The data collected from the pavement sections with similar characteristics such as traffic and pavement structure could be aggregated to develop homogenous models.

The development of a reliable prediction model needs certain requirements to be satisfied. Darter (1980) described the requirements and general development of reliable pavement performance models. The factors that must be considered include:

- Adequate Database: The database must be adequate and representative of the overall pavement network that the model is being developed to represent. The data collected must be measured accurately and without bias.

- Reliable Data: Care must be taken to assure the accuracy of the data obtained from historical records.

- Sufficient Amount of Data: The development of a reliable model requires the collection of a sufficient amount of data. 
- Inclusion of Variables: Every possible variable that may affect the performance of pavement should be considered initially. This list will typically be large. However, development of best possible regression model involves extensive knowledge about the problem at hand, and of the regression analysis program.

- Functional Form of the Model: The functional form of the model or the way in which the variables are arranged has a great effect on the regression model's reliability.

- Statistical Criteria: The final model should explain a high percentage of total variation about regression (or $\mathrm{R}^{2}$ ). The standard error of the estimate should be less than a practical value of usefulness. All estimated coefficients of the predictor variables should be statistically significant, and there should be no discernible patterns in the residuals.

\subsection{Comparison between Markov Chain and Regression Modeling}

The main assumption of a Markov Chain model is that the present state includes all the information needed for future predictions, meaning that information from previous years is not required. Therefore, all future states of pavement condition rely on transition

matrix defined at very first year. Use of Markov Chain in optimization process of pavement management system is complex and relies on a transition probabilities matrix, which has no viable calibration procedure. Weijde O.V (2013) reported that the steady state conditions could never be reached in Markov Chain models due to fluctuations in budgeting, pavement behavior, and transition probabilities. 
The regression models could formulate pavement condition prediction depending on independent forecasted variables of traffic load and age of pavement etc. These models could easily be used in a linear optimization models. The advantage of this method is that a standard linear programming solver can easily be used to solve the optimization problem.

\subsection{Data Used to Develop Pavement Prediction Models for Abu Dhabi}

Abu Dhabi Municipality assesses pavement condition through the use of windshield surveys and automated road analyzer. Pavement condition surveys are conducted on all flexible pavement sections every year. A 100 percent survey is conducted on all flexible pavement sections. Pavement condition surveys were conducted by trained personnel traveling at 15 to $20 \mathrm{Km} / \mathrm{hr}$ who record the presence of a variety of observed pavement distresses. Abu Dhabi Municipality also collects measurements of rutting, pavement roughness, and pavement condition index data utilizing the following field survey technologies:

- Weigh in Motion (WIM) System: Utilizing the IRD Traffic Recording System (TRS) and piezo-electric sensors provided classified traffic and vehicle axle load data for the design lane on the main carriageway.

- Automated Road Analyzer (ARAN): Utilizing the ARAN system provided pavement condition parameters for ride quality (roughness), rut depth, and riding comfort index. 
- Pavement rehabilitation and maintenance activities were recorded for each pavement section using pavement maintenance record maintained by the Abu Dhabi Municipality.

\subsection{Sample Location Site}

The general location of Ruwais Bypass is part of the E11 Expressway near Ruwais in Abu Dhabi emirate as shown in Figure 4.1 and is located between Station 63+600 to Station $143+000$ of the E11 expressway using the Abu Dhabi DoT expressway linear referencing system. The general orientation of the site is in a West to East direction with 3 lanes in each direction. There are also four interchanges located along the main project carriageway, which consisted of multiple ramps, cross roads and loop roads.

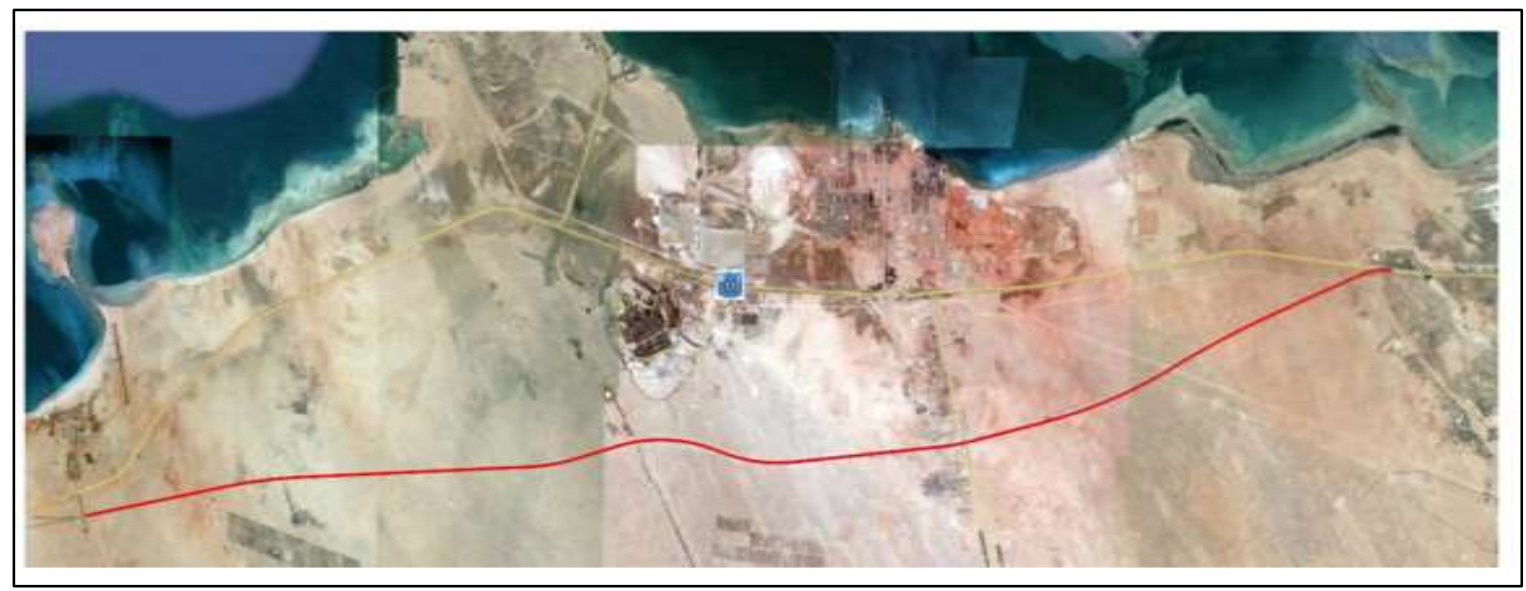

Figure 4.1 Site Location Main Carriageway

Source: Department of Transport Abu Dhabi, 2014

For the purpose of data collection the following lane convention has been used as illustrated in Figure 4.2 following and the chainage values are referenced in the prescribed direction for all lanes. 

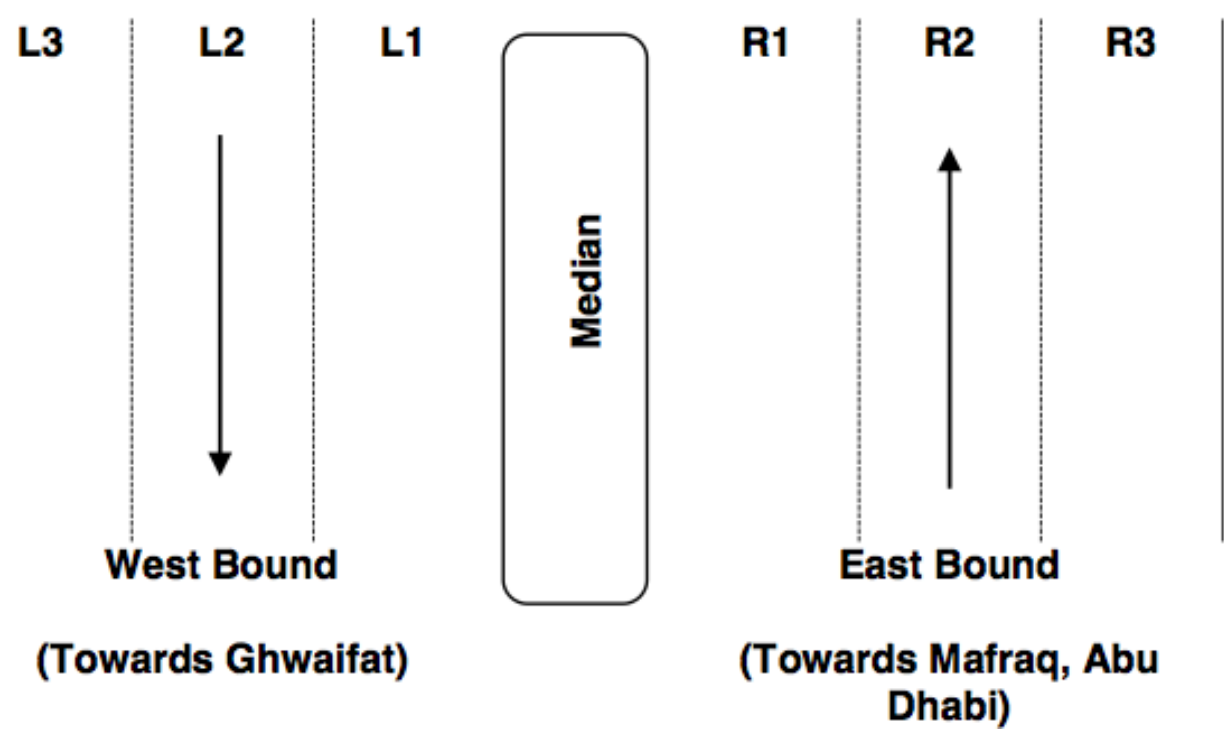

Figure 4.2 Lane Designation for Main Carriageway Data Collection Source: Department of Transport Abu Dhabi, 2014

As part of data collection, the carriageways were divided into different sections with homogenous pavement design and traffic loading. The section division for the sample location site is as follows:

- Westbound Carriageway (Towards Ghwaifat)- Six Sections

- Eastbound Carriageway (Towards Mafraq, Abu Dhabi) - Ten Sections

The two principal designs for the main carriageway of the project were full depth asphalt pavement with both cement bound and unbound bases. It was previously noted by the contractor that geo-grid or geo-textile was used in some locations where subgrade conditions were considered to be an issue. However, the exact locations of these areas 
were not made available. But they are not considered a major influence on the structural evaluation output. The chainage for homogenous pavement sections for westbound and eastbound carriageways of sample location site are shown in Table 4.1 and Table 4.2 respectively.

Table 4.1 Chainage for Westbound Carriageway

\begin{tabular}{c|c|c|c|c|}
\hline Section ID & \multicolumn{2}{c|}{ Construction Chainage } & \multicolumn{2}{c|}{ Equivalent } \\
\hline LHS-1 & $-5+400$ & $0+000$ & $63+600$ & $69+000$ \\
\hline LHS-2 & $0+000$ & $9+000$ & $69+000$ & $78+000$ \\
\hline LHS-3 & $9+000$ & $13+000$ & $78+000$ & $82+000$ \\
\hline LHS-4 & $13+000$ & $20+000$ & $82+000$ & $89+000$ \\
\hline LHS-5 & $20+000$ & $25+500$ & $89+000$ & $94+500$ \\
\hline LHS-6 & $25+500$ & $74+000$ & $94+500$ & $143+000$ \\
\hline
\end{tabular}

Source: Department of Transport Abu Dhabi, 2014

Table 4.2 Chainage for Eastbound Carriageway

\begin{tabular}{|c|c|c|c|c|}
\hline Section ID & \multicolumn{2}{c|}{ Construction Chainage } & \multicolumn{2}{c|}{ Equivalent } \\
\hline RHS-1 & $-5+400$ & $0+000$ & $63+600$ & $69+000$ \\
\hline RHS-2 & $0+000$ & $0+300$ & $69+000$ & $69+300$ \\
\hline RHS-3 & $0+300$ & $0+350$ & $69+300$ & $69+350$ \\
\hline RHS-4 & $0+350$ & $0+575$ & $69+350$ & $69+575$ \\
\hline RHS-5 & $0+575$ & $0+800$ & $69+575$ & $69+800$ \\
\hline RHS-6 & $0+800$ & $9+000$ & $69+800$ & $78+000$ \\
\hline RHS-7 & $9+000$ & $13+100$ & $78+000$ & $98+100$ \\
\hline RHS-8 & $13+100$ & $20+000$ & $98+100$ & $105+000$ \\
\hline RHS-9 & $20+000$ & $25+500$ & $105+000$ & $110+500$ \\
\hline RHS-10 & $25+500$ & $74+000$ & $110+500$ & $143+000$ \\
\hline
\end{tabular}

Source: Department of Transport Abu Dhabi, 2014

To simplify pavement condition modeling, the pavement sections were further classified into three classes as summarized in Table 4.3. The classification is based upon a defined range of traffic and pavement thickness adopted in the Emirate of Abu Dhabi. The traffic is generally represented by ESAL. These are considered the main influence 
factors to the performance prediction models. A general practice is to develop the initial default models using the available information and engineering judgment and then update the default model coefficients for individual pavement sections with data/performance available for each section.

Table 4.3 Influence Factors Classes Used in Default Prediction Models

\begin{tabular}{|l|l|l|l|}
\hline \multirow{2}{*}{ Influence Factors } & \multicolumn{3}{|c|}{ Classes for Influence Factors } \\
\cline { 2 - 4 } & \multicolumn{1}{|c|}{ Class 1 } & \multicolumn{1}{c|}{ Class 2} & Class 3 \\
\hline $\begin{array}{l}\text { Traffic (Total } \\
\text { ESALs per year) }\end{array}$ & $(<50,000)$ & $(50,000-500,000)$ & $(>500,000)$ \\
\hline $\begin{array}{l}\text { Structural Thickness } \\
\text { (Granular Base } \\
\text { Equivalency) }\end{array}$ & $(\mathrm{GBE}<500 \mathrm{~mm})$ & $(\mathrm{GBE}=500-750 \mathrm{~mm})$ & $(\mathrm{GBE}>750 \mathrm{~mm})$ \\
\hline
\end{tabular}

ESAL (Equivalent Single Axle Load)

\subsection{Pavement Prediction Models for Abu Dhabi}

The mathematical equations and models mentioned in the literature review chapter above are the models developed in different parts of the world which lead to the information about important variables and performance measures that should be considered in pavement performance modeling. The presented models are composed of various variables which were not readily available for calibration purposes. Several prediction models have been developed to predict pavement performance in terms of pavement conditioning index. As mentioned previously, the pavement performance depends on aging, cumulative traffic, and pavement structure. Road sections were categorized based on influence factors of traffic and pavement structural thickness. Pavement condition data for each section was analyzed and default pavement performance prediction models were developed. The developed models are presented in 
Table 4.4 and were calibrated using the data available for the Emirate of Abu Dhabi. As shown in Table 4.4 the values of $\mathrm{R}^{2}$ for all three models are reasonably high suggesting good correlation achieved bythe regression models. The value $\mathrm{R}^{2}$ is a statistical measure of how close the data are to the fitted regression model and is also known as the coefficient of determination/ The value of $R^{2}$ ranges from 0 to $100 \%$. An $R^{2}$ value of 0 $\%$ indicates that the mode cannot explain the variability of the response data around its mean, while $100 \%$ indicates that the model is prefect (in fact becomes deterministic) which explains all the variability of the response data around its mean.

\section{Table 4.4 Pavement Condition Index Prediction Models}

\begin{tabular}{|l|l|l|l|}
\hline S.No. & \multicolumn{1}{|c|}{ Classes } & \multicolumn{1}{|c|}{ Model } & \multicolumn{1}{|c|}{$\mathbf{R}^{2}$} \\
\hline 1 & Class 1 & PCI $=-0.026^{*} \mathrm{Age}^{\wedge} 2-2.721 * \mathrm{Age}+92.34$ & 0.78 \\
\hline 2 & Class 2 & $\mathrm{PCI}=-0.027^{*} \mathrm{Age}^{\wedge} 2-2.45 * \mathrm{Age}+81.34$ & 0.82 \\
\hline 3 & Class 3 & $\mathrm{PCI}=0.053^{*} \mathrm{Age}^{\wedge} 2-4.89 * \mathrm{Age}+89.3$ & 0.76 \\
\hline
\end{tabular}

Where, $\mathrm{PCI}=$ Pavement Condition Index (0-100) and Age= Age of Pavement (years)

The detailed results of the regression analysis are presented in Appendix A.

\subsection{Summary}

This chapter presented a review of performance measures, performance prediction models and development of pavement condition prediction model for the Emirate of Abu Dhabi. The developed model will be used in the optimization process to determine when the pavement needs application of maintenance and used along the optimization model to provide the basis of the proposed framework and assess in establishing the performancebased contracts for the Emirate of Abu Dhabi. 


\section{Chapter: Optimization Model}

\subsection{Introduction}

Optimization is an important tool to find an optimal solution for many complex problems. The long term planning of road maintenance allows for many possible maintenance scheduling schemes and they exhibit different costs, therefore running an optimization process provides a means of reducing the cost while maintaining the required quality of service. Pavement management systems involve many decision problems, which require optimal solution, such as decisions on alternative maintenance treatments, minimizing maintenance cost, and maximizing pavement performance. An optimization model can help

- to reach a decision on alternate maintenance solutions,

- to minimize maintenance cost, and

- $\quad$ to maximize the pavement performance.

This chapter presents a review of optimization strategies used in pavement management systems and the development of an optimization model for the proposed framework for establishing a performance-based pavement management contract for the Emirate of Abu Dhabi. An example is also presented to demonstrate the application of the proposed optimization model in performance-based pavement management systems. 


\subsection{Development of an Optimization Model}

Municipalities and roadway authorities allocate annual budgets to maintain their road network to set standards. The allocation of an annual budget for rehabilitation and maintenance $(\mathrm{R} \& \mathrm{M})$ activities requires a "what-if" analysis in order to prioritize and establish an effective road maintenance strategy. This strategy is implemented through a performance-based contract, which is monitored to understand how this budget allocation strategy influences the overall road network performance (Jesus M. de la Garza et al. 2011). The optimal budget allocation strategy should meet the budget constraints and performance goals. The framework proposed is to adopt $\mathrm{PBC}$ in the Emirate of Abu Dhabi that also involves an optimization tool to prioritize maintenance activities and allocate annual budgets. This research developed an optimization model in order to optimize the maintenance activities. The proposed optimization model has several components as follows:

- Identifying the road network information including road geometric and construction design history and data

- Evaluation of current needs/performance targets

- Identification of maintenance treatments

- Prediction of future road conditions

- Optimization model formulation

- Optimization outcome 


\subsubsection{Identifying Road Network Information}

It is essential to identify the road network to be considered for rehabilitation and maintenance activities. A database pertaining to the pavement conditions of all the Abu Dhabi road network is maintained and analyzed. The pavement condition rating analysis identifies the road conditions for all roads within the Emirate of Abu Dhabi. The road conditions are measured in terms of performance measures described in Chapter 4. The measured road conditions facilitate the prioritization of the road networks to be considered in optimization process for budget allocation purposes. The Abu Dhabi road network is divided into two areas: the island and the mainland. The description of the island and mainland is as follows:

The mainland of Abu Dhabi is off the Island and is a fastest growing area in Abu Dhabi where several sub-urban areas have been developed over the past two decades. The popular areas include within the mainland are:

- Bain AL Jessrain

- Al Raha

- Khalifa City A

- Khalifa City B

- Mohammed Bin Zayed City

The island of Abu Dhabi is the heart of the city, where the action is both commercially and where recreation is concentrated with the popular Corniche and the beaches along the coast. The popular areas include within the island are:

- Downtown Abu Dhabi

- Al Markaziyah

- Madinat Zayed

- West Abu Dhabi

- Al Khalidiyan

- Al Bateen 
- Central Abu Dhabi

- Al Muroor

- Al Karama

Figure 5.1 and Figure 5.2 below illustrate the pavement conditions identified for the Abu Dhabi road network in 2013.

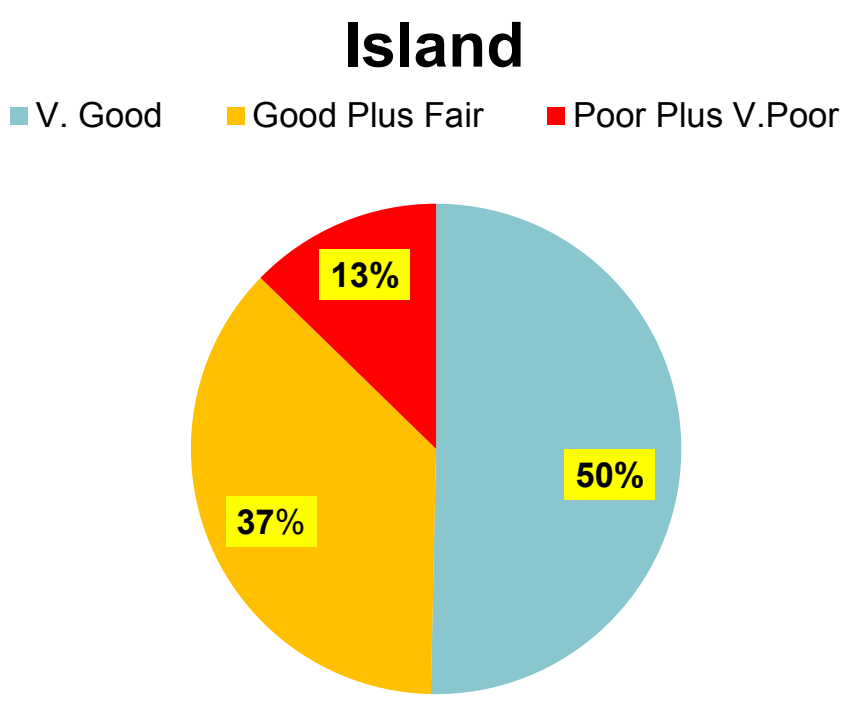

Figure 5.1 Road Conditions in Abu Dhabi Island

Source: Abu Dhabi Municipality data collection reports 2010-2011 


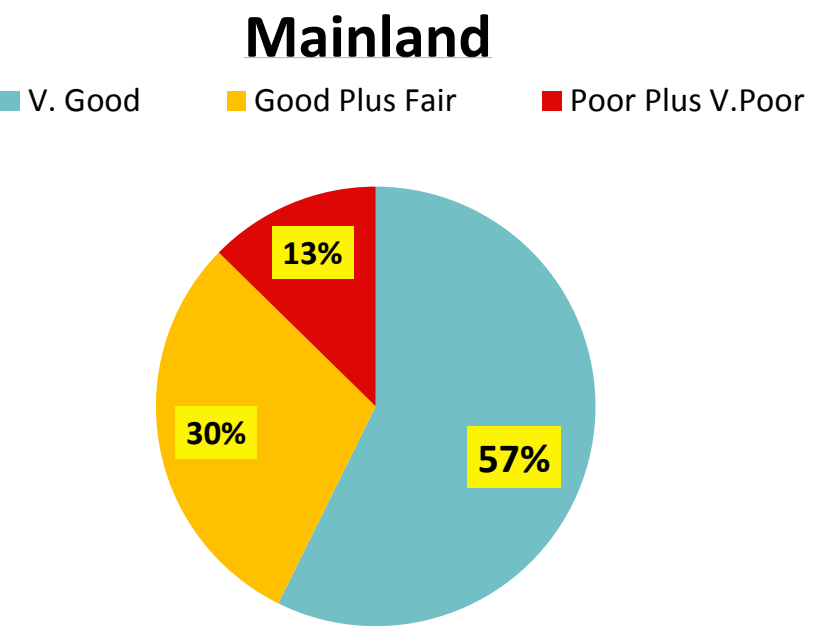

Figure 5.2 Road Conditions in Abu Dhabi Mainland

Source: Abu Dhabi Municipality data collection reports 2010-2011

The total pavement area included in Abu Dhabi is given in Table 5.1.

Table 5.1 Pavement Areas in Emirate of Abu Dhabi

\begin{tabular}{|c|c|c|c|}
\hline Geographic Area & $\begin{array}{c}\text { Abu Dhabi } \\
\text { Island }\end{array}$ & Mainland & Total \\
\hline Pavement $\left(\mathrm{m}^{2}\right)$ & 971,163 & $1,181,125$ & $\mathbf{2 , 1 5 2 , 2 8 8}$ \\
\hline
\end{tabular}

Source: Abu Dhabi Municipality data collection reports 2010-2011

The road network under consideration in this study is classified into several sections depending upon the pavement structure, traffic, and pavement conditions. The 
road sections requiring the allocation of maintenance activities are identified with their respective lengths and are considered in the optimization model as input variables.

\subsubsection{Evaluation of Current Needs/Performance Targets}

The evaluation of current road conditions and annual budgets are two requirements for setting performance targets for a given roadway network. However, the roadway authorities also define the minimum performance measure standards that are objectives to be achieved. Therefore, performance measure targets are introduced as constraints in the optimization model. Performance measure conditions such as very poor, poor, and fair at time 0 are equal to the baseline or current condition but are set to a target value during the planning horizon. However, some agencies also consider that performance targets vary linearly during the planning horizon, decreasing over time such as 25 in year 5 and 10 in year 15. In Abu Dhabi, the road conditions in terms of various performance measures are described in Table 5.2.

Table 5.2 Road Condition States

\begin{tabular}{|c|c|c|c|}
\hline \multirow{2}{*}{ Road Conditions } & \multicolumn{3}{|c|}{ Performance Measures } \\
\cline { 2 - 4 } & IRI (m/km) & Rut Depth (mm) & PCI \\
\hline Good & $<2$ & $<5$ & $>90$ \\
\hline Fair & $2-3$ & $5-10$ & $75-90$ \\
\hline Poor & $3-3.8$ & $11-20$ & $<75$ \\
\hline Very Poor & $>3.8$ & $>20$ & - \\
\hline
\end{tabular}

Source: Abu Dhabi Municipality data collection reports 214 


\subsubsection{Identification of Maintenance Treatments}

Maintenance treatments restore the pavement condition from a worse condition to a better condition. The expected performance targets for each condition state can be achieved through the application of maintenance treatments, considering budget and performance measure target constraints (Jesus M. de la Garza et al. 2011). The optimization model uses these constraints to identify treatments and respective costs during the planning horizon. A sample relationship between the road conditions and maintenance treatments is illustrated in Figure 5.3.

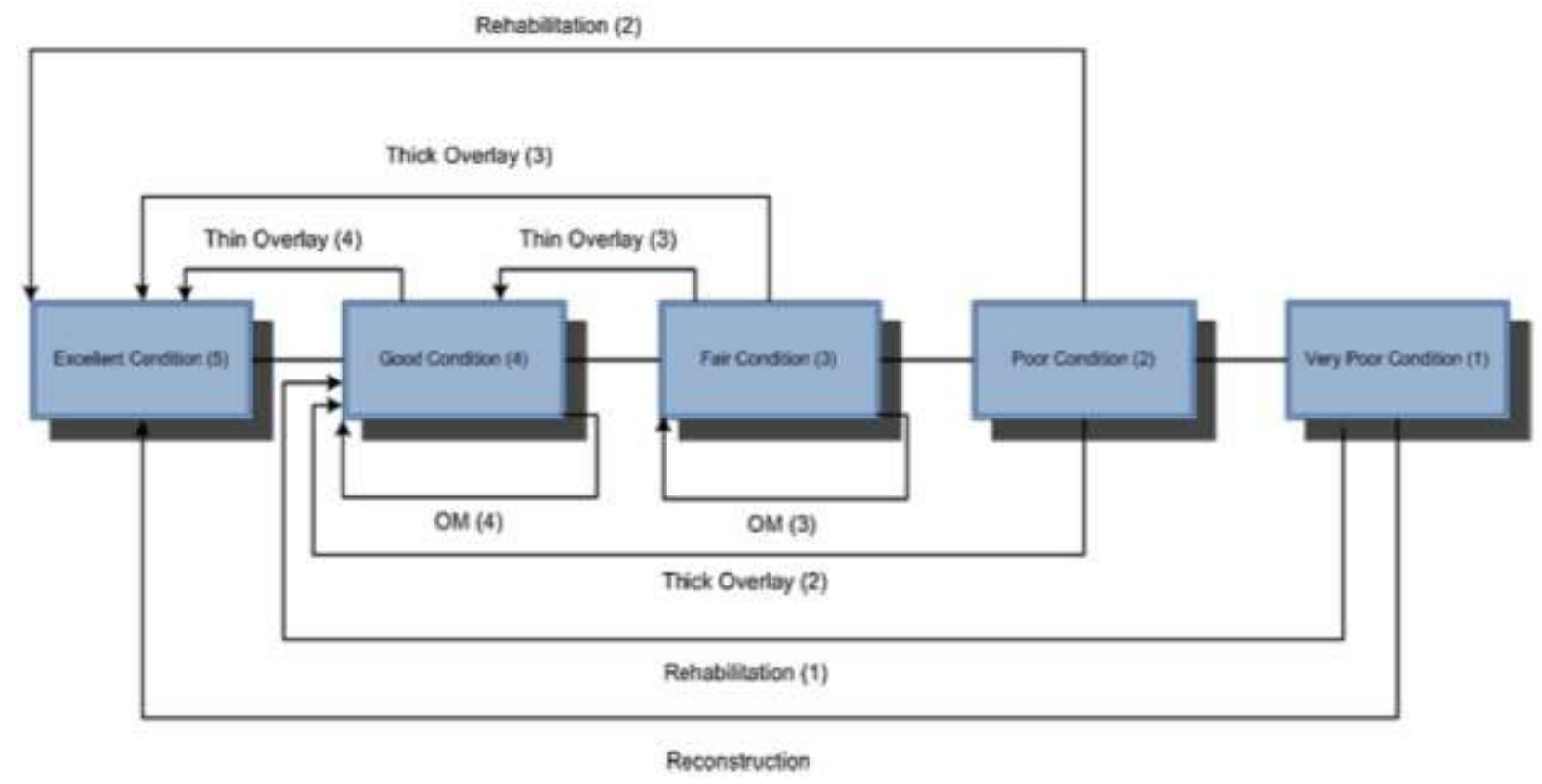

Figure 5.3 Pavement condition states and maintenance activities

Source: Jesus M. de la Garza et al., 2011 


\subsubsection{Prediction of Future Road Conditions}

As described in Chapter 2, reliable pavement deterioration/performance prediction models are beneficial for pavement management systems. Using pavement performance prediction models in optimization predict the optimal time for applying maintenance and rehabilitation treatments. It also determines the required long-term financial requirements or provides optimal solution within a given annual budget (A. Sadek et al. 1996). The pavement deterioration models developed using the Abu Dhabi pavement condition states will be adopted in the optimization model. The pavement deterioration rates, which were developed deterministically based on historical data, are uniform for successive years. Liu et al. (1997) favor this assumption by stating that it is reasonable to assume fixed yearly deterioration rates since the values of many parameters used in nonlinear deterioration models are not readily available, hence nonlinear deterioration models are not practical in real problems.

The optimization model developed in this research assumes that pavement deterioration materializes in increments of one condition state per year, that is, deterioration from an upstream condition to the next downstream condition only. For example, pavements in Good condition can deteriorate only to Fair condition each period provided that no maintenance activity is carried out. The pavement deterioration models developed for different classes of road sections will be used in the optimization process.

\subsubsection{Optimization model formulation}

The optimization formulation is in the form of an objective function and a set of constraints in terms of a system of equations or inequalities to form a mathematical 
optimization model. The optimization model components described above are presented in mathematical form to build an optimization model. Table 5.3 presents the potential components and functions used in developing an optimization model for the proposed pavement management system.

Table 5.3 Optimization model functions and components

\begin{tabular}{|c|c|}
\hline Functions & Components \\
\hline Objective & Minimize costs (Construction costs, maintenance costs etc.) \\
AND \\
Input Data and \\
Models \\
(Maximize pavement condition index, minimize roughness index, \\
rutting etc.)
\end{tabular}

\subsubsection{Objective Function}

The objective function of the optimization model defines the objectives to be achieved in the optimization process. As mentioned in Table 5.3 the objective function could be defined to minimize the overall maintenance cost and maximize the pavement performance in terms of improving the pavement condition index or decreasing the 
overall rut depth of all pavement sections. The proposed objective function for the optimization model is to minimize the maintenance cost as follows:

Minimize:

$$
\sum_{\mathrm{m}=1}^{\mathrm{M}} \sum_{\mathrm{s}=1}^{\mathrm{S}} \sum_{\mathrm{t}=1}^{\mathrm{T}} \mathrm{Xmst} \text { Ls Csmt }(1+\mathrm{R})^{\mathrm{t}} \quad \forall \mathrm{s}, \mathrm{m}, \mathrm{t}
$$

Where,

Xmst $=$ Treatment $\mathrm{m}$ applied at a pavement section $\mathrm{s}$ at time $\mathrm{t}(\mathrm{m})$

Csmt $=$ Unit cost for treatment $m$ applied at a pavement section $s$ at time $t(A E D / k m)$

Ls = length of pavement section $\mathrm{s}(\mathrm{km})$

$\mathrm{R}=$ Discount rate for calculating present value of future cost $(\%)$

\subsubsection{Constraints}

As mentioned in Table 5.3, the constraints for optimization process may include budget, minimum performance targets, treatment effects, limiting the number of treatment in one year. The constraints in an optimization model are referred with a statement as subject to as follows:

Subject to:

$\sum_{\mathrm{m}=1}^{\mathrm{M}} \mathrm{Xmst}=1 \quad \forall \mathrm{m}, \mathrm{s}, \mathrm{t}$

Xmst $=\left\{\begin{array}{c}1 \text { if maintenence treatment } m \text { is selected for section } s \text { at time } t \\ 0 \text { otherwise }\end{array}\right.$

$\sum_{s=1}^{\mathrm{S}} \sum_{\mathrm{m}=1}^{\mathrm{M}} \mathrm{Xmst} \operatorname{Ls} \operatorname{Cstm}(1+\mathrm{R})^{\mathrm{t}} \leq \mathrm{B}$, for $\mathrm{t}=1,2,3, \ldots \mathrm{T}$

Where, $\mathrm{B}=$ Total annual budget for horizon years 
PCIs $_{(\mathrm{t})}=\mathrm{F}($ AGEst $) \quad \forall \mathrm{s}, \mathrm{z}, \mathrm{t}$

Where, PCIs ${ }_{(t)}=$ Predicted pavement condition index for pavement section $\mathrm{s}$ at time $\mathrm{t}$, which is the function of pavement section age in terms of number of years as explained in Chapter 4.

$\operatorname{CPCIs}_{(\mathrm{t}+1)}=\mathrm{ABS}\left[\mathrm{PCIcs}_{\mathrm{t}}-\left(\mathrm{PCIs}_{\mathrm{t}}-\mathrm{PCIs}_{\mathrm{t}+1}\right)+(\mathrm{Xmst} \Delta \mathrm{PCIm})\right] \quad \forall \mathrm{s}, \mathrm{t}, \mathrm{m}$

Where, $\mathrm{CPCIs}_{(\mathrm{t}+1)}=$ cumulative pavement condition index for sections at year $\mathrm{t}+1$ and $\triangle P C I m=$ improvement in PCI associated with treatment $\mathrm{m}$.

$$
\begin{array}{lr}
\operatorname{CPCIs}_{(\mathrm{t}+1)} \geq \mathrm{PCI}_{\text {min }} & \forall \mathrm{s}, \mathrm{t} \\
\mathrm{CPCIs}_{(\mathrm{t}+1)} \leq \mathrm{PCI}_{\text {max }} & \forall \mathrm{s}, \mathrm{t}
\end{array}
$$

Where, PCIs $\min _{\text {min }}$ PCIs max $_{\text {ax }}=$ the minimum and maximum pavement performance measure targets set by the roadway authorities. The pavement condition index (PCI) is measured on a scale of 0 to 100 , with 100 being perfect, then the highest level of the PCI is 100 , i.e., $\mathrm{PCI}_{\max }$ is 100 .

\subsubsection{Optimization Model}

An optimization model is developed using linear programming and coded in LINGO. The code of the program is presented Appendix B. The program includes 186 constraints and 215 variables including 120 integer/binary variables. The binary variables were assigned to maintenance treatments for each pavement section at each successive 
year of maintenance program. The optimization model developed will aid the framework proposed for performance-based contracts.

\subsection{Application of Optimization Model}

In this section an example is presented to demonstrate the application of the optimization model developed in this thesis. In this example, for illustration purpose a road network consisting of 3 pavement sections is selected and objective is to prioritize the maintenance treatments for a performance-based contract. The initial/current pavement condition in terms of pavement condition index at year 0 is observed as 80 . For the purpose of pavement performance predictions, section 1, 2, and 3 are situated within zones 1,2 , and 3 , respectively. Table 5.4 shows the pavement sections information data including highway number, pavement section number, and section length.

Table 5.4 Example pavement information data

\begin{tabular}{|c|c|c|}
\hline $\begin{array}{c}\text { Highway No. and } \\
\text { Class No. }\end{array}$ & Section No-ID & Section Length (km) \\
\hline E11 (Class 3) & $1-3452$ & 14 \\
\hline E22 (Class 2) & $2-4034$ & 20 \\
\hline E45 (Class 1) & $3-6453$ & 10 \\
\hline
\end{tabular}

Other supporting data required for optimization process such as maintenance treatments and their effect and unit cost for maintenance treatment are presented in Table 5.5. The unit cost per $\mathrm{km}$ for treatment includes pavement maintenance cost and cost of roadside infrastructure 
Table 5.5 Maintenance treatments and unit cost input data

\begin{tabular}{|c|c|c|}
\hline Maintenance Treatments & Treatment effect $(\boldsymbol{P} \boldsymbol{P C I})$ & Unit Cost (AED/km) \\
\hline T1-Do nothing & 0 & 0 \\
\hline T2-Dressing & 10 & 500,000 \\
\hline T3- Overlay & 15 & $1,000,000$ \\
\hline T4-Resurfacing & 20 & $1,500,000$ \\
\hline
\end{tabular}

AED: Arab Emirates Dirham

The roadway authorities' policy input-data refers to pavement performance standards and total budget allocation for 5, 10, or 15 years road improvement program. The annual discount rate depends upon the current and future potential economic condition of the country. The input data pertaining to these policy variables such as annual discount rate, total budget, and the minimum and maximum PCI values are presented in Table 5.6 below.

Table 5.6 Policy input data for optimization

\begin{tabular}{|c|c|c|c|c|}
\hline Discount Rate & $\begin{array}{c}\text { Total Budget } \\
\text { (AED) }\end{array}$ & Horizon year & Min. PCI & Max. PCI \\
\hline $3 \%$ & $160,000,000$ & 10 & 90 & 100 \\
\hline
\end{tabular}

\subsubsection{Optimization Results and Discussion}

The optimization model for the application example was coded with LINGO, the code of the program is presented Appendix A. LINGO is an optimization modeling software used for building and compiling Linear, Nonlinear, and Integer programming. It is a comprehensive tool used for solving optimization problems in many industries i.e., business, engineering, medical, and applied mathematics. LINGO provides a completely 
integrated package that includes a powerful language for expressing optimization models, a full featured environment for building and editing problems, and a set of fast built-in solvers. The mathematical program coded for the optimization model of the application example includes 186 constraints and 215 variables including 120 integer/binary variables. The binary variables were assigned to maintenance treatments for each pavement section at each successive year of maintenance program.

The results of the optimization model for section 1,2, and 3 are presented in Table 5.7, Table 5.8, and Table 5.9 respectively. 
Table 5.7 Results of optimization model for pavement section 1

\begin{tabular}{|c|c|c|c|c|}
\hline Section-ID & Year & $\begin{array}{c}\text { Maintenance } \\
\text { Treatment }\end{array}$ & $\begin{array}{l}\text { Maintenance } \\
\text { Cost (AED) }\end{array}$ & CPCI \\
\hline $1-3452$ & 1 & 3 & $14,420,000$ & 90.16 \\
\hline $1-3452$ & 2 & 2 & $7,426,300$ & 95.43 \\
\hline $1-3452$ & 3 & 1 & 0 & 90.80 \\
\hline $1-3452$ & 4 & 2 & 7,878562 & 96.28 \\
\hline $1-3452$ & 5 & 1 & 0 & 91.87 \\
\hline $1-3452$ & 6 & 2 & $7,649,089$ & 97.56 \\
\hline $1-3452$ & 7 & 1 & 0 & 93.36 \\
\hline $1-3452$ & 8 & 2 & $8,867,391$ & 99.27 \\
\hline $1-3452$ & 9 & 1 & 0 & 95.28 \\
\hline $1-3452$ & 10 & 1 & 0 & 91.40 \\
\hline Total & & & $46,241,342$ & \\
\hline
\end{tabular}


Table 5.8 Results of optimization model for pavement section 2

\begin{tabular}{|c|c|c|c|c|}
\hline Section-ID & Year & $\begin{array}{c}\text { Maintenance } \\
\text { Treatment }\end{array}$ & $\begin{array}{c}\text { Maintenance } \\
\text { Cost (AED) }\end{array}$ & CPCI \\
\hline $2-4034$ & 1 & 3 & $20,600,000$ & 92.52 \\
\hline $2-4034$ & 2 & 2 & $10,609,000$ & 99.98 \\
\hline $2-4034$ & 3 & 1 & 0 & 97.40 \\
\hline $2-4034$ & 4 & 1 & 0 & 94.76 \\
\hline $2-4034$ & 5 & 1 & 0 & 92.06 \\
\hline $2-4034$ & 6 & 2 & $10,927,270$ & 99.31 \\
\hline $2-4034$ & 7 & 1 & 0 & 96.51 \\
\hline $2-4034$ & 8 & 1 & 0 & 93.65 \\
\hline $2-4034$ & 9 & 1 & 0 & 90.74 \\
\hline $2-4034$ & 10 & 2 & $13,439,163$ & 97.78 \\
\hline Total & & & $\mathbf{5 5 , 5 7 5 , 4 3 3}$ & \\
\hline
\end{tabular}


Table 5.9 Results of optimization model for pavement section 3

\begin{tabular}{|c|c|c|c|c|}
\hline Section-ID & Year & $\begin{array}{c}\text { Maintenance } \\
\text { Treatment }\end{array}$ & $\begin{array}{c}\text { Maintenance } \\
\text { Cost (AED) }\end{array}$ & CPCI \\
\hline $3-6453$ & 1 & 4 & $15,450,000$ & 97.25 \\
\hline $3-6453$ & 2 & 1 & 0 & 94.45 \\
\hline $3-6453$ & 3 & 1 & 0 & 91.60 \\
\hline $3-6453$ & 4 & 2 & $5,627,544$ & 98.70 \\
\hline $3-6453$ & 5 & 1 & 0 & 95.74 \\
\hline $3-6453$ & 6 & 1 & 0 & 92.73 \\
\hline $3-6453$ & 7 & 2 & $6,149,369$ & 99.68 \\
\hline $3-6453$ & 8 & 1 & 0 & 96.57 \\
\hline $3-6453$ & 9 & 1 & 0 & 93.40 \\
\hline $3-6453$ & 10 & 1 & 0 & 90.19 \\
\hline Total & & & $\mathbf{2 7 , 2 2 6 , 9 1 3}$ & \\
\hline
\end{tabular}

The graphical illustrations of the results obtained from the optimization model are presented in Figures 5.4 to 5.9. Figures 5.4 and 5.5 show the optimization results of section 1 (Class 3). Figures 5.6 and 5.7 show the optimization results of section 2 (Class 2), and Figures 5.8 and 5.9 show the optimization results of section 3 (Class 1) of the road. For example, as shown in Figure 5.4, PCI increases from 80 to 90 in response to the application of treatment type T1 at year 1. Similarly, at year 2, when PCI declines below 90 (target performance set in the model) then treatment T2 is applied to raise the PCI to above 90 . Whenever, PCI is below 90 then one type of treatments (T2, T3, or T4) is 
applied. The maintenance cost associated with each treatment applied is shown in the following figures. For example, in case of section 1 (Class 3) the total estimated maintenance cost is AED 46 Million (shown in Figure 5.5).

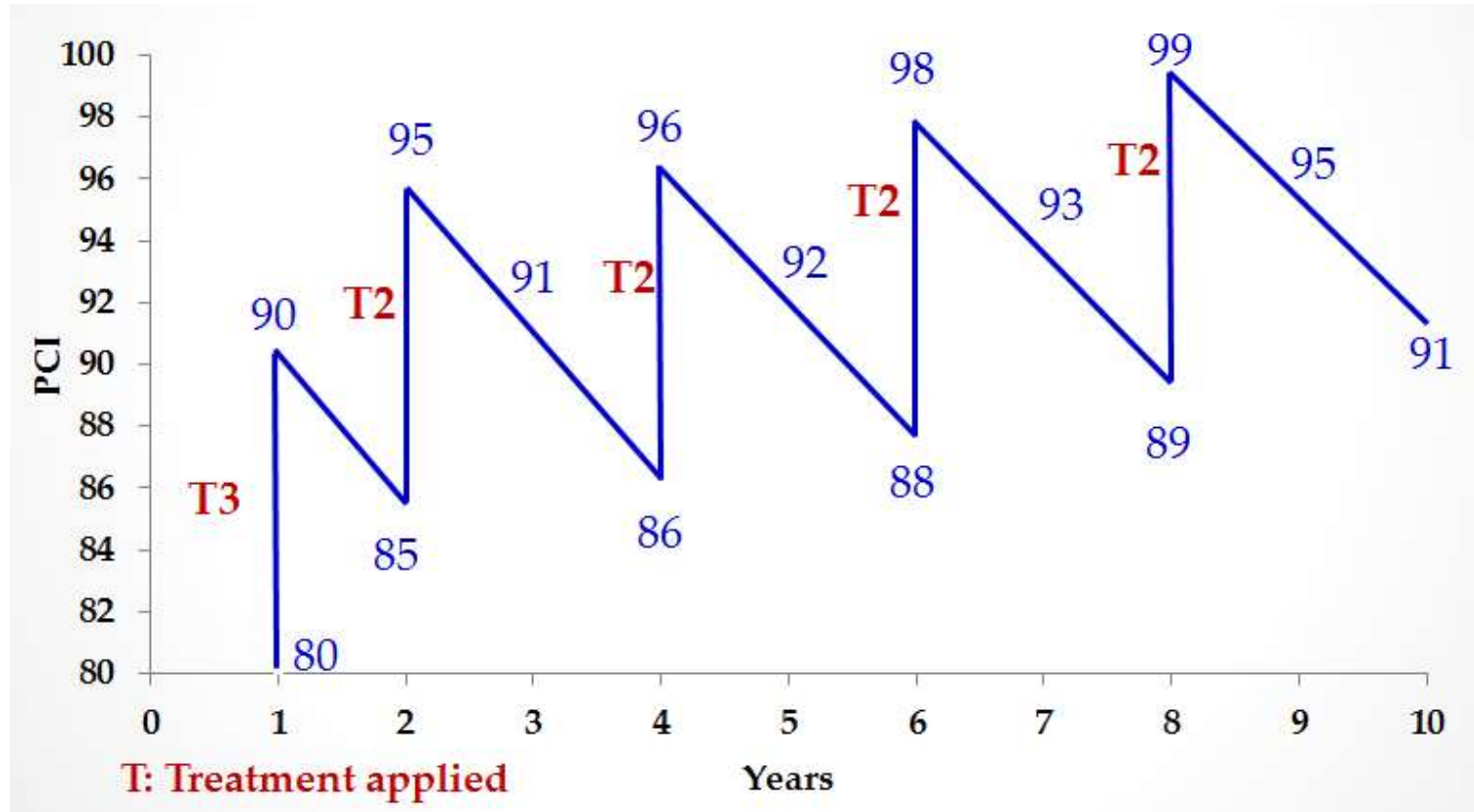

Figure 5.4 Pavement Condition Index (PCI) for pavement section 1 (Class 3)

Furthermore, Figure 5.4 gives the distribution of maintenance costs produced by the optimization mode suggested that optimum plan consists of selecting T3, T2, T2, T2, and T2 at year 1,2,4,6, and 8, respectively. Figure 5.5 shows the detailed cost per each maintenance treatment for the case at hand. Figures 5.6 to 5.9 illustrate similar results obtained for the two other road classes.

Figure 5.10 shows a breakdown of the allocated budget for the three pavement classes. 


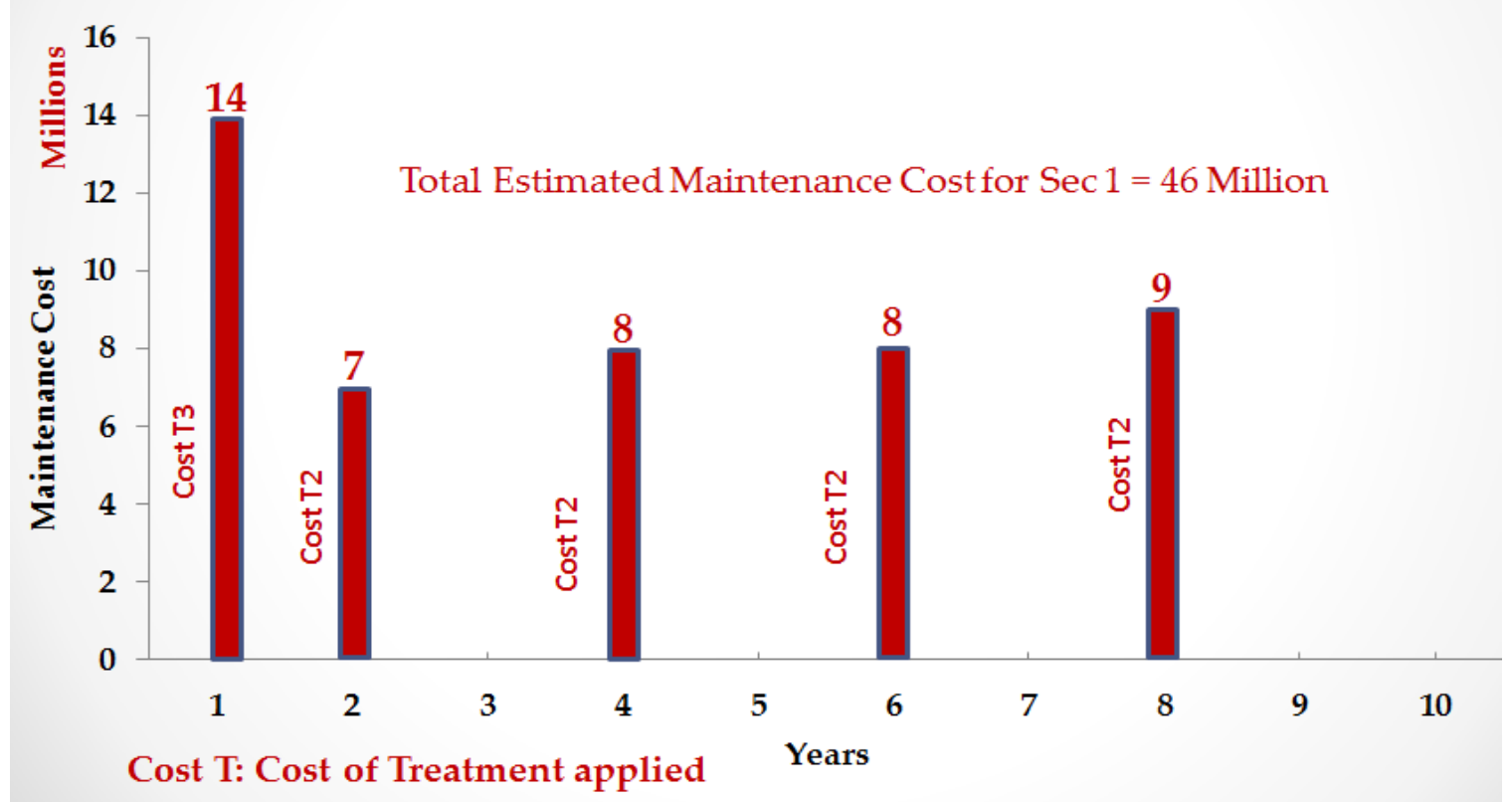

Figure 5.5 Estimated Maintenance cost for pavement section 1 (Class 3)

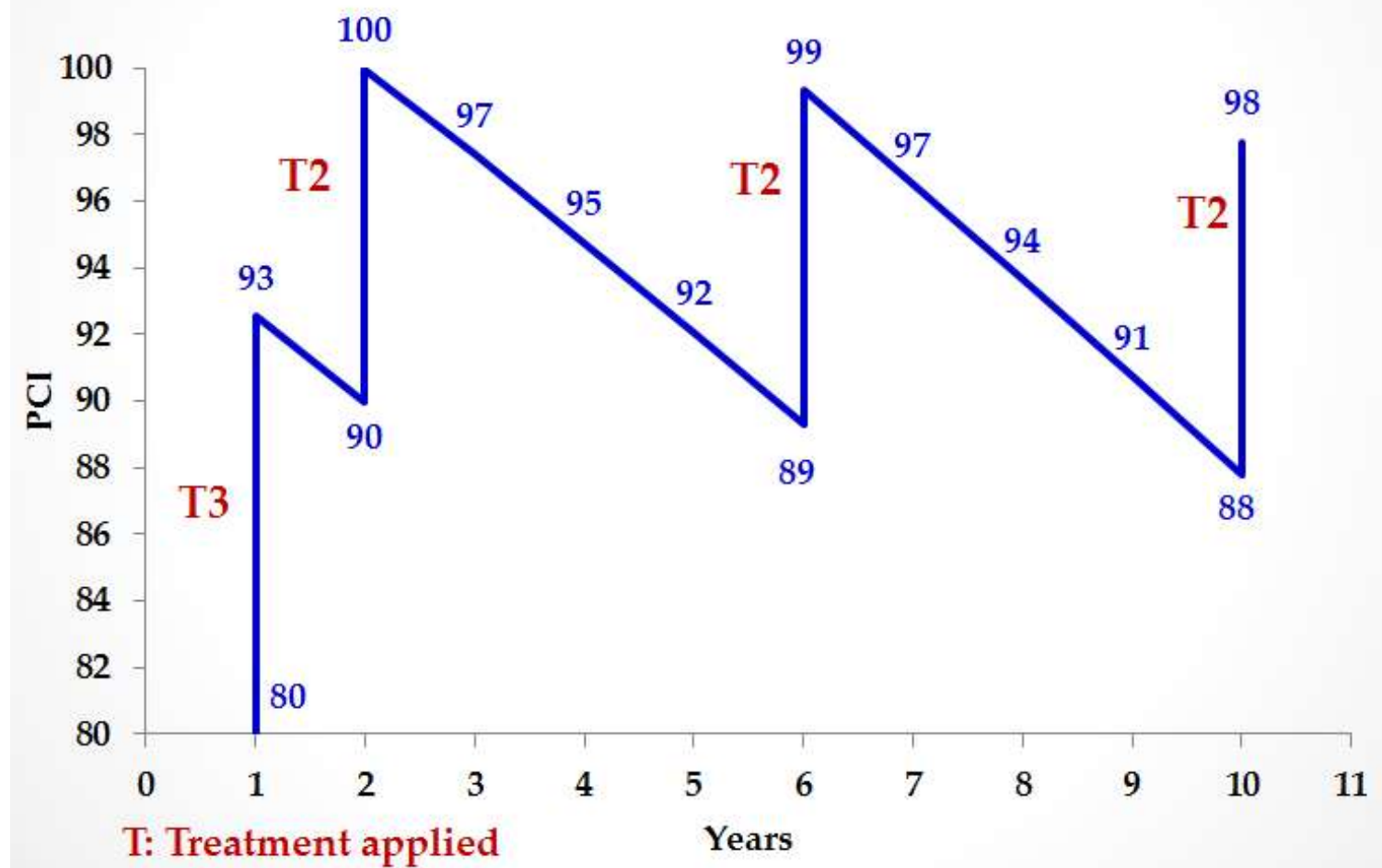

Figure 5.6 Pavement Condition Index (PCI) for pavement section 2 (Class 2) 


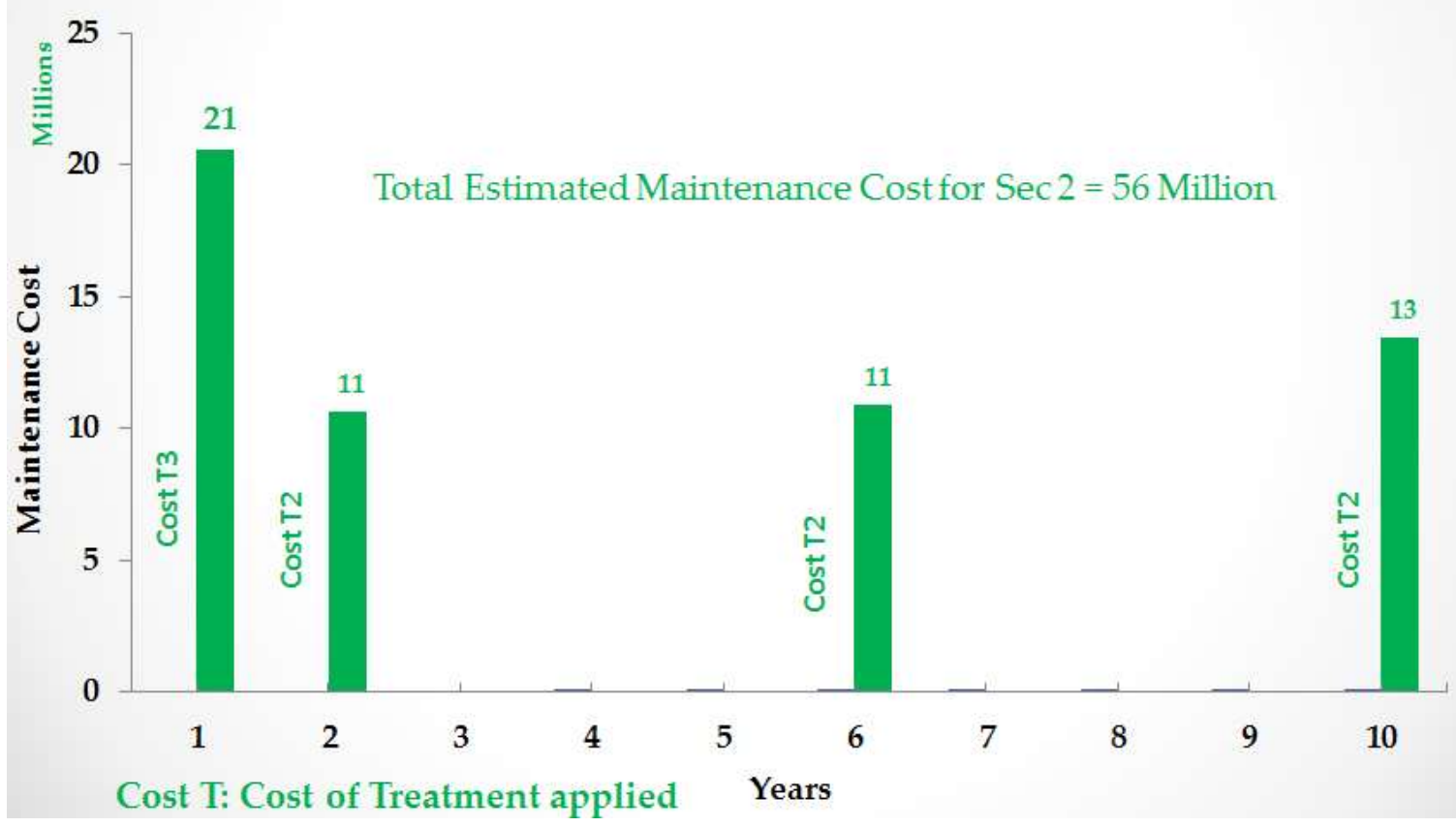

Figure 5.7 Estimated Maintenance cost for pavement section 2 (Class 2)

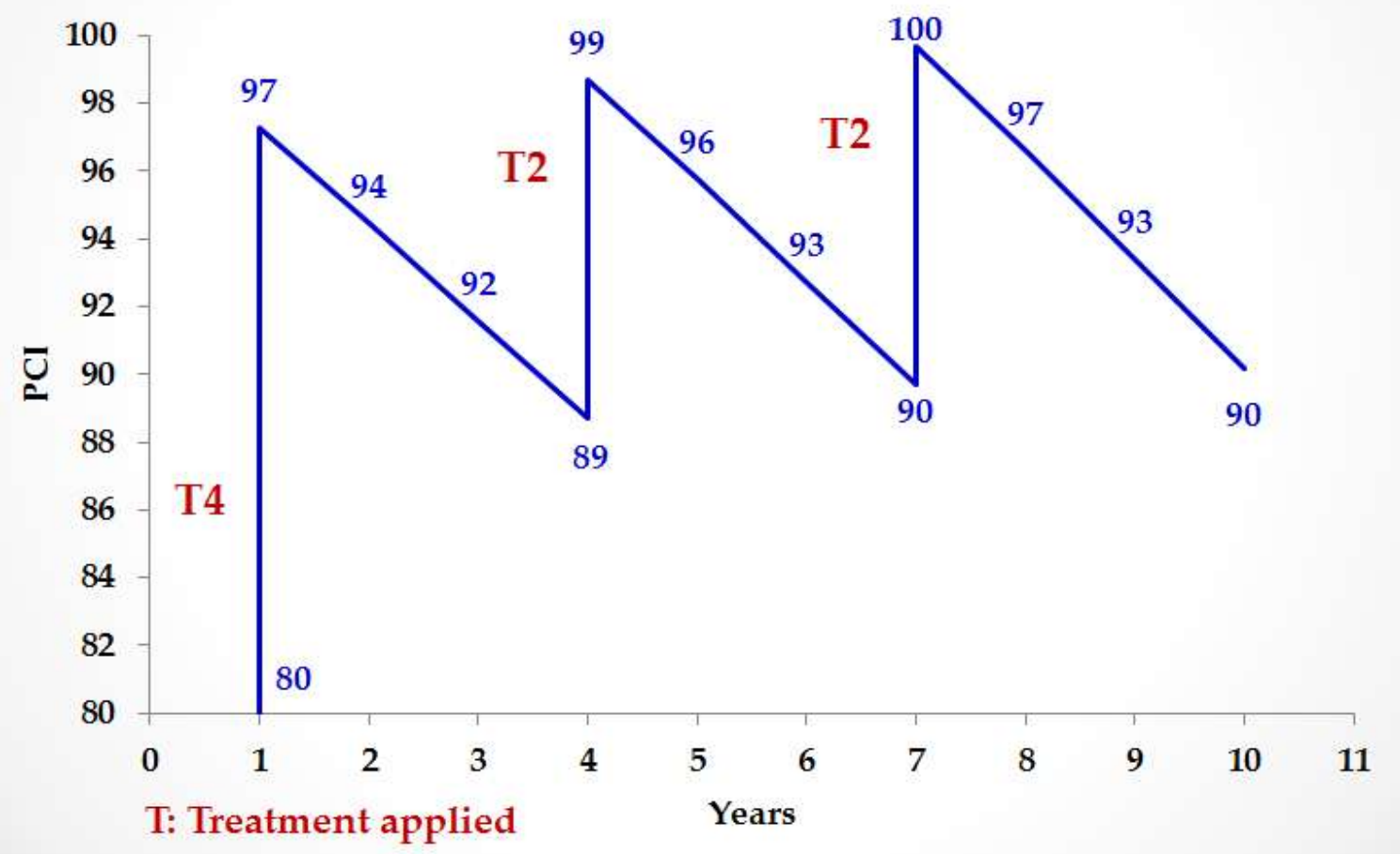

Figure 5.8 Pavement Condition Index (PCI) for pavement section 3 (Class 1) 


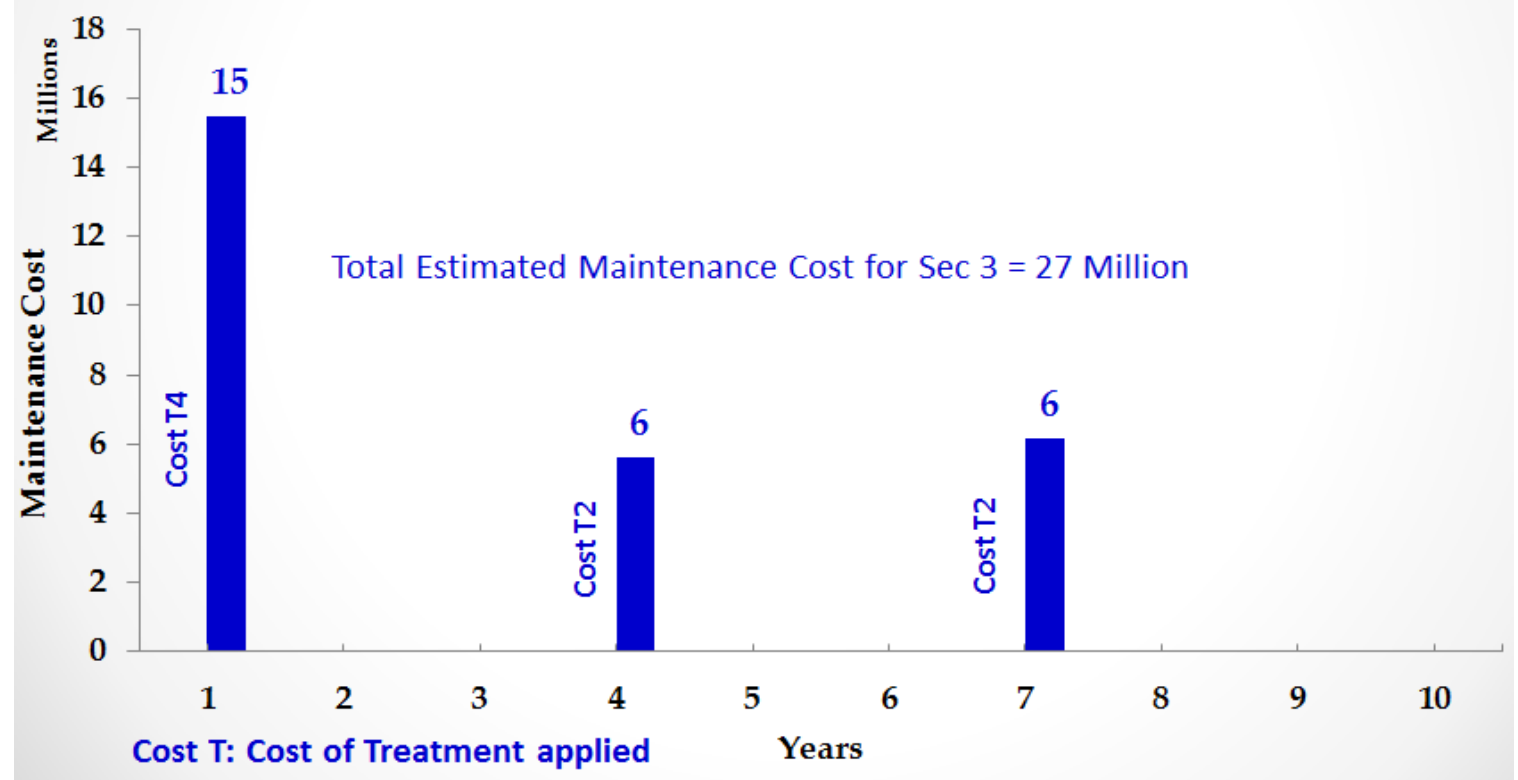

Figure 5.9 Estimated Maintenance cost for pavement section 3 (Class 1)

Figure 5.10 shows the total maintenance cost (129 Million) of all three sections of road considered in the optimization model.

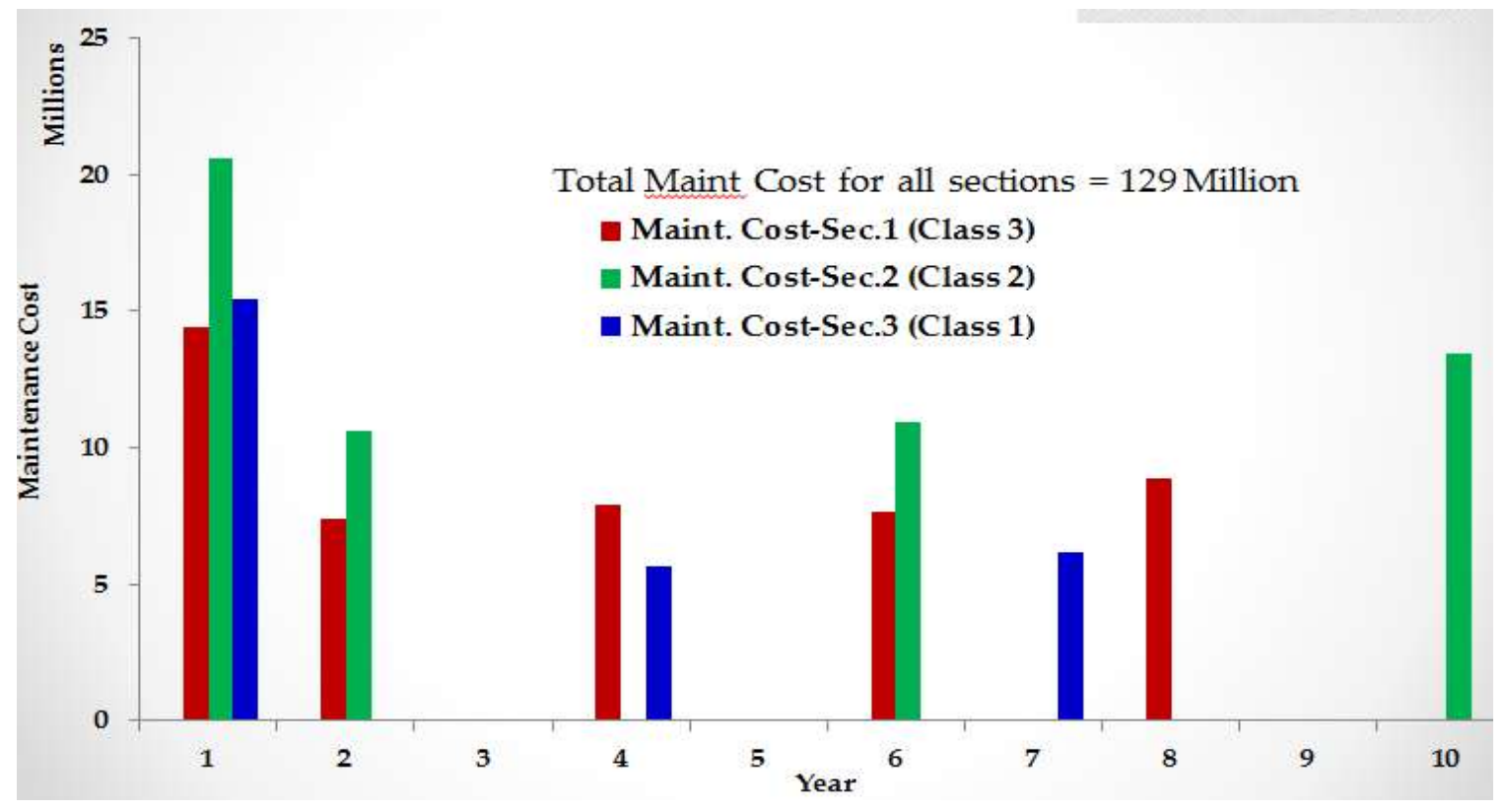

Figure 5.10 Total Estimated Maintenance cost for all three sections 
The optimization model results indicate that all pavement sections require maintenance treatment at very first year of road maintenance program since pavement condition index at very first year is below the target performance measure of 90 . However, the maintenance activities are undertaken over different years depending upon the predicted cumulative road condition index. The cumulative pavement condition index introduced in the proposed optimization model ensures that the pavement condition for a given horizon year depends upon both the current road condition and also the impact of pavement maintenance activities took place in earlier years.

\subsection{Summary}

This chapter presented brief description of optimization strategies used in pavement management systems, the framework and development of an optimization model for the framework proposed for performance-based contacts. An application example is also presented to demonstrate the abilities of the proposed optimization model to perform its intended function. The optimization model results owed the usefulness of developed optimization model as an useful tool that satisfies the objectives defined for the proposed framework. T.he model was utilized to demonstrate its applications in a case study using typical road section from the Emirate of Abu Dhabi 


\section{Chapter: Performance Based Road Asset Management Framework for Abu Dhabi}

\subsection{Introduction}

In this chapter, the developed framework is presented that would facilitate a successful implementation of the PBC in the Emirate of Abu Dhabi. The various components of the framework were identified by performing an extensive literature review of the existing performance-based road maintenance contracts around the world and the existing approaches commonly used in the public and private sector for measuring and monitoring performance. Once the components were identified, the sections in each component and the content for those sections were developed.

As shown in Figure 6.1, the proposed framework includes two layers. The Layer 1 illustrates the stages of the PBC while the Layer 2 includes the components referred as supporting pillars required for an effective and successful implementation of the PBC.

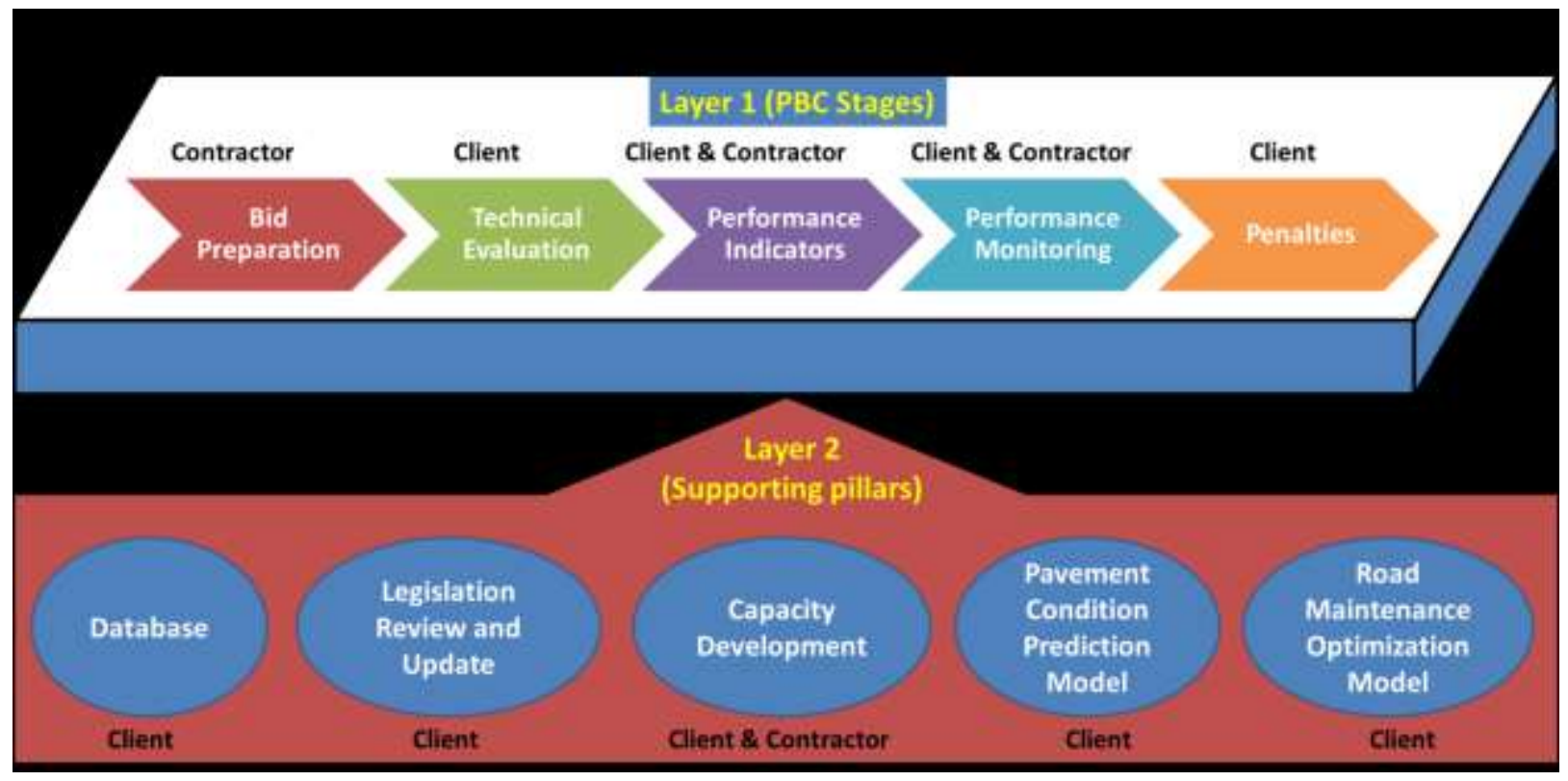

Figure 6.1 Proposed framework for implementing PBC 
As illustrated in the proposed framework, both Client and Contractor shall work together for the success of adopting and implementing the PBC. The Client (road authorities) has to play a major in many of the components including Technical Evaluation, Penalties, Database, Legislation Review and Update, Pavement Condition Predication Models and Optimization Models. The Contractor could assist the Client in components, for example, Bid Preparation, Performance Indicators and Monitoring, and Capacity Development for staff with Client as well as with Contractor.

In the $\mathrm{PBC}$ the role of a Consultant is essentially to verify the Contractor's compliance with the service levels, which is substantially different from their traditional role of "directing" works execution.

The following sections provide more details for each component proposed in the framework.

\subsection{Bid Preparation}

Bid preparation refers to preparing the bidding documents. It is the responsibility of the contractor to make sure that the information in the bidding document is correct, since he has to assume responsibility for meeting the performance criteria.

The bidding documents would include a number of steps, for example, to define the road network to be contracted out, make an inventory of the assets involved and determine its condition, select and define the performance standards, select and define the methods of measuring those standards, define the likely maintenance and possibly 
rehabilitation works, and prepare preliminary cost estimates. The data on the inventory and the conditions of the assets have to be checked from contractors.

This stage is an important step to prepare the requirement of the projects including preparing contract documents. For the preparation of bidding documents, existing bidding documents used for road construction can be used, but they will have to be adapted to suit the special nature of PBC. The PBC that are being used in other countries might be helpful.

It is important, powerful, and rewarding that all parties be involved at this stage including Client, Contractor, and end user because the selection of the best contractor brings benefit to all parties involved. Pre bidding includes all technical details and conditions for optimum safety and reliability prior to moving to the next stage. The finances must be secured on a multi-year basis at the pre bidding stage.

The concept of PBC should be clearly understood by the road agency including its objectives. The objectives for example, could be to lower the costs, to implement higher level government directives, to manage the road network with fewer staff, to improve user satisfaction. On the basis of the main objectives, the road agencies should choose the suitable PBC options.

\subsection{Technical Evaluation}

The Technical Evaluation stage is the process of assessing the bids to select the best bidder. Technical Evaluation is the sole responsibility of the Client. It is wide recognized that under PBC, the value-based method is usually applied to select the bidder rather than the low-cost method. For example, in Finland, the selection criteria are 
weighted $75 \%$ to price and $25 \%$ to the technical aspect. In Washington, DC, the selection is based on the technical aspect and the price; the contract price has the biggest weight of $50 \%$, the technical aspect $20 \%$, staffing $5 \%$, management plan $5 \%$, quality control, $5 \%$, and past performances $15 \%$ quality, but the lowest bidder was not always the winner.

It is proposed to adopt the evaluation criteria and weights presented in Table 6.1 to award PBC in Abu Dhabi.

Table 6.1 Proposed evaluation criteria to award PBC in Abu Dhabi

\begin{tabular}{|c|c|c|}
\hline Criterion & Description & Weight \\
\hline Technical & $\begin{array}{l}\text { Experience, knowledge and understanding of issues relating } \\
\text { to preservation and maintenance of the assets covered by this } \\
\text { Invitation for Bids. Soundness of technical approach for } \\
\text { meeting the performance measures for all of the assets. }\end{array}$ & $20 \%$ \\
\hline \multirow{3}{*}{$\begin{array}{l}\text { Staffing, } \\
\text { Quality } \\
\text { Control/Quality } \\
\text { Assurance, } \\
\text { Management }\end{array}$} & Staffing Plan & $5 \%$ \\
\hline & Management Plan & $5 \%$ \\
\hline & Quality Control/Quality Assurance Plan. & $5 \%$ \\
\hline $\begin{array}{c}\text { Past } \\
\text { Performance }\end{array}$ & $\begin{array}{l}\text { The extent to which the Prime Contractor's and } \\
\text { subcontractors' past performance on similar asset } \\
\text { preservation, maintenance, and management con- tracts } \\
\text { demonstrates a likelihood of successfully performing all of } \\
\text { the tasks set forth in this Invitation for Bids. }\end{array}$ & $15 \%$ \\
\hline Cost & $\begin{array}{l}\text { The extent to which proposed costs are realistic and reflect } \\
\text { the likely overall cost to the government over the term of the } \\
\text { contract. }\end{array}$ & $50 \%$ \\
\hline
\end{tabular}

Source: Adopted from Gajurel, 2014 


\subsection{Performance Indicators}

The stage of Performance Indicator refers to setting indicators to assess the performance of the PBC. It is the responsibility of the Client and Contract to clearly define and objectively measurable performance indicators. The objective of setting performance indicators is to satisfy a set of goals such as to minimize total systems cost, including the long-term cost of preserving the road, and cost to the road user, and to satisfy comfort and safety of road users.

Examples of the typical performance indicators are as follows:

- International Roughness Index (IRI) to measure the roughness of the road surface, which affects vehicle operating cost;

- The absence of potholes and the control of cracks and rutting, which effects safety and pavement performance;

- The minimum amount of friction between tires and the road surface for safety reasons;

- The maximum amount of siltation or other obstruction of the drainage system to avoid destruction of the road structure.

The proposed performance indicators to be adopted for PBC in Abu Dhabi are presented in Table 6.2.

Table 6.2 Proposed Performance Indicators for PBC for Abu Dhabi

\begin{tabular}{|c|c|}
\hline Performance Measures & Performance LOS \\
\hline Potholes & $\begin{array}{c}\text { Not more than } 3 \text { potholes with a diameter greater } \\
\text { than } 70 \mathrm{~mm} \text { on any } 10 \mathrm{~km} \text { section }\end{array}$ \\
\hline Roughness (asphalt) & IRI $<2.0$ \\
\hline Rutting mm & $<10 \mathrm{~mm}$ \\
\hline Cracks & Sealed $100 \%$ \\
\hline
\end{tabular}

Source: Adopted from Gajurel, 2014 


\subsection{Performance Monitoring}

Monitoring the performance of the contractor is a key to the success of PBC. It is the responsibility of Client and Contractor to work together and establish a monitoring system to maintain the quality of work and also to record the data for future contracts. Appropriate control procedures as well as penalties for non-compliance have to be well defined in the contract documents. At present, road authorities in Abu Dhabi follow the criteria and standards developed for their traditional methods of contracting to evaluate the performance of contractors in maintaining road infrastructure systems. These standards have not been properly defined to monitor PBC. The development of revised performance evaluation procedures will ensure the reliability of the overall performance in $\mathrm{PBC}$.

Researchers (De la Garza et al., 2009, Piñero, 2003, Piñero and De la Garza, 2004), de la Garza et al. 2008, 2009) identified five components in order to develop a framework for monitoring performance in PBC. These five components can be applied as guidelines to establish a performance monitoring system for PBC in Abu Dhabi. These components are:

1. Level of Service Effectiveness indicates the extent to which the performance criteria and performance targets defined in the contract are being met.

2. Timeliness of Response evaluates the response time of the contractor to service requests related to events or deficient elements in the roadway that need to be attended in a timely manner.

3. Safety Procedures evaluates if a safety program is properly implemented by the contractor. This component is very important to ensure that the roadway users 
as well as the maintenance crews performing the work are exposed to minimum risk of accidents.

4. Quality of Services assesses the customer perceptions with respect to the condition of the assets and contractor performance. Customers are the ultimate evaluators of the quality of the service provided; therefore, it is extremely important to assess their satisfaction.

5. Cost-Efficiency assesses the cost savings, if any, accrued by the government as a result of engaging a contractor to perform performance-based road maintenance services.

\subsection{Penalties}

Often, in traditional contracts penalties are not applied as specified to remedy the Contractors' failure to comply with the routine maintenance requirements. In PBC, it is recommended that a mechanism be included by Client to allow for penalties to be applied when the desired quality or level of service is not achieved. It is proposed that penalties should apply for failure to meet the performance criteria. Table 6.3 presents a list of the proposed penalties that could be considered to apply for PBC in Abu Dhabi. As shown in Table 6.3 for each item penalties for non-compliance are proposed in order to deter the contractor from failing to comply. For example, a pothole left unrepaired beyond the specified time limit will currently cost the Contractor about AED 3,500 per day until it is patched. The total amount of penalties is deducted from the monthly payments. 
Table 6.3 Proposed penalties for failure to meet the performance criteria

\begin{tabular}{|c|c|c|c|}
\hline Sections & Parameter & Requirement & $\begin{array}{c}\text { Proposed Penalty } \\
\text { (AED) }\end{array}$ \\
\hline \multirow{7}{*}{$\begin{array}{c}\text { Subject to } \\
\text { Rehabilitation }\end{array}$} & Pavement Roughness & $\begin{array}{c}\text { IRImax. }=3(\mathrm{AC}) \\
\text { IRImax. }=3.5 \\
(\mathrm{ST} / \mathrm{RC})\end{array}$ & 2000/week/km \\
\hline & Pavement Rut Depth & $1 \mathrm{~cm} \max$. & 4,000/week $/ \mathrm{km}$ \\
\hline & Pavement Edge drop & $0 \mathrm{~cm}$ & 4,000/week $/ \mathrm{km}$ \\
\hline & Pothole dia. $>2.5 \mathrm{~cm}$ & $100 \%$ patched & $4,000 /$ week $/ \mathrm{km}$ \\
\hline & Cracking & $100 \%$ sealed & 2000/week/km \\
\hline & $\begin{array}{l}\text { Concrete pavement } \\
\text { joint cracks }\end{array}$ & $100 \%$ sealed & 2000/week/km \\
\hline & Raveling & $\begin{array}{l}0 \% \text {, and }<2 \% \text { if } \\
\text { surface treatment }\end{array}$ & 2000/week/km \\
\hline \multirow{6}{*}{$\begin{array}{c}\text { Subject to } \\
\text { Routine } \\
\text { Maintenance }\end{array}$} & Cracking & $100 \%$ sealed & 2000/week/km \\
\hline & Pothole & $100 \%$ patched & 4,000/week/km \\
\hline & Raveling & $100 \%$ patched & 2000/week/km \\
\hline & Paved Shoulders & $\begin{array}{c}\text { Pothole } / \text { raveling }=0 \\
\text { Edge drop }=0 ; \\
\text { Rutting }<12 \mathrm{~mm} \\
\text { Cracks sealed up } \\
100 \%\end{array}$ & 4,000/week $/ \mathrm{km}$ \\
\hline & Unpaved shoulders & $\begin{array}{l}\text { No erosion, no rut, } \\
\text { good transversal } \\
\text { slope; edge drop }<2 \\
\text { cm; width }>=3 \mathrm{~m} .\end{array}$ & 4,000/week $/ \mathrm{km}$ \\
\hline & Bush Clearing & $\begin{array}{c}\text { Bush height }< \\
15 \mathrm{~cm} \text { over } 15 \mathrm{~m} .\end{array}$ & 500/ha/week \\
\hline
\end{tabular}

Source: Adopted from Maria and Gerard, 2011

AC: Asphalt Concrete, ST = Surface Treatment, and RC: Reinforced Concrete 


\subsection{Database}

The database component belongs to Layer 2 of the proposed framework. A database must include a thorough knowledge of the network, its performance and desired future service and performance levels need to exist or be developed. It is the responsibility of the Client to develop and maintain a comprehensive database. Database is one of the supporting pillars to support the components of the Layer 1 of the proposed framework. In Abu Dhabi currently there is a database management system (DBMS). However, it is proposed to regularly update and expand the current DBMS of Abu Dhabi. The database forms the backbone of road maintenance. The database shall be expanded to comprise the network referencing system around which is built an inventory of the network, and provides the framework within which all information about, or associated with the road network is stored and retrieved. It is proposed that the data collected provides information on the road inventory, pavement condition (riding quality, surface distress, and pavement strength), and traffic characteristics. The selection of data items to be collected must therefore satisfy the following criteria:

- Relevance

- Appropriateness

- Reliability

- Affordability

\subsection{Legislation Review and Update}

The review and update of the legislation is another supporting pillar to facilitate an effective and successful implementation of the PBC. It is the responsibility of the Client to regularly review and update the legislation because successful performance contracting 
requires a robust legal, regulatory and institutional framework. The regulatory framework cannot be neglected, so the PBC should follow the legislative framework. Therefore, the selected PBC format needs to comply with the country's legal and regulatory framework. Some aspects of the contract format may be dictated by the prevailing environment. In this case the road authority may need to promote necessary changes to achieve the desirable format. For example, like many countries in Abu Dhabi the maximum maintenance contract duration is restricted to three years, making it necessary to change laws in order to accommodate long-term contracts.

However, if the legislation permits a maximum three year contract, the road authority may start with a three year contract. Once the appropriate changes permitting longer-term contracts are approved in the legislation, the agency can move to longer-term contracts. The length of the contract should be long enough for staff to retain technical skills to ensure consistent delivery but not too long to eliminate local competition.

For the long-term contracts, the authority requires performance security and the contractor needs payment security depending on the value of the contract. Performance security requires determining what steps to take if the performance quality is not met by the contractor. And the payment security requires establishing how to handle a situation when the payment is not done on time or owner is unable to make payment. Under PBC, specific performance bonds should be kept as a security with renewal options or the contracts could be made short term. 


\subsection{Capacity Development}

Capacity development refers to providing training courses related to PBC to build skills, expertise, and understanding of the staff at Client (road authorities), and Contractors. One of the critical and important supporting pillars to ensure the success of the PBC is capacity development. Capacity development is an important component that would have a major role to play in bringing about the shift from traditional approach and to help ensure that PBC works effectively.

Introduction of $\mathrm{PBC}$ can go relatively smoothly or be a disruptive experience for several reasons, in part, because staff and contractors must be prepared to make a significant cultural change. The staff at road authorities and Contractors have to acquire new skills and expertise to be effective in this new role of managing PBC. Some countries may decide to seek technical assistance from countries more experienced in the PBC approach, to build up their capacity. Others may find it more cost effective to engage consultants for assisting with this role, provided the domestic consulting industry possesses appropriate skills.

Some examples of topics on which capacity development training could reap large benefits are as follows:

- Understanding and use of performance measures and standards

- Effective performance monitoring and evaluation of contractor performance

Eventually there is a needed to develop a PBC culture such as knowing the asset, managing risks and determining the sustainable level of service for the funds available. 


\subsection{Pavement Condition Prediction Models}

The pavement condition prediction models are statistical models to predict the condition of future based on given inputs such age, traffic load and thickness of pavement. These models shall be robust and accurate and must be calibrated and validated based on available historical data. These models shall be developed and updated regularly by Client (road authorities). Pavement condition prediction models serve as an important supporting pillar for success of the PBC. In Chapter 4, pavement condition prediction models are developed for Abu Dhabi. These models can assist in estimating the potential risk associated with $\mathrm{PBC}$ for road authorities as well as for contractors.

\subsection{Road Maintenance Optimization Model}

The last supporting pillar in the proposed framework is the road maintenance optimization model. The purpose of the optimization model is to streamline rehabilitation and maintenance activities and allocate budget for maintenance program. Like pavement condition prediction models, the optimization model shall be developed, maintained and updated by road authorities. More use of these models will help in improving the quality

of these models as well as assist in developing an effective and efficient road maintenance mechanism. 


\section{Chapter: Conclusions and Recommendations}

\subsection{Conclusions}

Reducing maintenance cost of road pavements and maintaining the efficiency of the road infrastructure system is an important challenge for any country in the world including the Emirate of Abu Dhabi. It has been a common practice to apply the traditional method of contracts for road maintenance in the Gulf region. The traditional road maintenance contract is based on the amount of work done and payment is given based on a mutually agreed unit rate with the contractors. The road authorities in Abu Dhabi has been faced with difficulties in controlling quality, time, and cost effectively using these traditional methods of contracting. For instance, escalation of cost and time, and delays in completion of maintenance work are the main problems associated with the traditional methods of contracting.

In the late $1990 \mathrm{~s}$, road professionals and engineers started to introduce an efficient method to resolve the shortcomings and problems associated with traditional methods of contracting. The PBC method has significant potential to improve the maintenance and management of the road infrastructure system. In fact, PBC has reduced maintenance costs by 10-50 percent in many countries around the world (Zietlow, 2005).

As PBC has excellent success records in minimizing road maintenance costs in many developed and developing countries over the last two decades, there is a need to assess its applicability in Abu Dhabi. In this research a framework is developed based on a thorough examination and assessment of the current traditional pavement management system implemented in Abu Dhabi. The proposed framework will assist Abu Dhabi pavement authorities in the decision-making processes for the effective utilization of 
resources to manage road maintenance contracts. The framework will help reduce maintenance costs by 10 to $40 \%$ as reported in many other countries. The proposed framework necessitates the identification of many of the cornerstones to effectively manage the pavement condition in the Emirate of Abu Dhabi.

The proposed framework has two layers, one reflects typical stages of PBC and the second layers includes important supporting pillars required to facilitate successful implementation of PBC. The details of these components are discussed in Chapter 6 of this thesis. These components are listed below:

- Layer 1 PBC stages:

○ Pre-Bidding

- Technical Evaluation

- Performance Indicators

○ Performance Monitoring

- Penalties

- Layer 2 supporting pillars:

- Database

- Legislation review and update

- Capacity Development (Training)

- Pavement Condition Prediction Model

○ Road Maintenance Optimization Model

The pavement condition prediction model and optimization model are developed using data provided by road authorities in Abu Dhabi. These models could assist in customizing Highway Development and Management Model (HDM) for Abu Dhabi. The models 
while were developed based on data and pavement condition in Abu Dhabi, their implementation in other Emirates of UAE or other nations in the Gulf region is a straightforward methodology.

\subsection{Recommendations}

- It is recommended to gradually adopt $\mathrm{PBC}$ for road maintenance projects in Abu Dhabi because PBC has been successful in reducing the road management cost in many countries. It would be wise to start with a few pilot projects using PBC. The proposed framework would be helpful in implementing PBC for pilot projects.

- It is recommended that a robust database be developed including a detailed knowledge of the road network, its performance and desired future service and performance standards. The database would be helpful in developing and updating statistical models to estimate and project maintenance cost to assist decision makers in optimizing maintenance strategies.

- The regular training of the staff at road authorities including Department of Transport and Municipalities is necessary to develop capacity for managing PBC in Abu Dhabi. The capacity development will help in establishing a "partnering" relationship between the contractor and client and changing the mindset of staff from the role of a micromanager to the role of a strategic manager. The regular training would assist in acquiring a new set of skills and expertise to enable staff to effectively develop and manage a PBC program.

- Commitment of higher level government and stable multi-year funding must be arranged before embarking a PBC. Stable funds and support from higher management would play a key role in successful implementation of PBC. 
- Some aspects of the current legislation, for example, in Abu Dhabi the maximum maintenance contact duration is restricted to three years that shall be revised in order to accommodate long-term contracts.

\subsection{Future Work}

Given the uncertainty due to the limitations of data availability the effect of only few maintenance actions on pavement performance were studied. In addition, the effects of maintenance on deterioration processes and type of distresses were limited to only few maintenance strategies. It is suggested for future work to collect more data and do more research to refine the proposed pavement prediction models and extend the proposed optimization model to include more options of alternate maintenance strategies. In addition, it is required to research and to determine the data required to use Markov or other alternate approaches for predicting the performance of pavement.

It is suggested to carry out research on operational details of the components identified in the proposed framework, such operational details will help in implementing PBC. For example, in case of capacity development it is required to determine what type of training and how often training shall be provided to staff of Client and Contractor. Similarly, in case of legislation review and update, it is required to research and prepare details to improve legislation process to facilitate $\mathrm{PBC}$ adoption.

A continued research is needed to develop automated updating conditions of the road status and use the long term history to improve the decision making process for future PBC. It is suggested to extend this research by adding a component in the proposed framework related to risk management to assess and evaluate the risk of implementing PBC. 
It is also suggested to extend the research by adding cost of other road assets, for example, roadside infrastructure, and road furniture including barriers, sign boards, and road markings to develop a comprehensive framework for road asset management. 


\section{Chapter: References}

AASHO, 1962. Road Test-Report 5, Pavement Research, Special Report 51E, Highway Research Board, Washington, D.C.

AASHTO, 1993. Guide for the Design of Pavement Structures, American Association of State Highway and Transportation Officials, Washington, D.C.

AASHTO, 2002. A Guide for Methods and Procedures Contract Maintenance, AASHTO Subcommittee on Maintenance, Washington, D.C.

Abaza, K.A., 2002. An optimum flexible pavement life-cycle analysis model, Journal of Transportation Engineering, ASCE, 128(6), pp.542-549.

Abaza, K.A. and Abu-Eisheh, S.A., 2003. An optimum design approach for flexible pavements. International Journal of Pavement Engineering, 4 (1), pp.1-11.

Abaynayaka, S.W., Morosiuk, G. and Hide, H., 1977. Prediction of road construction and vehicle operating costs in developing countries, Proceedings of the Institution of Civil Engineers, UK, 419-446.

Abu Dhabi Municipality data collection reports, 2010-2011, and 2014. Issued by Abu Dhabi Municipality, Abu Dhabi.

A. Sadek, T. Freeman, M. Demetsky, 1996. Deterioration prediction modeling of Virginia's interstate highway system, Transportation Research Record 1524, pp.118-129.

Anastasopoulos, P. C., McCullouch, B. G., Gkritza, K., Mannering, F. L., Sinha, K. C., 2010. Cost Savings Analysis of Performance-Based Contracts for Highway Maintenance Operations, Journal of Infrastructure Systems, 16(4), pp.251-263.

Bennett, C.R., 1996. The new HDM-4 model, Proceedings of the Combined 18th ARRB Transport Research Conference and Transit New Zealand Symposium, Christchurch, New Zealand.

Butt, A. A., Shahin, M. Y., Feighan, K. J., Carpenter, S. H., 1987. Pavement Performance Prediction Model using the Markov Process, Transportation Research Record, (1123).

Bennett, C.R. and I. Greenwood, 2004. Modelling road user and environmental effects, Volume 7. Highway Development and Management Series, HDM-4, International Study of Highway Development and Management (ISOHDM), World Road Association (PIARC), Paris, and The World Bank, Washington, DC, USA.

C. Liu, A. Hammad, Y. Itoh, 1997. Maintenance strategy optimization of bridge decks using genetic algorithm, Journal of Transportation Engineering 123 (2), pp. 91-100. 
CRRI, 1982. Road user cost study in India, Final report, Central Road Research Institute, New Delhi, India.

Cundill, M., 1993. The Road Transport Investment Model, RTIM3, Transport Research Laboratory, Crowthorrne, UK.

Darter, M.I., J.M. Becker, M.B. Snyder, and R.E. Smith, 1985. Portland Cement Concrete Pavement Evaluation System-COPES, National Cooperative Highway Research Program Report 277, TRB, National Research Council, Washington, D.C.

Darter, M.I. Requirements for Reliable Predictive Pavement Models, 1980. Transportation Research Record 766, TRB, National Research Council, Washington, D.C., pp. 25-31.

Dekker, R., Nicolai, R.P. and Kallenberg, L.C.M., 2007. Maintenance and Markov Decision Models, in Encyclopedia of Statistics in Quality and Reliability, Ruggeri, F., Kennett, R. and Faltin, F.W. (eds.), John Wiley \& Sons Ltd, Chichester, UK, pp. 993-1000.

de la Garza, J.M., Piñ ero, J.C. and Ozbek, M.E., 2008. Sampling procedure for performancebased road maintenance evaluation, Transportation Research Record: Journal of the Transportation Research Board, Vol. 2044, pp. 11-8.

de la Garza, J.M., Pinero, J.C. and Ozbek, M.E., 2009, A framework for monitoring performance based road maintenance contract, Proceedings of the Associated Schools of Construction $45^{\text {th }}$ Annual International Conference, Gainesville, FL, April 1-4, pp. 433-41.

Dekker, R., Nicolai, R.P. and Kallenberg, L.C.M., 2007. Maintenance and Markov Decision Models, in Encyclopedia of Statistics in Quality and Reliability, Ruggeri, F., Kennett, R. and Faltin, F.W. (eds.), John Wiley \& Sons Ltd, Chichester, UK, pp. 993-1000.

Deshpande, V.P., Damnjanovic, I. and Gardoni, P., 2008. Modeling the effects of rehabilitation actions on the reliability of flexible pavements, Transportation Research Board 87th Annual Meeting, Washington DC, USA.

Department of Transport Abu Dhabi, 2014. Road Asset Management report issued by DoT, Abu Dhabi.

Djarf, L., 1995. Road deterioration and maintenance effects models in cold climates, Swedish Road Research Institute, Sweden.

Durango, P. L., 2002. Adaptive Optimization Models for Infrastructure Management, PhD Thesis, University of California at Berkeley, California. USA.

Durango, P. L., and Madanat, S. M., 2002. Optimal Maintenance and Repair Policies in Infrastructure Management Under Uncertain Facility Deterioration Rates: An Adaptive Control Approach, Transportation Research Part A: Policy and Practice, 36(9), pp.763-778.

FHWA, 1991. Using Pavement Performance Data to Develop Mechanistic-Empirical Concepts for Deteriorated and Rehabilitated Pavements - Interim Report, Contract No. DTF61- 90-200011, Federal Highway Administration, Washington, D.C. 
FHWA, 1998. Highway Economic Requirements System, HERS, Federal Highway Administration, Washington, DC, USA.

FHWA, 2002. Contract Administration: Technology and Practice in Europe, Federal Highway Administration U.S. Department of Transportation, FHWA-PL-02-0xx, Washington DC.

FHWA, 2002. Analysis of PMS Data for Engineering Applications-Reference Manual, Federal Highway Administration, NHI Course No. 131105, Washington, D.C.

Fugro Roadware Inc, 2012. Experience, Innovation, Service report. [online] Available at: < http://www.roadware.com/related/down-loads/General_Brochure_01,2012, > [Accessed 10 August 2014].

Gajurel, A., 2014. Performance Based Contracts for Road Projects: Comparative Analysis of Different Types, C Springer India 2014. ISBN 978-81-322-1301-7.

Giglio, J M., Ankner, W. D., 1998. Public-Private Partnerships: Brave New World, TR News(198), pp.28.

Geipot, 1982. Research on the interrelationships between costs of highway construction, maintenance and utilization, Final report (12 volumes), Brasilia, Brazil.

Golabi, K., Kulkarni, R., and Way, G., 1982. A Statewide Pavement Management System, Interfaces, 12, pp.5-21.

Gupta. D., Vedantam, A., and Azadivar, J., 2011. Optimal Contract Mechanism Design for Performance- Based Contracts, published by Minnesota Department of Transportation Research Services Section 395 John Ireland Boulevard, Mail Stop 330 St. Paul, Minnesota 55155.

Hide, H., 1982. Vehicle operating costs in the Caribbean: Results of a survey of vehicle operators, TRRL Report 1031, Transport and Road Research Laboratory, Crowthorne, UK.

Haas, R., Yeaman, J., Raymond, C., Falls, L. C., 2001. Pavement Management In Long Term Performance Based Network Contracts, Proc., 5th International Conference on Managing Pavements, Seattle, Washington.

Haas, R., Hudson, W. R., Zaniewski, J. P., 1994. Modern Pavement Management, Krieger Publishing Company, Malabar, Florida.

Hicks, G., Seeds, S.B., and Peshkin, D.G., 2000, Selecting a preventive Maintenance Treatment for Flexible Pavements.

Jain, S.S., Parida, M. and Thube, D.T., 2006. HDM-4 based optimal maintenance strategies for low-volume roads in India, Road \& Transport Research, Australia, 16(4), pp.3-15.

Jesus M. de la Garza, Sercan Akyildiz, Doug R. Bish, Denise A. Krueger, 2011. Network-level optimization of pavement maintenance renewal strategies, Advanced Engineering Informatics 25, pp.699-712. 
Juan Carlos Piñero., 2003. A Framework for Monitoring Performance-Based Road Maintenance , $\mathrm{PhD}$. Thesis, Faculty of the Virginia Polytechnic Institute and State University, Blacksburg, Virginia.

Jackson, N., and J. Mahoney, 1990. Washington State Pavement Management System, Federal Highway Administration, Text for Advanced Course of Pavement Management, Nov. 1990.

Kadar, P., and Henning, T., 2007. Evaluating the Network Condition Changes of Transit Networks Managed Under PSMC Procurement Options, Land Transport New Zealand, No. 324.

Keir, M., and Blerk, G.V., 2006. A Preview of the Performance Specified Maintenance Contract (PSMC) Model Using a Case Study of MSMC 001, Proceedings of the NZIHT Annual Conference (2013), Auckland.

Kannemeyer, L., 2003. Modelling Rutting in Flexible Pavement in HDM-4, Draft Report.

Lamptey, G., Ahmad, M., Labi, S., and Sinha, K.C., 2005. Life Cycle Cost Analysis for INDOT Pavement Design Procedures, Final Report FHWA/IN/JTRP-2004/28, Purdue University, Lafayette, Indiana.

Lytton, R. L., 1987. Concepts of Pavement Performance Prediction and Modeling, Proceedings of 2nd North American Conference on Managing Pavements, Public

Roads, Toronto, Vol. 2.

Li, N., 1997. Development of A Probabilistic Based, Integrated Pavement Management System, PhD. Thesis, University of Waterloo, Waterloo. Ontario.

Li, Z., 2005. A Probabilistic and Adaptive Approach to Modeling Performance of Pavement Infrastructure, $\mathrm{PhD}$. Thesis, University of Texas at Austin, Texas.

Lichiello, P., and Turnock, B. J., 2002. Guidebook for Performance Measurement,Turning PointCollaboration for a New Century in Public Health, [online] Available at: <

http://www.turningpointprogram.org/Pages/pdfs/perform_manage/pmc_guide.pdf $>$ [Accessed 10 July 2014].

Lukanen, E.O., and C. Han, 1994. Performance History and Prediction Modeling for Minnesota Pavements, Third International Conference on Managing Pavements, Proceedings, Vol. 1, TRB, National Research Council, Washington, D.C., 1994, pp. 63-73.

Madanat, S., Bulusu, S., Mahmoud, A., 1995. Estimation of Infrastructure Distress Initiation and Progression Models, Journal of Infrastructure Systems, 1, 146.

Mahoney, J., 1990. Introduction to Prediction Models and Performance Curves, FHWA Advanced Course on Pavement Management.

Mamlouk, M.S., Zaniewski, J.P., and He, W., 2000. Analysis and design optimization of flexible pavement, Journal of Transportation Engineering, ASCE, 126 (2), 161-167. 
Monismith, C.L., N. Ogawa, and C.R,1975. Freeme. Deformation Characteristics of Subgrade Soils due to Repeated Loading, Transportation Research Record 537, TRB, National Research Council, Washington, D.C.

Moavenzadeh, F., Stafford, J.H., Suhbrier, J. and Alexander, J., 1971. Highway design study phase I: IBRD Economics Department, International Bank for Reconstruction and Development, Washington DC, USA.

Maria, M. S. and Gerard, L., 2011. Performance-based Road Rehabilitation and Maintenance Contracts (CREMA) in Argentina: A Review of Fifteen Years of Experience (1996-2010), (C) The International Bank for Reconstruction and Development, The World Bank.

Manion, M., and Tighe, S. L., 1990. Performance-Specified Maintenance Contracts: Adding Value through Improved Safety Performance, Transportation Research Record, Journal of the Transportation Research Board, 1990(-1), pp.72-79.

Morcous, G. , 2002. Modeling Bridge Deterioration using Case-Based Reasoning, Journal of Infrastructure Systems, V.8, pp.86.

Moynihan, G., Zhou, H., Cui, Q., 2009. Stochastic Modeling for Pavement Warranty Cost Estimation, Journal of Construction Engineering and Management, pp.135-352.

Mahoney, J.,1990. Introduction to Prediction Models and Performance Curves, Course Text, FHWA Advanced Course on Pavement Management.

Mbwana, J. R., and Turnquist M. A.,1996. Optimization Modeling for an Enhanced NetworkLevel Pavement Management System, Transportation Research Record 1524, Transportation Research Board, National Research Council, pp.76-85.

Morosiuk, G., Riley, M.J. and Odoki, J.B., 2004. Modelling road deterioration and works effects, Volume 6, Version 2. Highway Development and Management Series, HDM4. International Study of Highway Development and Management (ISOHDM), World Road Association (PIARC), Paris, France.

NCHRP., 2009. Synthesis of Highway Practice 386 : Performance Based Contracting for Maintenance, Transportation Research Board of National Academies, Washington, D.C.

NDLI, 1995. Modelling road user effects in HDM-4, Final report, Asian Development Bank RETA 5549 and N.D. Lea International, Vancouver, Canada.

Owen, M., 2000. Managing the Risk in a New Performance-based Environment, Technical Report of Transit New Zealand. Wellington. [online] Available at: < http://www.transit.govt.nz > [Accessed 12 July 2008]. 
Odoki, J.B., Kerali, G.R.H., 2002. Analytical framework and model descriptions, Volume 4. Highway Development and Management Series, HDM-4, International Study of Highway Development and Management (ISOHDM), World Road Association (PIARC), Paris, France.

O'Brien, L.G,1989. Evolution and Benefits of Preventive Maintenance Strategies, NCHRP Synthesis 153, Transportation Research Board, 69 pp.

Ozbek, M.E., Jesus M. de la Garza, and Piñero, J.C, 2010. Implementation of Level-of-Service Component for Performance-Based Road Maintenance Contracts, Transportation Research Record: Journal of the Transportation Research Board, No. 2150, Transportation Research Board of the National Academies, Washington, D.C., pp. 1-9.

Paterson, W.D.O., 1987. Road Deterioration and Maintenance Effects: Models for Planning and Management, World Bank, Washington, D.C.

Panthi, K., 2009. A Methodological Framework for Modeling Pavement Maintenance Costs for Projects with Performance-Based Contracts, PhD. Thesis, Florida International University, Florida, USA.

PIARC, 2002. Highway Development and Management Model, HDM-4. International Study of Highway Development and Management (ISOHDM), World Road Association (PIARC), Paris France.

Piñ ero, J.C., 2003. A framework for monitoring performance-based road maintenance, Doctor of Philosophy, Faculty of the Virginia Polytechnic Institute and State University, Blacksburg, VA.

Piñero, J. C., and Jesus, M., 2004. Issues Related to the Assessment of Performance-Based Road Maintenance Contracts, Conference Proceeding Paper ASCE, pp. 1-8.

Plasmeijer, R. P., 1999. Maintenance Optimization Techniques for the Preservation of Highways, Tinbergen Institute research series (No. 213).

Queiroz, C.A.V., and W. Ronald Hudson, 1982. Improved Pavement Performance Relationships in Brazil. Fifth International Conference on the Structural Design of Asphalt Pavements, Proceedings, Vol. 1, The University of Michigan, Ann Arbor, Michigan, pp. 500-510.

Queiroz, C., 1999. Contractual Procedures to Involve the Private Sector in Road Maintenance and Rehabilitation, Transport Sector Familiarization Program, World Bank, Washington, DC.

Riley, M.J., Bennett, C.R., Saunders, D.R. and Kim, A., 1994. Optimizing design standards for new pavements using Highway Design and Standards Model HDM-III, Transportation Research Record, 1449, Washington DC, USA, pp.64-71.

Robinson, J. A., and McDonald, G. C., 1991. Issues Related to Field Reliability and Warranty Data, Data Quality Control: Theory and Pragmatics, pp.69-89.

Sadek, T. Freeman, M. Demetsky, 1996. Deterioration prediction modeling of Virginia's interstate highway system, Transportation Research Record 1524, pp.118-129. 
Sanchez-Silva, M., Arroyo, O., Junca, M., Caro, S. and Caicedo, B., 2005. Reliability based design optimization of asphalt pavements, International Journal of Pavement Engineering, 6 (4), 281-294.

Segal, G. F., Moore, A. T., McCarthy, S., 2003. Contracting for Road and Highway Maintenance, Reason Public Policy Institute.

SAIC., 2006. Performance Contracting Framework Fostered by Highways for LIFE, Federal Highway Administration (FHWA).

Segal, G. F., Moore, A. T., McCarthy, S., 2003. Contracting for Road and Highway Maintenance, Reason Public Policy Institute, February.

Sultana, M., Rahman, A., and Chowdhury, S., 2013. A review of performance based maintenance of road infrastructure by contracting, International Journal of Productivity and Performance Management Vol. 62 No. 3, pp. 276-292.

Sultana, M., Rahman, A., and Chowdhury, S., 2012. Performance Based Maintenance of Road Infrastructure by Contracting - A Challenge for Developing Countries, Journal of Service Science and Management, V.5, pp.118-123.

TAC., 1997. Pavement Design and Management Guide, Transportation Association of Canada, Canada.

TRL., 1993. A guide to the structural design of bitumen-surfaced roads in tropical and subtropical countries, Overseas Road Note 31, Overseas Center, Crowthorne, Berkshire,UK.

Tsunokawa, K., Hiep, D.V. and Ul-Islam, R., 2006. True optimization of pavement maintenance option with what-if models, Computer-Aided Civil and Infrastructure Engineering, 21(3), 193204.

Wang, K. C. P., Zaniewski, J., and Way, G., 1994. Probabilistic Behavior of Pavements, ASCE Journal of Transportation Engineering, 120(3), pp.358-374.

Watanatada, T., Harral, C.G., Paterson, W.D.O., Dhareshwar, A.M., Bhandari, A. and Tsunokawa, K., 1987. The Highway Design and Maintenance Standards Model: Volume 1, Johns Hopkins, The World Bank, Washington DC, USA.

Weijde, O.V., 2013. Markov Decision Processes for Road Maintenance Optimization, Erasmus University Rotterda.

World Bank., 2005. Performance-Based Contracting for Preservation and Improvement of Road Assets, Transport Note no.TN, 27, The World Bank, Washington, DC.

Zietlow, G., 2005. Cutting Costs and Improving Quality through Performance-Based Road Management and Maintenance Contracts-the Latin American and OECD Experiences, Senior Road Executives Programme, Restructuring Road Management, University of Birmingham, UK. 
Zaniewski, J.P., Rohan W. Perera, and Michael S. Mamlouk, 1990. Feedback of Pavement Management Performance Data for Pavement Design, Transportation Research Record 1272, TRB, National Research Council, Washington, D.C, pp. 74-79. 


\section{Appendices}

Appendix A : Detail Results of the Regression Analysis 


\section{Regression Analysis-Class 1}

\begin{tabular}{|c|c|c|c|c|}
\hline \multicolumn{5}{|c|}{ Iteration History $^{b}$} \\
\hline \multirow[b]{2}{*}{ Iteration Number ${ }^{3}$} & \multirow{2}{*}{$\begin{array}{l}\text { Residual } \\
\text { Sum of } \\
\text { Squares }\end{array}$} & \multicolumn{3}{|c|}{ Parameter } \\
\hline & & A & $B$ & $\mathrm{C}$ \\
\hline 1.0 & 159147.326 & 90.000 & .000 & .000 \\
\hline 1.1 & 2582.552 & 92.340 & -.026 & -2.721 \\
\hline 2.0 & 2582.552 & 92.340 & -.026 & -2.721 \\
\hline 2.1 & 2582.552 & 92.340 & -.026 & -2.721 \\
\hline
\end{tabular}

Derivatives are calculated numerically.

a. Major iteration number is displayed to the left of the decimal, and minor iteration number is to the right of the decimal.

b. Run stopped after 4 model evaluations and 2 derivative evaluations because the relative reduction between successive residual sums of squares is at most SSCON $=1.00 \mathrm{E}-008$.

Parameter Estimates

\begin{tabular}{|c|c|c|c|c|}
\hline \multirow[b]{2}{*}{ Parameter } & \multirow[b]{2}{*}{ Estimate } & \multirow[b]{2}{*}{ Std. Error } & \multicolumn{2}{|c|}{$95 \%$ Confidence Interval } \\
\hline & & & Lower Bound & Upper Bound \\
\hline $\bar{A}$ & 92.340 & .210 & 91.417 & 92.243 \\
\hline B & -.026 & .010 & -.042 & -.005 \\
\hline C & -.026 & .099 & -2.934 & -2.546 \\
\hline
\end{tabular}

Correlations of Parameter Estimates

\begin{tabular}{|l|r|r|r|}
\hline & \multicolumn{1}{|c|}{$\mathrm{A}$} & \multicolumn{1}{|c|}{$\mathrm{B}$} & \multicolumn{1}{c|}{$\mathrm{C}$} \\
\hline $\mathrm{A}$ & 1.000 & .681 & -.819 \\
$\mathrm{~B}$ & .681 & 1.000 & -.965 \\
$\mathrm{C}$ & -.819 & -.965 & 1.000 \\
\hline
\end{tabular}

\section{ANOVA $^{\mathrm{a}}$}

\begin{tabular}{|l|r|r|r|}
\hline Source & \multicolumn{1}{|c|}{$\begin{array}{c}\text { Sum of } \\
\text { Squares }\end{array}$} & df & \multicolumn{1}{c|}{$\begin{array}{c}\text { Mean } \\
\text { Squares }\end{array}$} \\
\hline Regression & \multicolumn{1}{|c|}{3757716.8} & 3 & 1252572.3 \\
Residual & 2582.552 & 618 & 4.179 \\
Uncorrected Total & 3760299.3 & 621 & \\
Corrected Total & 11738.879 & 620 & \\
\hline
\end{tabular}

Dependent variable: $\mathrm{PCl}$

a. $R$ squared $=1-($ Residual Sum of Squares $) /($ Corrected Sum of Squares $)=.780$.

\section{Descriptives}

\section{Descriptive Statistics}

\begin{tabular}{|l|r|r|r|r|r|}
\hline & \multicolumn{1}{|c|}{$\mathrm{N}$} & Minimum & Maximum & \multicolumn{1}{c|}{ Mean } & Std. Deviation \\
\hline PCl & 621 & 59.53 & 95.34 & 77.2164 & 9.64396 \\
Valid N (listwise) & 621 & & & & \\
\hline
\end{tabular}




\section{Graph}

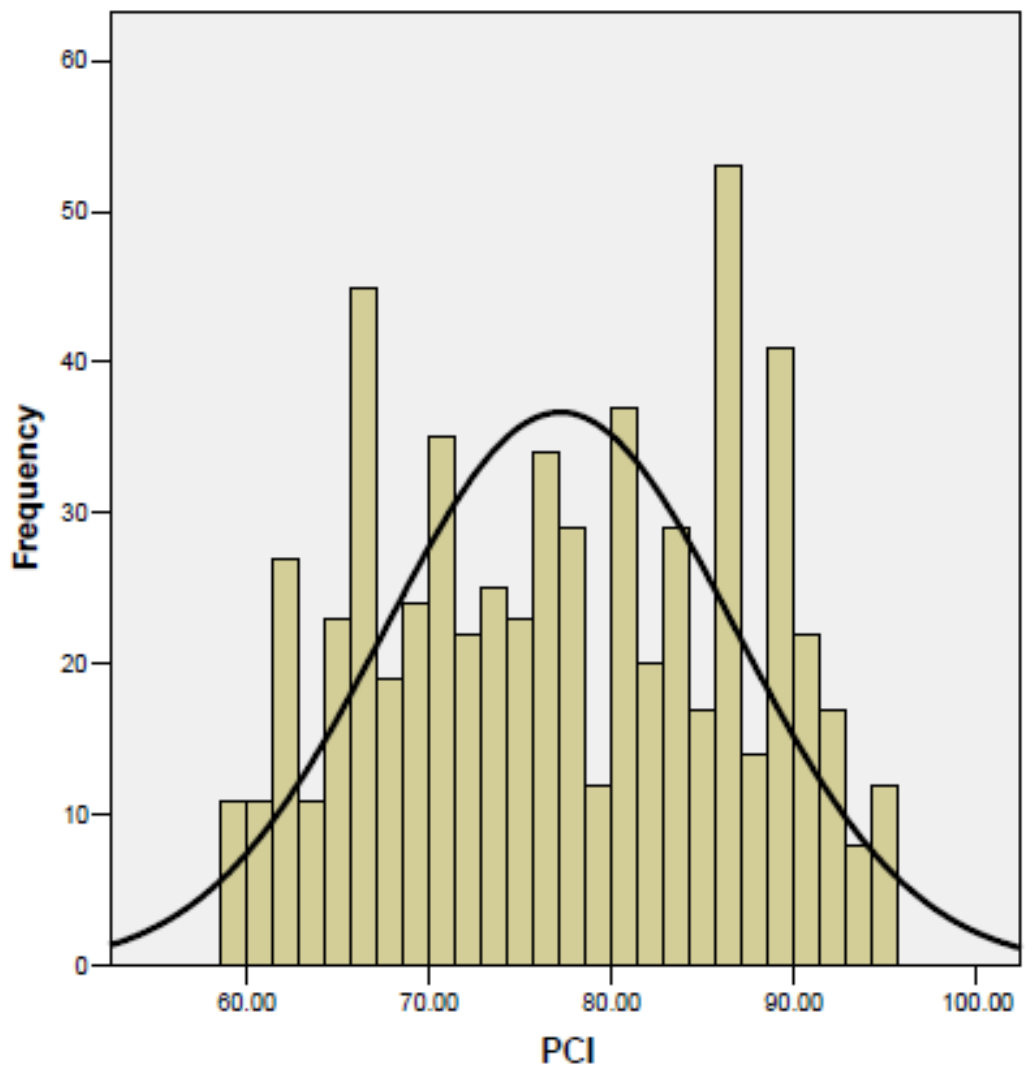

Mean $=77.2164$

Std. Dev. $=9.64396$ 


\section{Regression Analysis- Class 2}

\section{Iteration History ${ }^{\mathrm{b}}$}

\begin{tabular}{|c|c|c|c|c|}
\hline \multirow[b]{2}{*}{ Iteration Number" } & \multirow{2}{*}{$\begin{array}{l}\text { Residual } \\
\text { Sum of } \\
\text { Souares }\end{array}$} & \multicolumn{3}{|c|}{ Parameter } \\
\hline & & A & B & $\mathrm{C}$ \\
\hline 1.0 & 157157.475 & 85000 & .000 & .000 \\
\hline 1.1 & 2139.648 & 81.341 & -.027 & -2.452 \\
\hline 20 & 2139.846 & 81.341 & -.027 & -2.452 \\
\hline
\end{tabular}

Derivatives are calculated numerically.

a. Major iteration number is displayed to the left of the decimal, and minor iteration number is to the right of the decimal.

b. Run stopped after 3 model evaluations and 2 derivative evaluations because the relative reduction between successive parameter estimates is at most $\mathrm{PCON}=1.00 \mathrm{E}-008$.

\section{Parameter Estimates}

\begin{tabular}{|l|r|r|r|r|}
\hline & & & \multicolumn{2}{|c|}{$95 \%$ Confidence Interval } \\
\cline { 4 - 5 } Parameter & Estimate & Std. Error & Lower Bound & Upper Bound \\
\hline A & 81.341 & .221 & 80.385 & 81.253 \\
B & -.027 & .010 & -.045 & -.008 \\
C & -2.452 & .101 & -2.630 & -2.234 \\
\hline
\end{tabular}

Correlations of Parameter Estimates

\begin{tabular}{|l|r|r|r|}
\hline & \multicolumn{1}{|l|}{ A } & \multicolumn{1}{|c|}{ B } & \multicolumn{1}{c|}{ C } \\
\hline A & 1.000 & -.674 & -.819 \\
B & -.674 & 1.000 & .962 \\
C & -.819 & .962 & 1.000 \\
\hline
\end{tabular}

\section{ANONA}

\begin{tabular}{|l|r|r|r|}
\hline Source & \multicolumn{1}{|c|}{$\begin{array}{c}\text { Sum of } \\
\text { Squares }\end{array}$} & df & \multicolumn{1}{c|}{$\begin{array}{c}\text { Mean } \\
\text { Squares }\end{array}$} \\
\hline Regression & 2615147.7 & 3 & 871715.89 \\
Residual & 2139.646 & 534 & 4.007 \\
Uncorrected Total & 2617287.3 & 537 & \\
Corrected Total & 11886.924 & 536 & \\
\hline
\end{tabular}

Dependent variable: $\mathrm{PCl}$

a. R squared $=1$ - (Residual Sum of Squares $) /($ Corrected Sum of Squares $)=.82$.

\section{Descriptives}

\section{Descriptive Statistics}

\begin{tabular}{|l|r|r|r|r|r|}
\hline & \multicolumn{1}{|c|}{$\mathrm{N}$} & Minimum & Maximum & \multicolumn{1}{c|}{ Mean } & Std. Deviation \\
\hline PCl & 537 & 56.52 & 84.34 & 69.4485 & 7.13473 \\
Valid N (listwise) & 537 & & & & \\
\hline
\end{tabular}


Graph

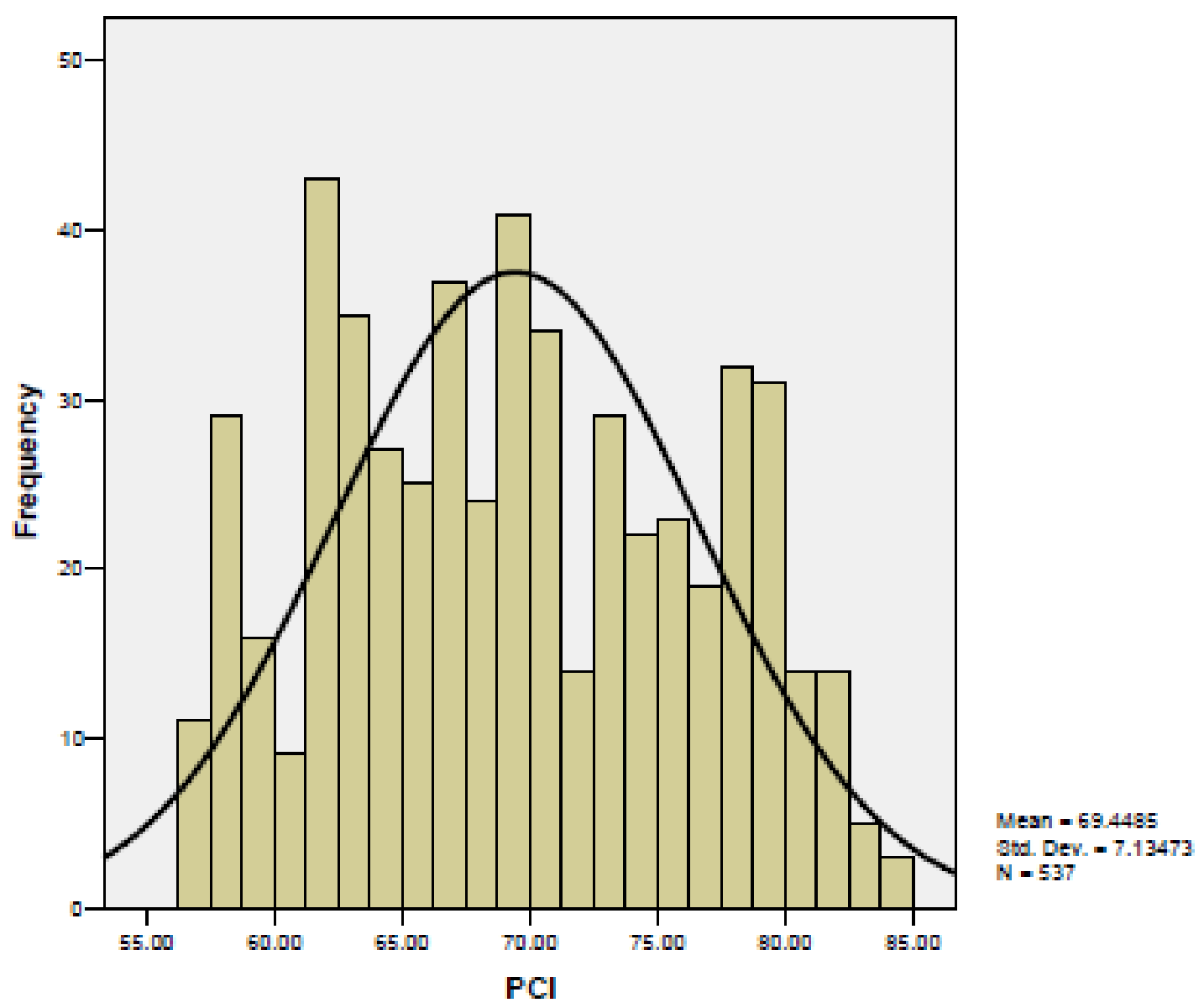




\section{Regression Analysis-Class 3}

\begin{tabular}{|c|c|c|c|c|}
\hline \multicolumn{5}{|c|}{ Iteration History } \\
\hline \multirow[b]{2}{*}{ Iteration Number ${ }^{3}$} & \multirow{2}{*}{$\begin{array}{l}\text { Residual } \\
\text { Sum of } \\
\text { Squares }\end{array}$} & \multicolumn{3}{|c|}{ Parameter } \\
\hline & & A & $\mathrm{B}$ & $\mathrm{C}$ \\
\hline 1.0 & 227004.549 & 85.000 & .000 & .000 \\
\hline 1.1 & 3586.150 & 89.306 & .053 & -4.890 \\
\hline 2.0 & 3586.150 & 89.306 & .053 & -4.890 \\
\hline
\end{tabular}

Derivatives are calculated numerically.

a. Major iteration number is displayed to the left of the decimal, and minor iteration number is to the right of the decimal.

b. Run stopped after 3 model evaluations and 2 derivative evaluations because the relative reduction between successive parameter estimates is at most $\mathrm{PCON}=1.00 \mathrm{E}-008$.

\section{Parameter Estimates}

\begin{tabular}{|l|r|r|r|r|}
\hline & & & \multicolumn{2}{|c|}{$95 \%$ Confidence Interval } \\
\cline { 4 - 5 } Parameter & Estimate & Std. Error & Lower Bound & Upper Bound \\
\hline A & 89.306 & .364 & 87.702 & 89.131 \\
B & .053 & .017 & .010 & .076 \\
C & -4.890 & .174 & -5.150 & -4.464 \\
\hline
\end{tabular}

\section{Correlations of Parameter Estimates}

\begin{tabular}{|l|r|r|r|}
\hline & A & \multicolumn{1}{|c|}{ B } & C \\
\hline A & 1.000 & .661 & -.803 \\
B & .681 & 1.000 & -.964 \\
C & -.803 & -.964 & 1.000 \\
\hline
\end{tabular}

ANOVA $^{\mathrm{a}}$
\begin{tabular}{|l|r|r|r|}
\hline & \multicolumn{1}{c|}{ Sum of } & \multicolumn{1}{c|}{ Mean } \\
Source & \multicolumn{1}{c|}{ Squares } & df & \multicolumn{1}{c|}{ Squares } \\
\hline Regression & 1840836.8 & 3 & 613612.27 \\
Residual & 3586.150 & 398 & 8.988 \\
Uncorrected Total & 1844423.0 & 402 & \\
Corrected Total & 144942.29 & 401 & \\
\hline
\end{tabular}

Dependent variable: $\mathrm{PCl}$

a. R squared $=1-($ Residual Sum of Squares $) /($ Corrected Sum of Squares $)=.760$

\section{Descriptives}

\section{Descriptive Statistics}

\begin{tabular}{|l|r|r|r|r|r|}
\hline & \multicolumn{1}{|c|}{$\mathrm{N}$} & Minimum & Maximum & Mean & Std. Deviation \\
\hline $\mathrm{PCl}$ & 402 & 40.70 & 84.30 & 68.1672 & 14.50804 \\
Valid N (listwise) & 402 & & & & \\
\hline
\end{tabular}


Graph

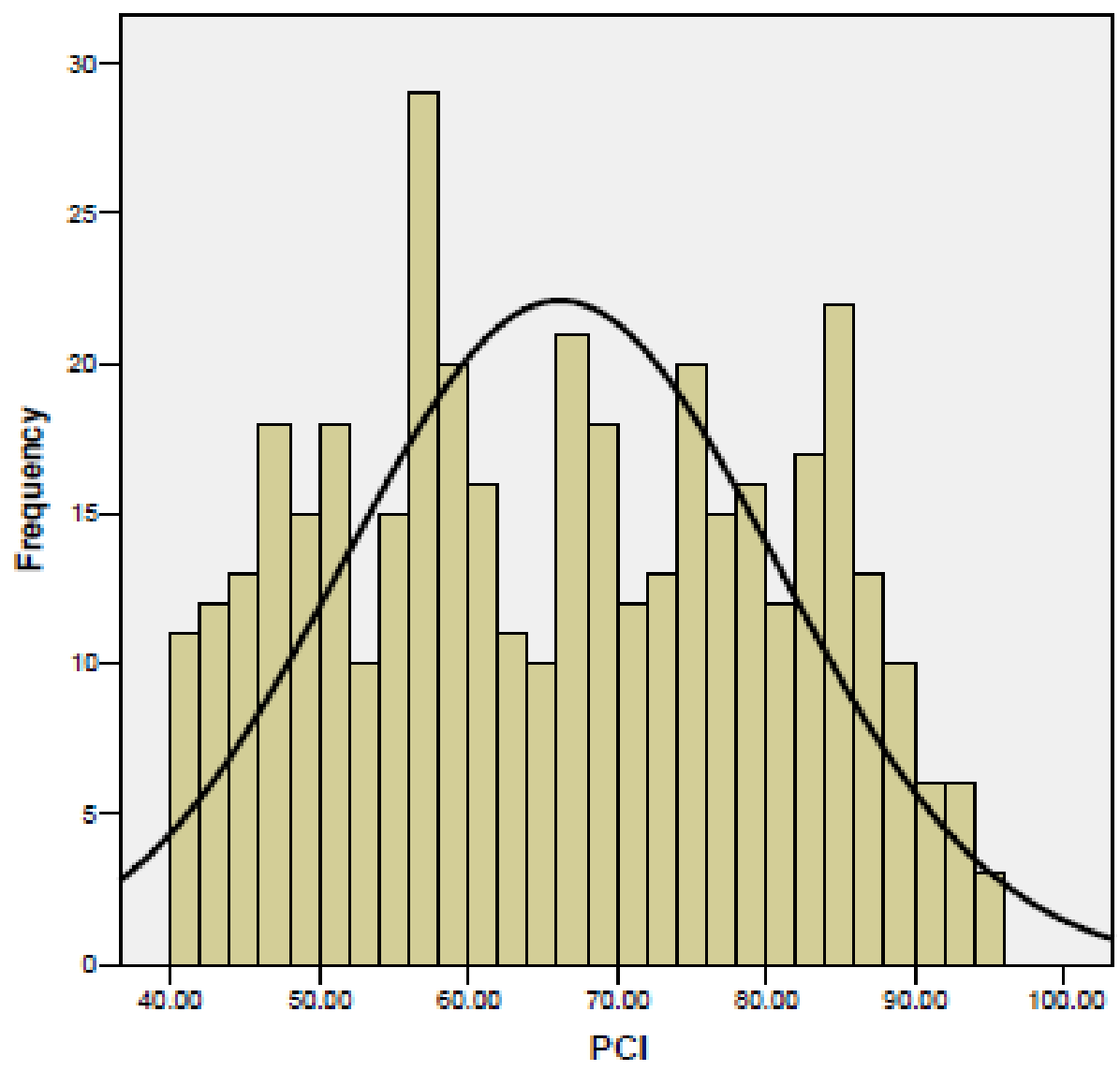

Mean - 66.1672

Std. Dev. - 14.50994

$\mathrm{N}=402$ 
Class 1: PCI-AGE 1

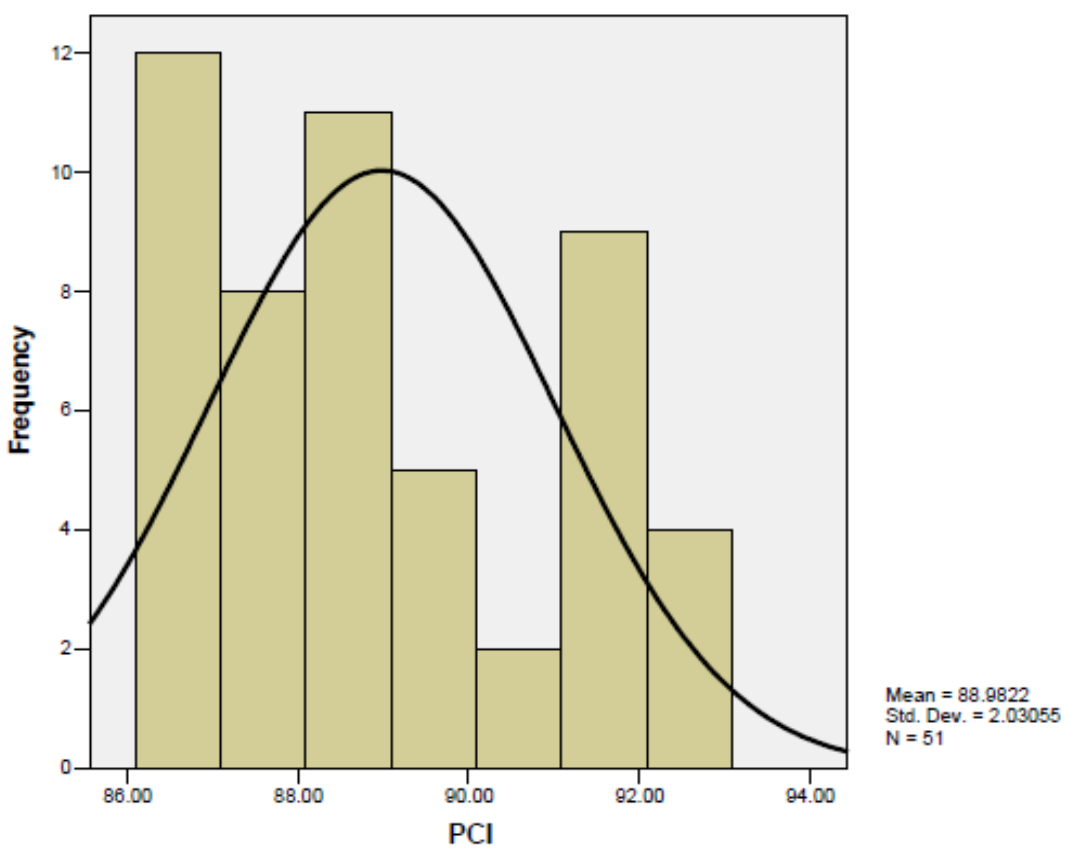

Class 1- PCI -AGE 2

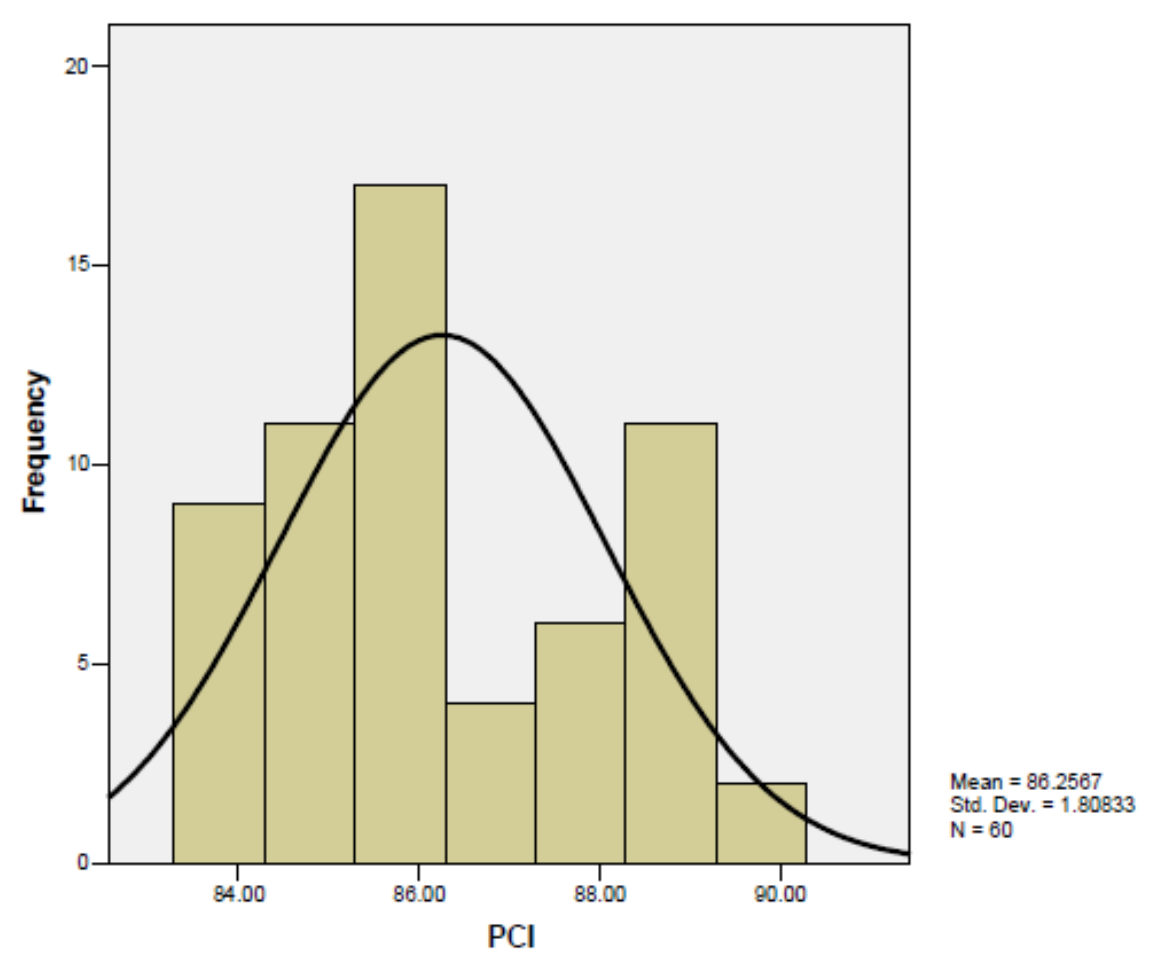




\section{Class 1-PCl: AGE 3}

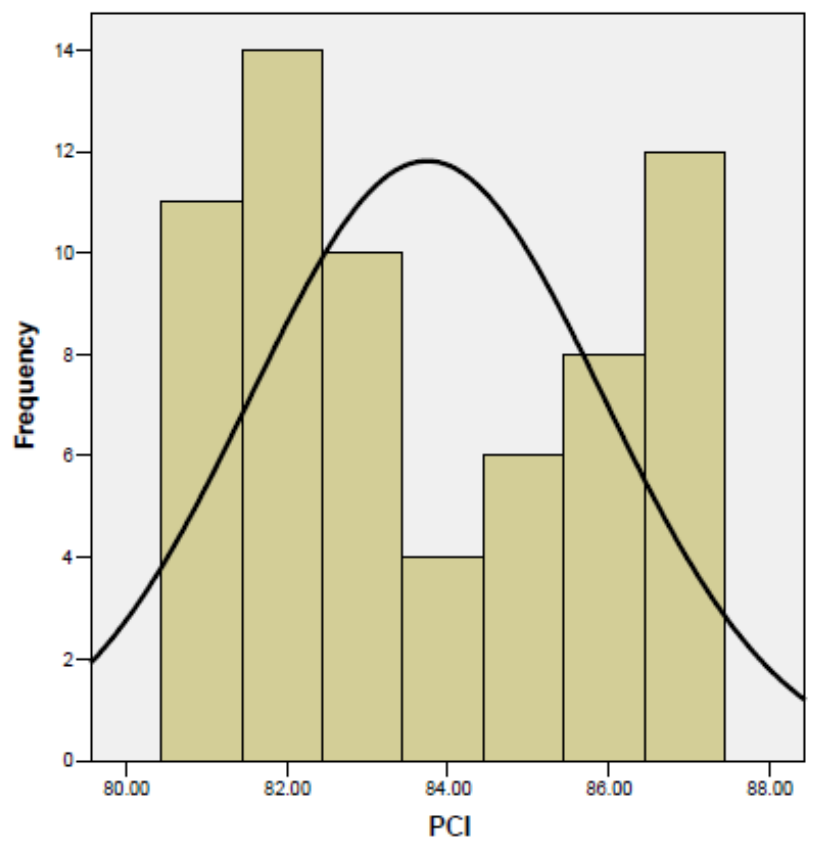

Mean $=83.74$

Std. Dev. $=2.18517$

Class 1 PCl -AGE 4

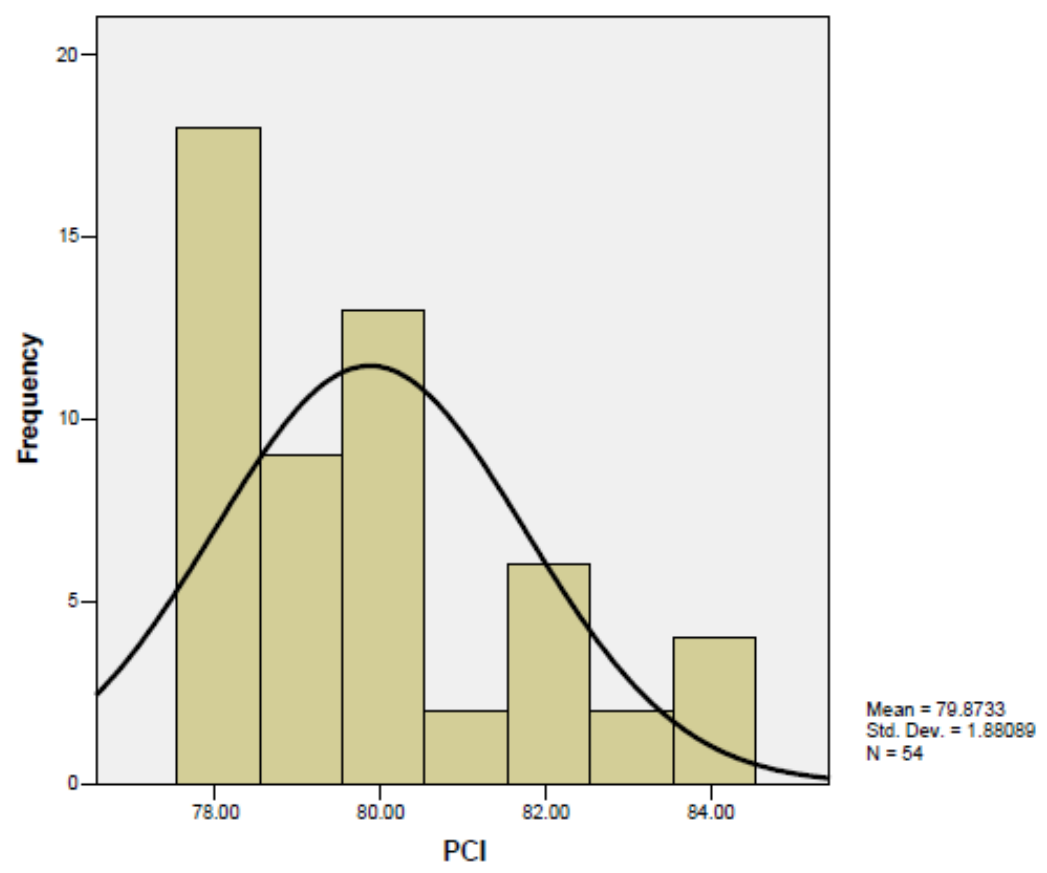




\section{Class 1- PCl:AGE 5}

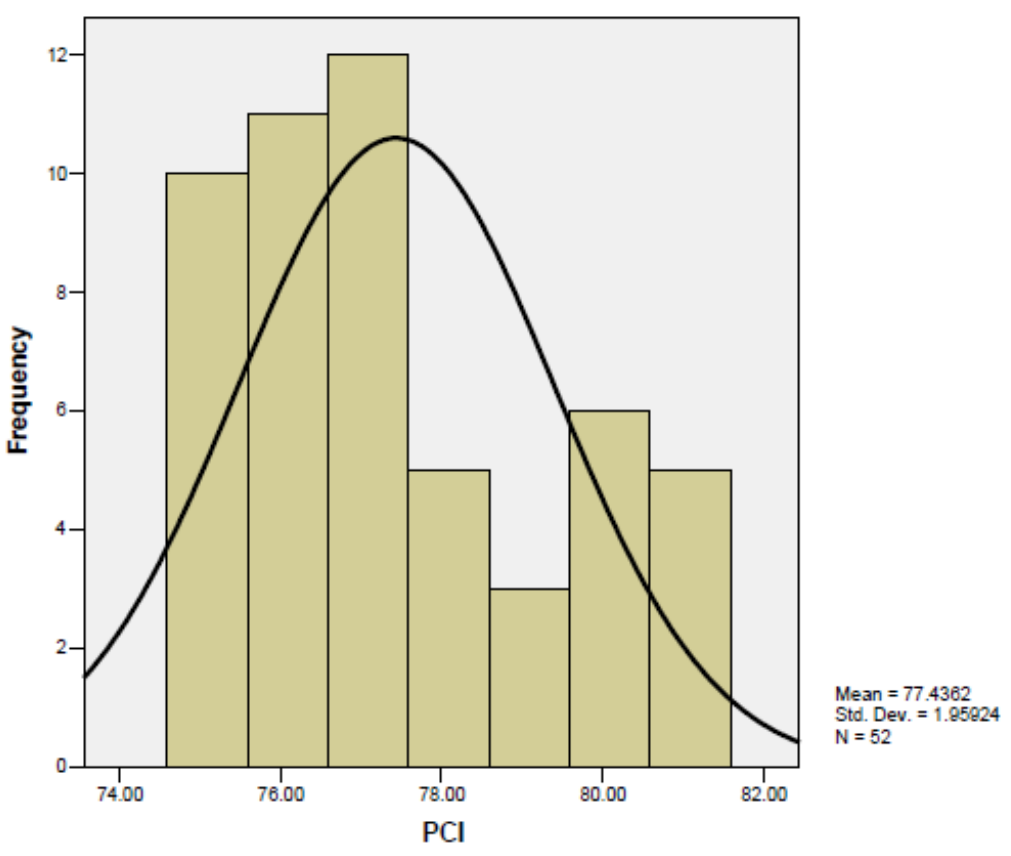

Class 1: PCI-AGE 6

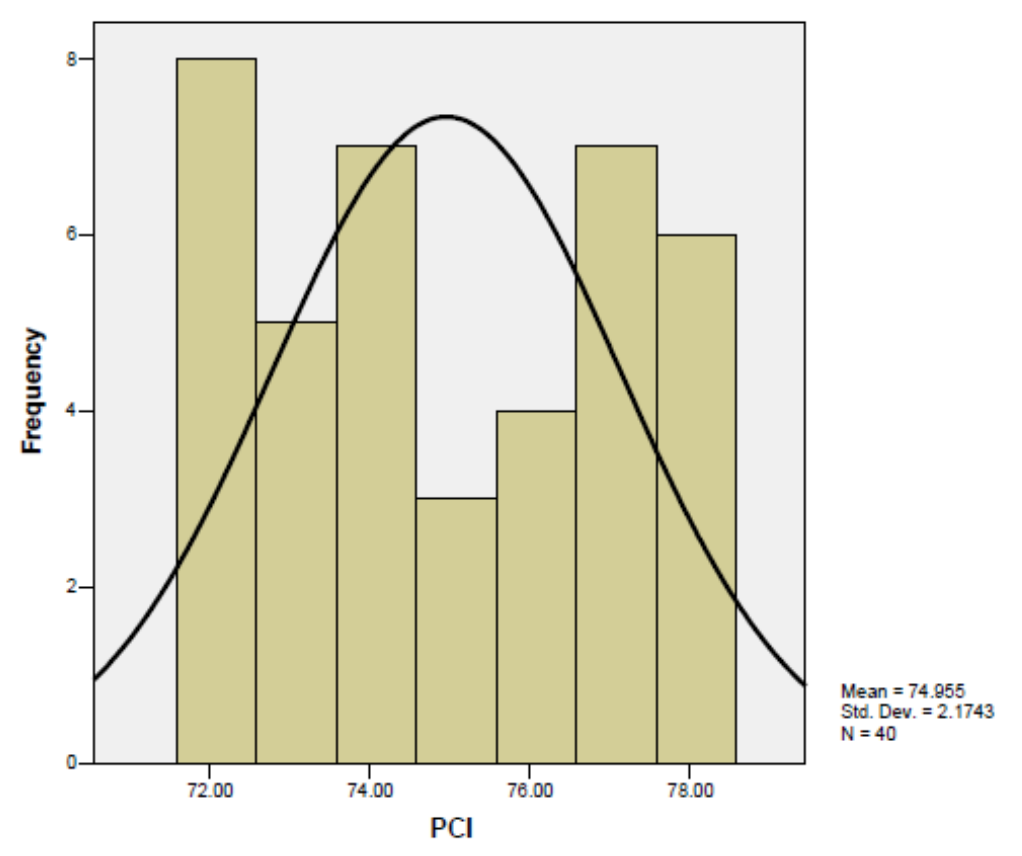




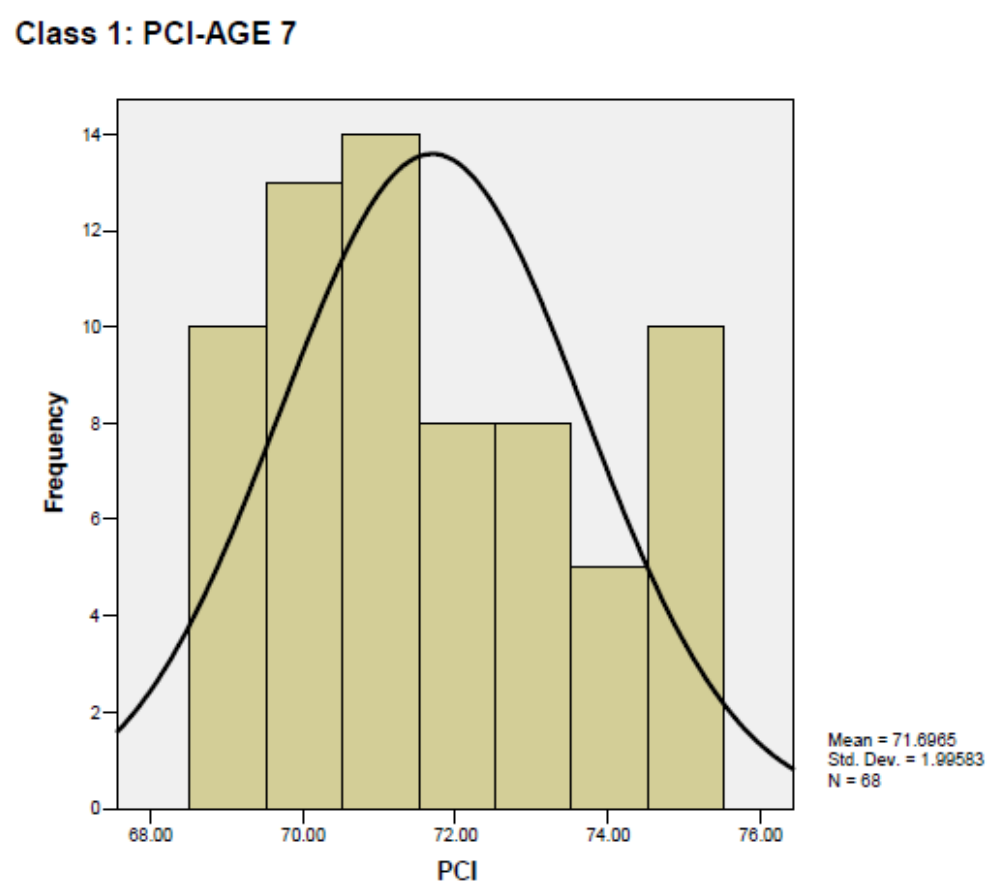

Class 1: PCI-AGE 8

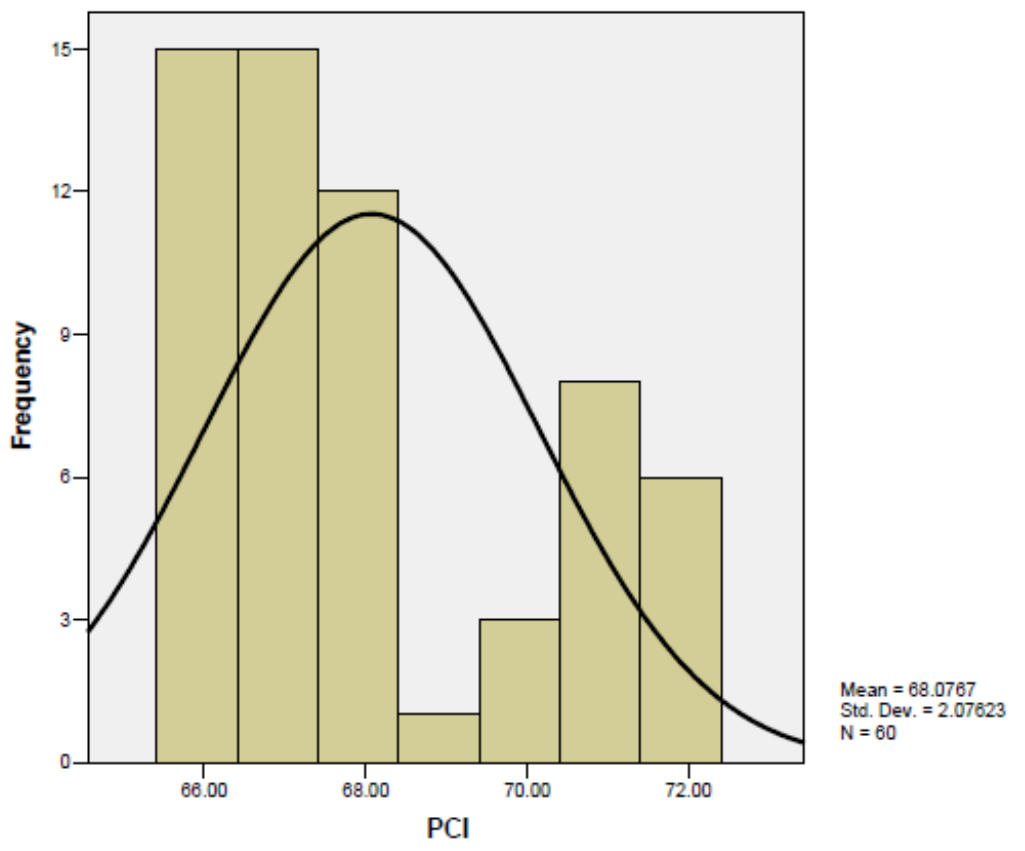


Class 1: PCI-AGE 9

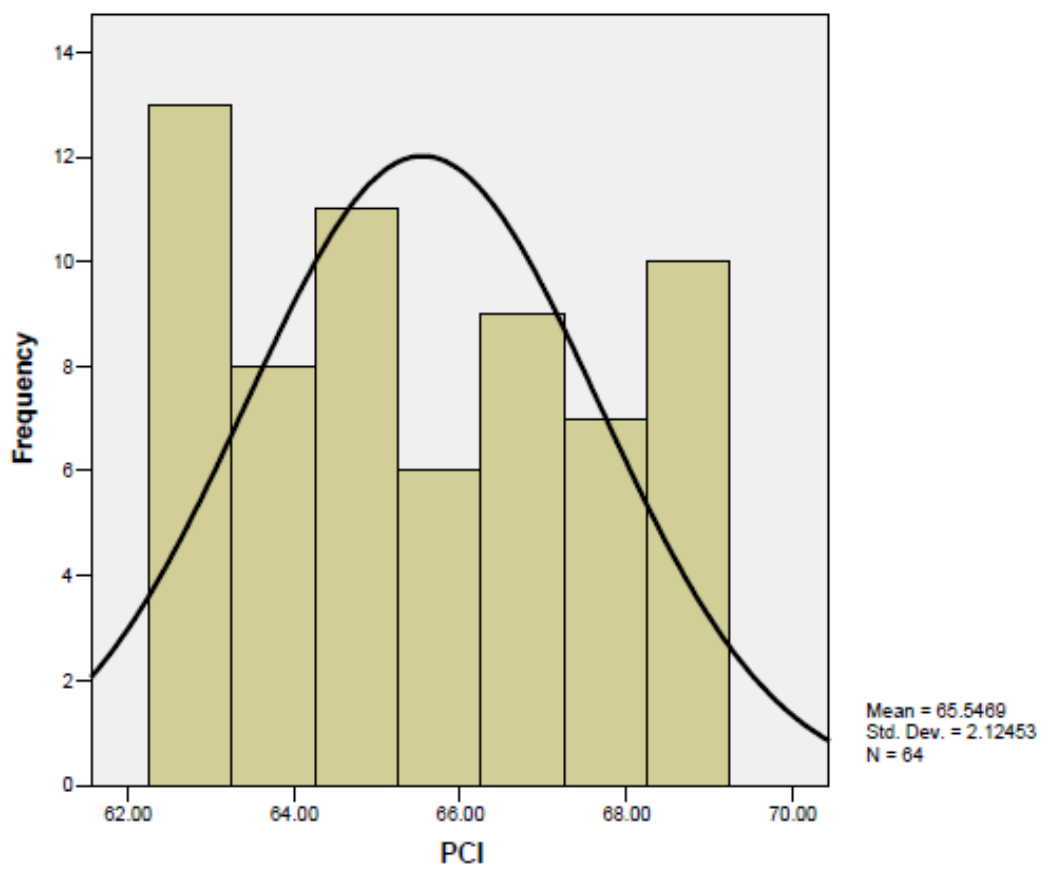

Class 1: PCI-AGE 10

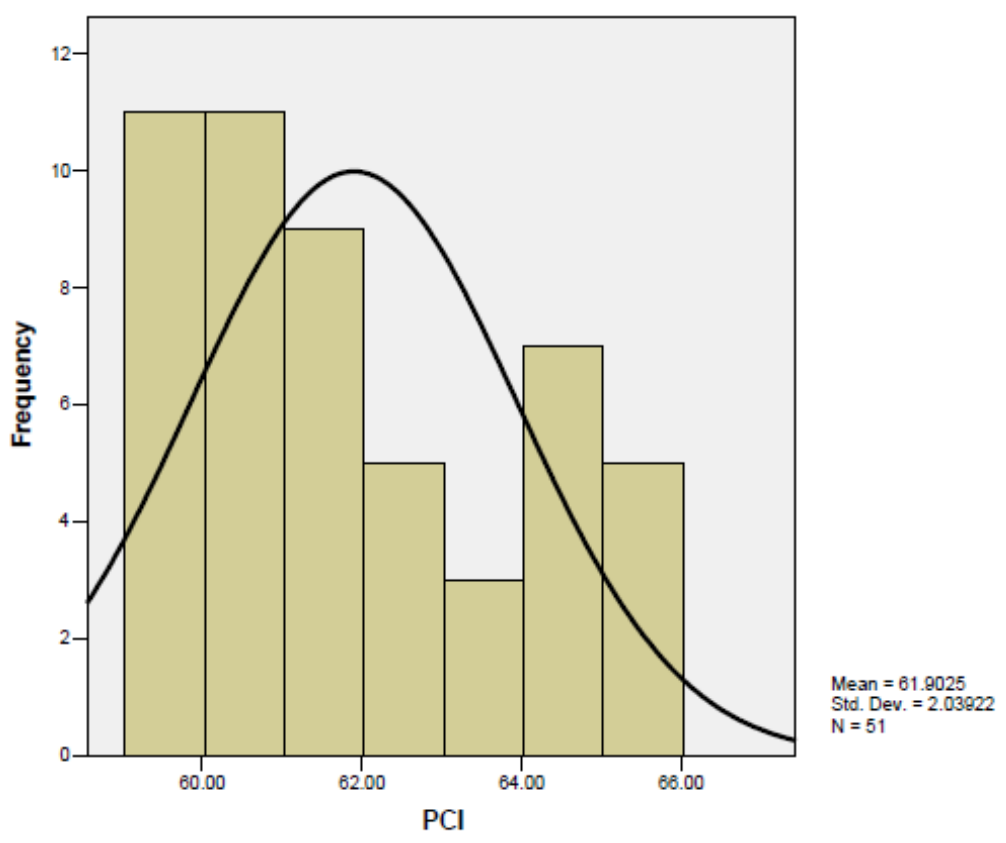


Appendix B : Code of the Optimization Model 
$\mathrm{MIN}=\mathrm{TMC}$;

IINPUT DATA FOR LENGTHS OF SECTIONS:

$\mathrm{LSI}=14$

LS2=20;

LS3=10:

IDISCOUNT RATE:

DSRATE $=0.03$;

IUNIT COST FOR TREATMENT /KM:

UCTR1 $=0$ :

UCTR2 $=500000$,

UCTR $3=1000000$ :

UCTR4 $=1500000$ :

TTREATMENT EFFECTS-PCI GAIN:

$\mathrm{PCIM1}=0$;

PCIM2 $=10$;

PCIM3 = 15:

PCIM4 $=20$;

IINPUT DATA FOR YEARS:

Y $0=0$ :

$\mathrm{Y} 1=1$ :

$\mathrm{Y} 2=2$ :

$\mathrm{Y} 3-3$ :

$\mathrm{Y} 4=4$ :

$\mathrm{Y} 5=5$ :

Y 6-6:

$\mathrm{Y} 7=7$;

$\mathrm{Y} 8=8$;

Y9 9:

$\mathrm{Y} 10=10$;

PCImin $=90$; 


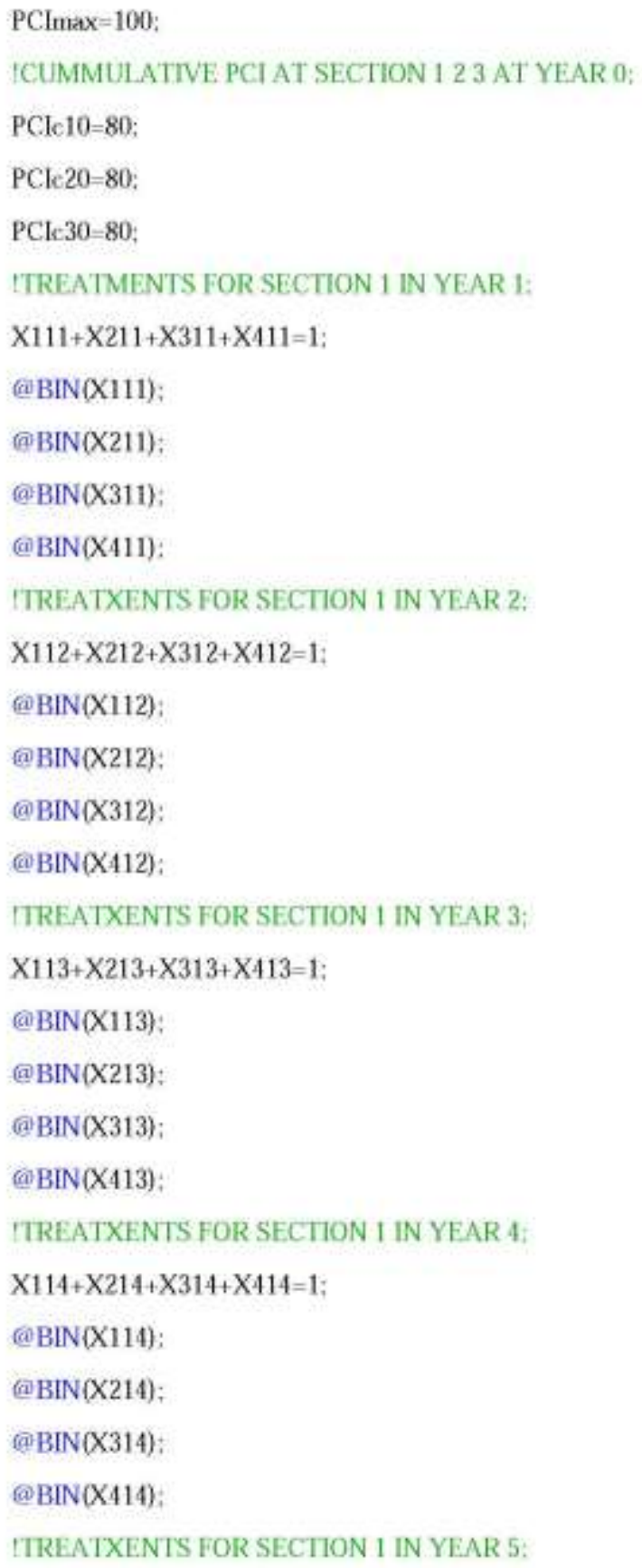




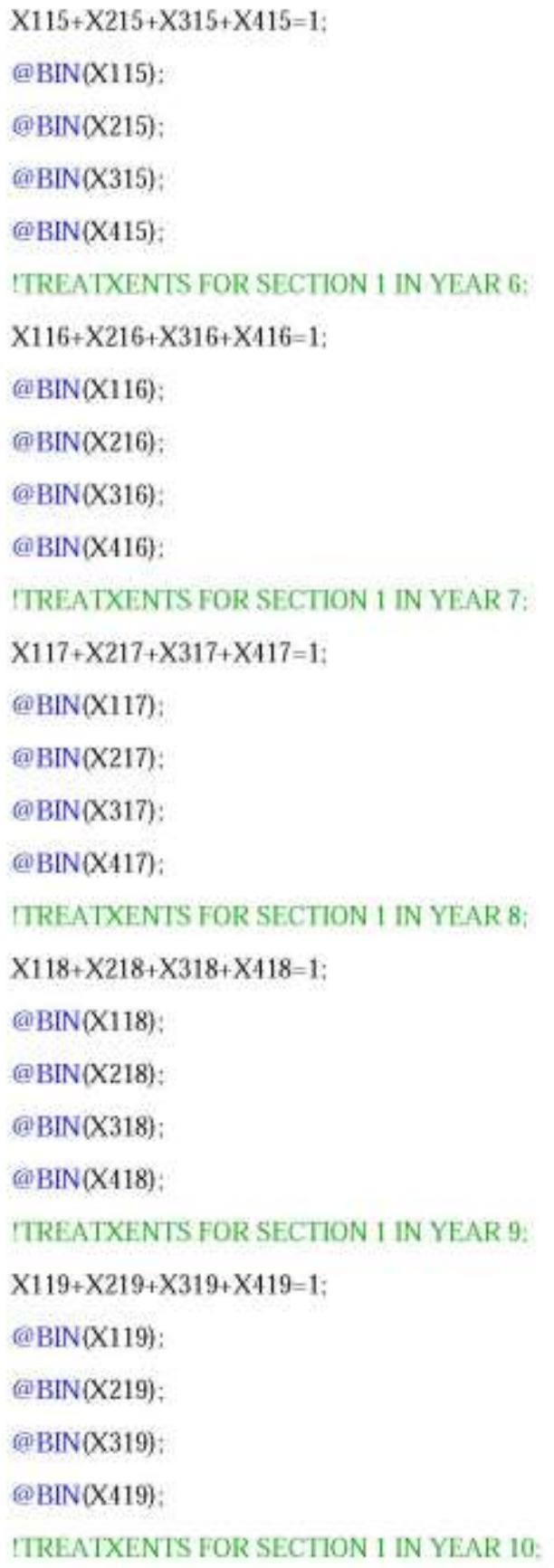




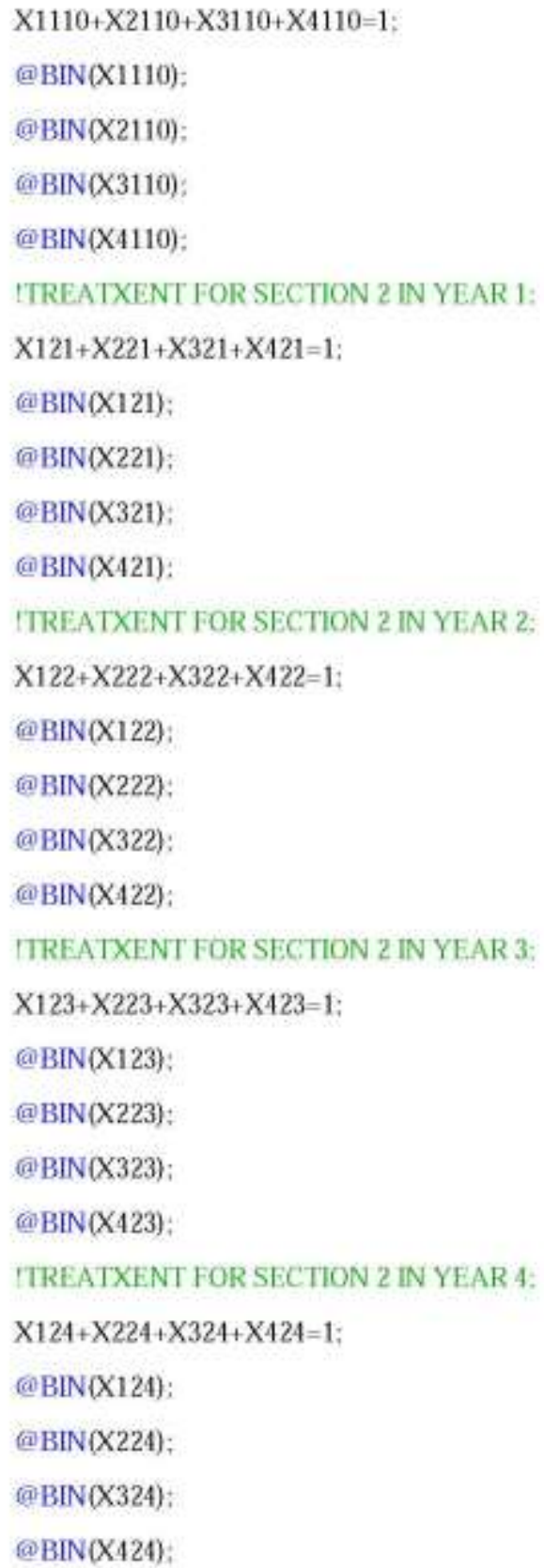




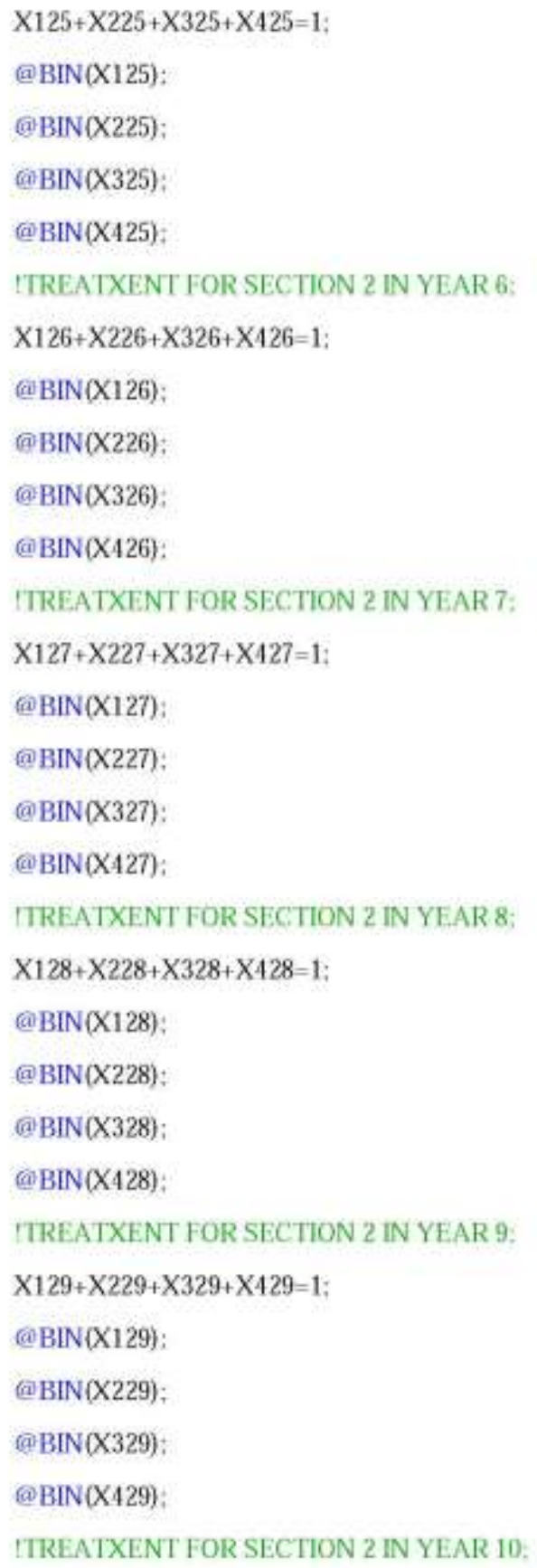




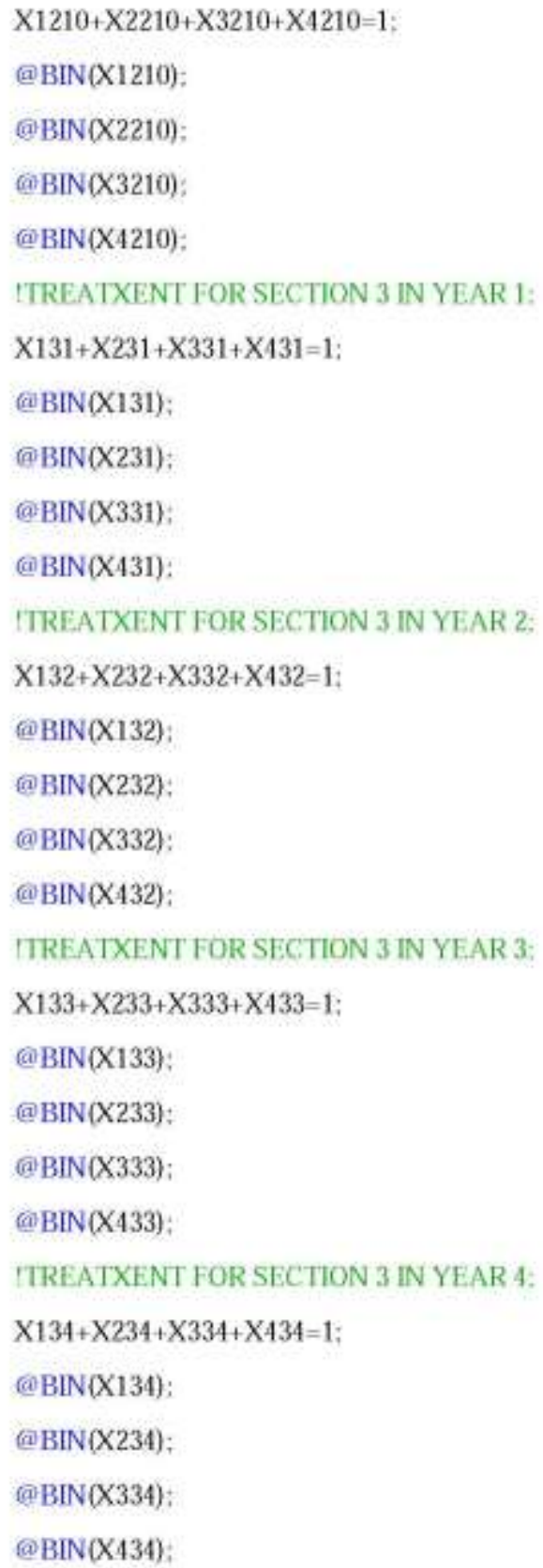




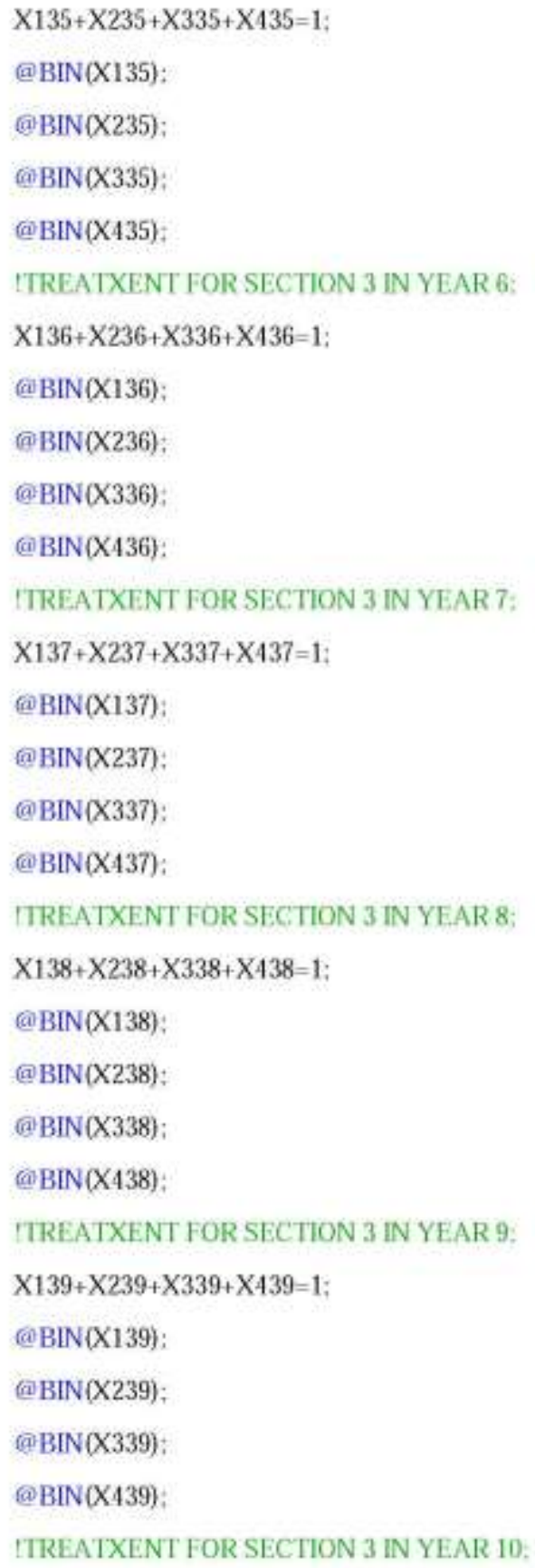




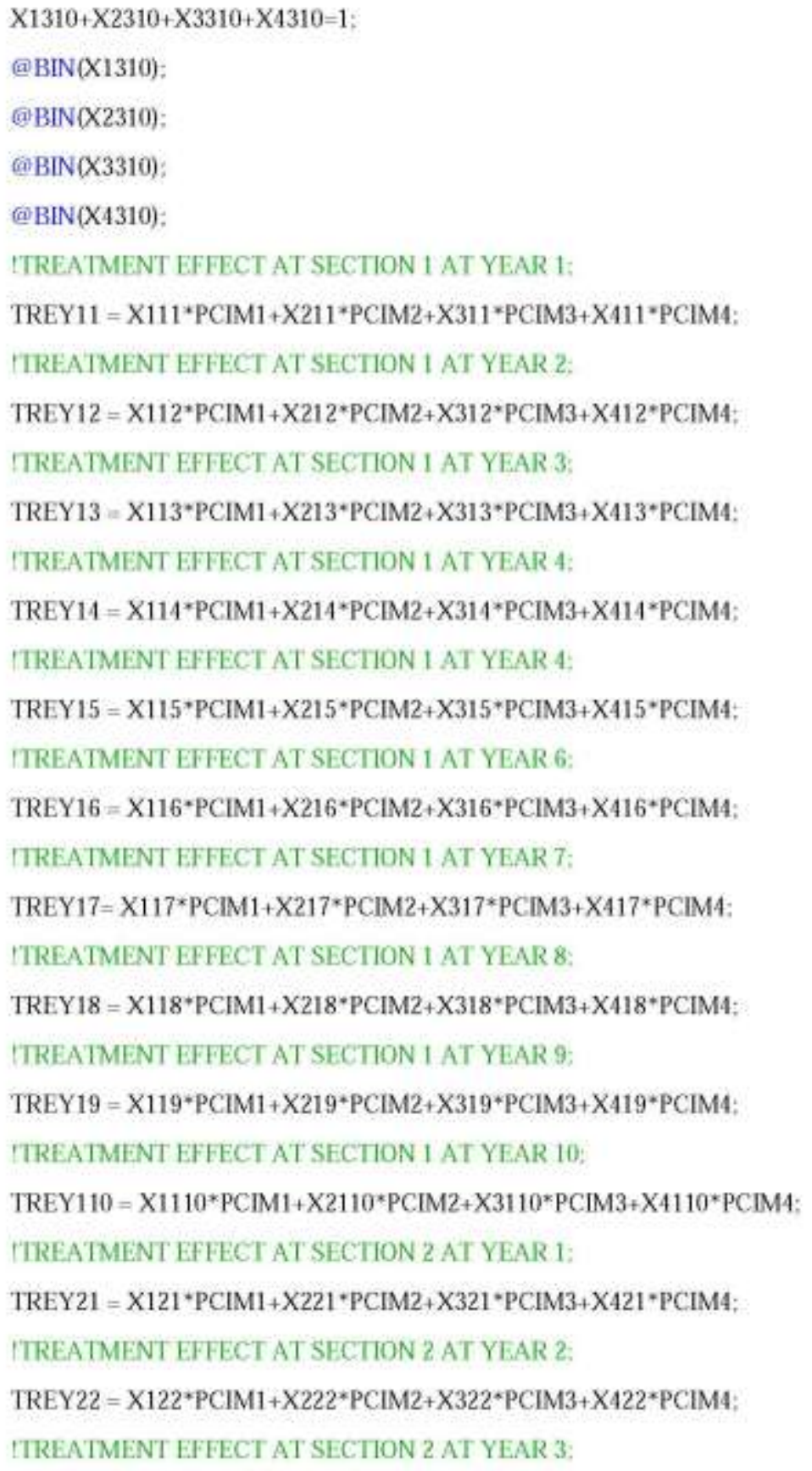


TREY23 = X123*PCIM1+X223*PCIM2+X323*PCIM3+X423*PCIM4; ITREATMENT EFFECT AT SECTION 2 AT YEAR 4:

TREY24 =X124*PCIM1+X224*PCIM2+X324*PCIM $3+\mathrm{X} 424 * \mathrm{PCIM} 4 ;$ ITREATMENT EFFECT AT SECTION 2 AT YEAR 4:

TREY25 = X125*PCIM1+X225*PCIM2+X325*PCIM3+X425*PCIM4: ITREATMENT EFFECT AT SECTION 2 AT YEAR 6; TREY $26=\mathrm{X} 126 * \mathrm{PCIM} 1+\mathrm{X} 226 * \mathrm{PCIM} 2+\mathrm{X} 326 * \mathrm{PCIM} 3+\mathrm{X} 426 * \mathrm{PCIM} 4:$ ITREATMENT EFFECT AT SECTION 2 AT YEAR 7 :

TREY $27=\mathrm{X} 127 * \mathrm{PCIM} 1+\mathrm{X} 227 * \mathrm{PCIM} 2+\mathrm{X} 327 * \mathrm{PCIM} 3+\mathrm{X} 427 * \mathrm{PCIM} 4$ TTREATMENT EFFECT AT SECTION 2 AT YEAR 8 ; TREY28 $=\mathrm{X} 128 * \mathrm{PCIM} 1+\mathrm{X} 228 * \mathrm{PCIM} 2+\mathrm{X} 328 * \mathrm{PCIM}+\mathrm{X} 428 * \mathrm{PCIM} 4$ ITREATMENT EFFECT AT SECTION 2 AT YEAR 9: TREY29 $=$ X129*PCIM1+X229*PCIM2+X329*PCIM3+X429*PCIM4 ITREATMENT EFFECT AT SECTION 2 AT YEAR $10:$

TREY210 $=\mathrm{X} 1210 * \mathrm{PCIM}+\mathrm{X} 2210 * \mathrm{PCIM} 2+\mathrm{X} 3210 * \mathrm{PCIM} 3+\mathrm{X} 4210 * \mathrm{PCIM} 4:$ ITREATMENT EFFECT AT SECTION 3 AT YEAR 1: TREY $31=\mathrm{X} 131 * \mathrm{PCIM} 1+\mathrm{X} 231 * \mathrm{PCIM}+\mathrm{X} 331 * \mathrm{PCIM} 3+\mathrm{X} 431 * \mathrm{PCIM} 4$ ITREATMENT EFFECT AT SECTION 3 AT YEAR 2: TREY $32=\mathrm{X} 132 * \mathrm{PCIM} 1+\mathrm{X} 232 * \mathrm{PCIM} 2+\mathrm{X} 332 * \mathrm{PCIM} 3+\mathrm{X} 432 * \mathrm{PCIM} 4:$ ITREATMENT EFFECT AT SECTION 3 AT YEAR 3: TREY33 = X133*PCIM1+X233*PCIM2+X333*PCIM3+X433*PCIM4: ITREATMENT EFFECT AT SECTION 3 AT YEAR 4: TREY34 $=$ X134*PCIM1+X234*PCIM2+X334*PCIM3+X434*PCIM4: ITREATMENT EFFECT AT SECTION 3 AT YEAR 4:

TREY $35=$ X135*PCIM1+X235*PCIM2+X335*PCIM3+X435*PCIM4; TTREATMENT EFFECT AT SECTION 3 AT YEAR 6: TREY $36=\mathrm{X} 136 * \mathrm{PCIM} 1+\mathrm{X} 236 * \mathrm{PCIM} 2+\mathrm{X} 336 * \mathrm{PCIM} 3+\mathrm{X} 436 * \mathrm{PCIM} 4$ ITREATMENT EFFECT AT SECTION 3 AT YEAR 7; TREY $37=\mathrm{X} 137 * \mathrm{PCIM} 1+\mathrm{X} 237 * \mathrm{PCIM} 2+\mathrm{X} 337 * \mathrm{PCIM} 3+\mathrm{X} 437 * \mathrm{PCIM} 4$ ITREATMENT EFFECT AT SECTION 3 AT YEAR 8: 
TREY $38=\mathrm{X} 138 * \mathrm{PCIM} 1+\mathrm{X} 238 * \mathrm{PCIM} 2+\mathrm{X} 338 * \mathrm{PCIM} 3+\mathrm{X} 438 * \mathrm{PCIM} 4$

ITREATMENT EFFECT AT SECTION 3 AT YEAR 9:

TREY39 = X139*PCIM1+X239*PCIM2+X339*PCIM $3+$ X439*PCIM4;

ITREATMENT EFFECT AT SECTION 3 AT YEAR 10:

TREY310 $=$ X1310*PCIM1+X2310*PCIM2+X3310*PCIM3+X4310*PCIM4:

ICOST FOR TREATEMENT FOR SECTION 1 AT YEAR 1:

CS1Y1 $1=L_{S 1}^{*}(1+D S R A T E)^{\wedge} Y 1^{*}\left(X 111^{*} U C T R 1+X 211^{*} U C T R 2+X 311^{*} U C T R 3+X 411^{* U C T R} 4\right):$

ICOST FOR TREATEMENT FOR SECTION 1 AT YEAR 2;

CS1Y2 LS1 $^{*}\left(1+\right.$ DSRATE$^{*} \mathrm{Y}^{*}\left(\mathrm{X} 112^{*} \mathrm{UCTR} 1+\mathrm{X} 212^{*} \mathrm{UCTR} 2+\mathrm{X} 312^{*} \mathrm{UCTR} 3+\mathrm{X} 412^{*} \mathrm{UCTR} 4\right)$; ICOST FOR TREATEMENT FOR SECTION 1 AT YEAR 3:

CSIY3 LS1*(1+DSRATE) Y $3^{*}\left(\mathrm{X} 113^{*} \mathrm{UCTR} 1+\mathrm{X} 213^{*} \mathrm{UCTR}^{2}+\mathrm{X} 313^{*} \mathrm{UCTR} 3+\mathrm{X} 413^{*} \mathrm{UCTR} 4\right)$ ICOST FOR TREATEMENT FOR SECTION 1 AT YEAR 4:

CS1Y4 $\mathrm{LS1}^{*}(1+\mathrm{DSRATE})^{\wedge} \mathrm{Y}^{*}\left(\mathrm{X} 114^{*} \mathrm{UCTR} 1+\mathrm{X} 214^{*} \mathrm{UCTR} 2+\mathrm{X} 314^{*} \mathrm{UCTR} 3+\mathrm{X} 414^{*} \mathrm{UCTR} 4\right)$ ICOST FOR TREATEMENT FOR SECTION 1 AT YEAR 5:

CS1Y5=IS1 * $(1+\text { DSRATE })^{\wedge} \mathrm{Y}^{*}\left(\mathrm{X} 115^{*} \mathrm{UCTR}^{+}+\mathrm{X} 215^{*} \mathrm{UCTR} 2+\mathrm{X} 315^{*} \mathrm{UCTR} 3+\mathrm{X} 415^{*} \mathrm{UCTR} 4\right)$ ICOST FOR TREATEMENT FOR SECTION 1 AT YEAR 6:

CS1Y6 $\mathrm{LS1}^{*}(1+\mathrm{DSRATE})^{\wedge} \mathrm{Y} 3^{*}\left(\mathrm{X} 116^{*} \mathrm{UCTR} 1+\mathrm{X} 216^{*} \mathrm{UCTR} 2+\mathrm{X} 316^{*} \mathrm{UCTR} 3+\mathrm{X} 416^{*} \mathrm{UCTR}^{-}\right)$: ICOST FOR TREATEMENT FOR SECTION 1 AT YEAR 7:

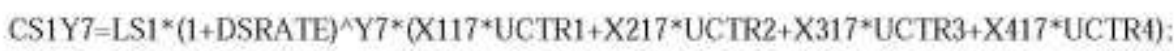
ICOST FOR TREATEMENT FOR SECTION 1 AT YEAR 8.

CSIY8=LS1*(1+DSRATE) Y8*(X118*UCTR1+X218*UCTR2+X318*UCTR3+X418*UCTR4): ICOST FOR TREATEMENT FOR SECTION 1 AT YEAR 9;

CS1Y9 LS1 $^{*}(1+\text { DSRATE })^{\wedge}$ Y $^{*}($ X119*UCTR1+X219*UCTR2+X319*UCTR3+X419*UCTR4): ICOST FOR TREATEMENT FOR SECTION 1 AT YEAR 10:

CS1Y10 $=\mathrm{LS}^{*}{ }^{*}(1+\mathrm{DSRATE})^{\wedge} \mathrm{Y} 3^{*}\left(X 1110^{*} \mathrm{UCTR} 1+\mathrm{X} 2110^{*} \mathrm{UCTR}^{*}+\mathrm{X} 3110^{*} \mathrm{UCTR}^{*}+\mathrm{X} 4110^{*} \mathrm{UCTR} 4\right)$; TTOTAL MAINTENANCE COST FOR SECTION 1:

TMCS1 $=$ CS1Y $1+\operatorname{CS} 1 Y 2+\operatorname{CS} 1 Y 3+\operatorname{CS} 1 Y 4+\operatorname{CS} 1 Y 5+\operatorname{CS} 1 Y 6+\mathrm{CS} 1 Y 7+\operatorname{CS} 1 Y 8+\mathrm{CS} 1 Y 9+\mathrm{CS} 1 \mathrm{Y} 10=$

ITOTAL MAINTENANCE COST FOR SECTION 2 :

$\mathrm{TMCS} 2=\operatorname{CS} 2 \mathrm{Y} 1+\operatorname{cS} 2 \mathrm{Y} 2+\operatorname{CS} 2 \mathrm{Y} 3+\operatorname{CS} 2 \mathrm{Y} 4+\operatorname{CS} 2 \mathrm{Y} 5+\operatorname{CS} 2 \mathrm{Y} 6+\operatorname{CS} 2 \mathrm{Y} 7+\operatorname{cS} 2 \mathrm{Y} 8+\operatorname{CS} 2 \mathrm{Y} 9+\operatorname{cS} 2 \mathrm{Y} 10$

ITOTAL MAINTENANCE COST FOR SECTION 3: 
$\mathrm{TMCS} 3=\operatorname{cs} 3 \mathrm{Y} 1+\operatorname{cs} 3 \mathrm{Y} 2+\operatorname{cs} 3 \mathrm{Y} 3+\operatorname{cs} 3 \mathrm{Y} 4+\operatorname{cs} 3 \mathrm{Y} 5+\operatorname{cs} 3 \mathrm{Y} 6+\operatorname{cs} 3 \mathrm{Y} 7+\operatorname{cs} 3 \mathrm{Y} 8+\operatorname{CS} 3 \mathrm{Y} 9+\operatorname{cs} 3 \mathrm{Y} 10=$

IOVERALI TOTAL MAINTENANCE COST:

$\mathrm{TMC}=\mathrm{TMCS} 1+\mathrm{TMCS} 2+\mathrm{TMCS} 3$ :

$1 \mathrm{~B}=1234 \mathrm{E} 24$ :

$\mathrm{TMC}<\mathrm{B}$;

ICOST FOR TREATEMENT FOR SECTION 2 AT YEAR 1:

CS2Y $1=\mathrm{LS}_{2}^{*}(1+\mathrm{DSRATE})^{\wedge} \mathrm{Y} 1^{*}\left(\mathrm{X} 121 * \mathrm{UCTR} 1+\mathrm{X} 221^{*} \mathrm{UCTR} 2+\mathrm{X} 321^{*} \mathrm{UCTR} 3+\mathrm{X} 421 * \mathrm{UCTR} 4\right)$ : ICOST FOR TREATEMENT FOR SECTION 2 AT YEAR 2;

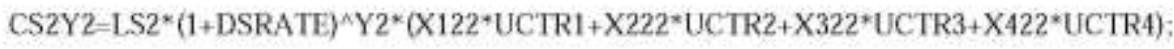
ICOST FOR TREATEMENT FOR SECTION 2 AT YEAR 3 ;

CS2Y3 LS2*(1+DSRATE $)^{\wedge} \mathrm{Y}^{*}\left(\mathrm{X} 123 * \mathrm{UCTR} 1+\mathrm{X} 223^{*} \mathrm{UCTR}^{2}+\mathrm{X} 323^{*} \mathrm{UCTR} 3+\mathrm{X} 423^{*} \mathrm{UCTR} 4\right)$ : ICOST FOR TREATEMENT FOR SECTION 2 AT YEAR 4:

CS2Y4=LS2* $(1+\text { DSRATE })^{\wedge} 4^{*}\left(X 124^{*} U C T R 1+X 224^{*}\right.$ UCTR2+X324*UCTR3+X424*UCTR4); ICOST FOR TREATEMENT FOR SECTION 2 AT YEAR 5 :

CS2Y5=LS2* $(1+\text { DSRATE })^{\wedge} \mathrm{Y}^{*}(\mathrm{X} 125 * \mathrm{UCTR}+\mathrm{X} 225 * \mathrm{UCTR} 2+\mathrm{X} 325 * \mathrm{UCTR} 3+\mathrm{X} 425 * \mathrm{UCTR} 4)$; ICOST FOR TREATEMENT FOR SECTION 2 AT YEAR 6:

CS2Y6 LS2*(1+DSRATE $)^{\wedge} \mathrm{Y}^{*}\left(\mathrm{X} 126^{*} \mathrm{UCTR} 1+\mathrm{X} 226^{*} \mathrm{UCTR} 2+\mathrm{X} 326^{*} \mathrm{UCTR} 3+\mathrm{X} 426^{*} \mathrm{UCTR} 4\right)$; ICOST FOR TREATEMENT FOR SECTION 2 AT YEAR 7:

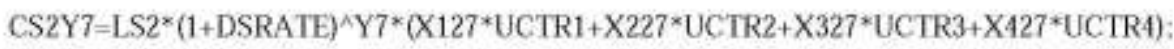
ICOST FOR TREATEMENT FOR SECTION 2 AT YEAR 8 ,

CS2Y8 LS2 $^{*}\left(1+\mathrm{DSRATE}^{\wedge} \mathrm{Y}^{*}\left(\mathrm{X} 128^{*} \mathrm{UCTR} 1+\mathrm{X} 228^{*} \mathrm{UCTR} 2+\mathrm{X} 328^{*} \mathrm{UCTR} 3+\mathrm{X} 428^{*} \mathrm{UCTR} 4\right)\right.$ : ICOST FOR TREATEMENT FOR SECTION 2 AT YEAR 9;

CS2Y9=LS2*(1+DSRATE $)^{\wedge} \mathrm{Y}^{*}\left(\mathrm{X} 129 * \mathrm{UCTR} 1+\mathrm{X} 229 * \mathrm{UCTR} 2+\mathrm{X} 329^{*} \mathrm{UCTR} 3+\mathrm{X} 429 *\right.$ UCTR4 $)$ : ICOST FOR TREATEMENT FOR SECTION 2 AT YEAR 10:

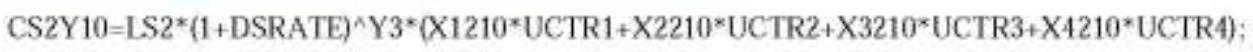
ICOST FOR TREATEMENT FOR SECTION 3 AT YEAR 1:

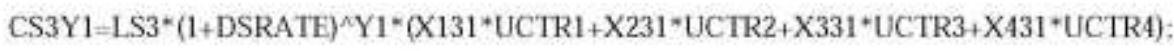
ICOST FOR TREATEMENT FOR SECTION 3 AT YEAR 2 :

CS3Y2 LS3*(1+DSRATE) ${ }^{\wedge} 2^{*}\left(\right.$ X $132 * U C T R 1+X 232^{*}$ UCTR $\left.2+X 332 * U C T R 3+X 432 * U C T R 4\right)$ ICOST FOR TREATEMENT FOR SECTION 3 AT YEAR 3 : 


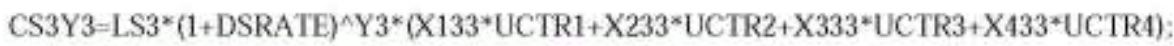
ICOST FOR TREATEMENT FOR SECTION 3 AT YEAR 4:

CS3Y4 LS3 $^{*}(1+\text { DSRATE })^{\wedge} 4^{*}\left(X 134^{*} U_{C T R} 1+X 234^{*} U_{C T R} 2+X 334^{*} U C T R 3+X 434^{*} U_{C T R} 4\right)$ ICOST FOR TREATEMENT FOR SECTION 3 AT YEAR 5 :

CS3Y5 LS3* $^{*}(1+\text { DSRATE })^{\wedge} \mathrm{Y}^{*}(\mathrm{X} 135 *$ UCTR1+X235*UCTR2+X335*UCTR3+X435*UCTR4): ICOST FOR TREATEMENT FOR SECTION 3 AT YEAR 6:

CS3Y $6=\mathrm{LS}^{*}(1+\mathrm{DSRATE})^{\wedge} \mathrm{Y}^{*}\left(\mathrm{X} 136^{*} \mathrm{UCTR} 1+\mathrm{X} 236^{*} \mathrm{UCTR} 2+\mathrm{X} 336^{*} \mathrm{UCTR} 3+\mathrm{X} 436 * \mathrm{UCTR} 4\right)$ : ICOST FOR TREATEMENT FOR SECTION 3 AT YEAR 7 ;

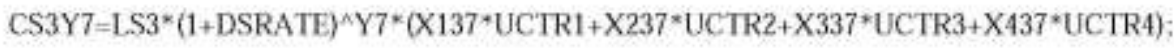
ICOST FOR TREATEMENT FOR SECTION 3 AT YEAR 8:

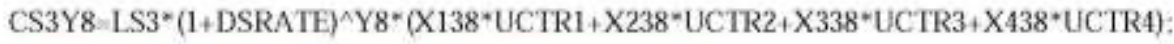
ICOST FOR TREATEMENT FOR SECTION 3 AT YEAR 9:

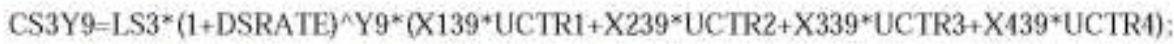
ICOST FOR TREATEMENT FOR SECTION 3 AT YEAR 10:

CS3Y10 $=\mathrm{LS}^{*}(1+\mathrm{DSRATE})^{\wedge} \mathrm{Y}^{*}\left(\mathrm{X} 1310^{*} \mathrm{UCTR} 1+\mathrm{X} 2310^{*} \mathrm{UCTR} 2+\mathrm{X} 3310^{*} \mathrm{UCTR} 3+\mathrm{X} 4310^{*} \mathrm{UCTR} 4\right) ;$ IPRIDICTED PCI AT SECTION 1 FOR YEARS 0 - 10:

PCI10-(0.053*Y0*2-4.89*Y0+89.3):

PCII $1=\left(0.053 * Y 11^{\wedge}-4.89^{*} \mathrm{Y} 1+89.3\right):$

$\mathrm{PCI12}=\left(0.053^{*} \mathrm{Y} 22^{*}-4.89 * \mathrm{Y} 2+89.3\right):$

PCI13 $=\left(0.053^{*} \mathrm{Y}^{*} 2-4.89 * \mathrm{Y} 3+89.3\right)$;

PCII $=\left(0.053^{*} \mathrm{Y}^{\wedge} 2-4.89^{*} \mathrm{Y} 4+89.3\right)$;

$\mathrm{PCI15}=\left(0.053^{*} \mathrm{Y} 55^{*}-4.89^{*} \mathrm{Y} 5+89.3\right)$;

PCI16 $=\left(0.053^{*} \mathrm{Y} 66^{\wedge} 2-4.89 * \mathrm{Y} 6+89.3\right)$;

PCII $7=\left(0.053^{*} \mathrm{Y}^{* 2} 2-4.89^{*} \mathrm{Y} 7+89.3\right)$ :

PCI18 $=\left(0.053^{*} \mathrm{Y}^{*} 2-4.89^{*} \mathrm{Y} 8+89.3\right)$;

PCI19=(0.053*Y9*2-4.89*Y9+89.3):

PC.1110 $=\left(0.053^{*} Y 10^{*} 2-4.89^{*} \mathrm{Y} 10+89.3\right)$;

ICUMMULATTVE PCI AT SECTION 1 AT YEAR1:

PCIc11=@ABS(PClc10-(PCI10-PCH1)+TREY11);

PCle11 s=PCImin: 


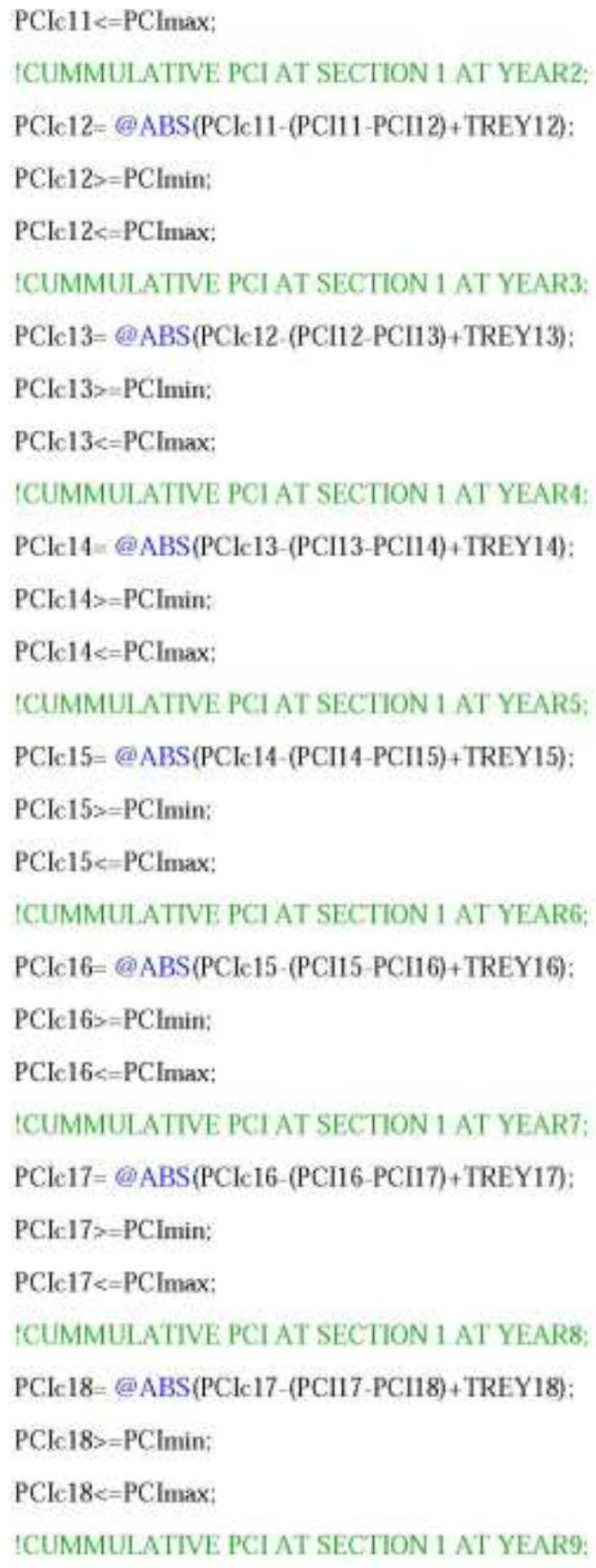




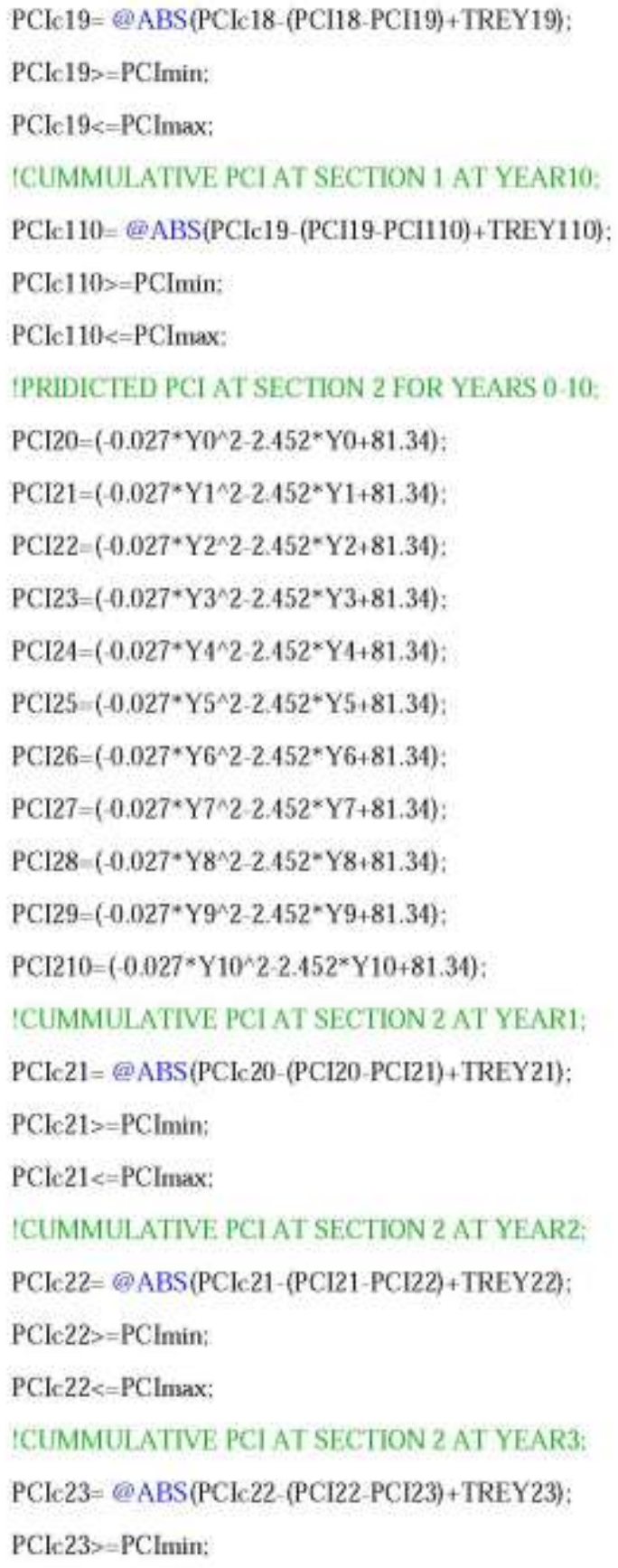


PCIc23<=PClmax;

ICUMMULATIVE PCI AT SECTION 2 AT YEAR4;

$\mathrm{PCI} 24=$ ABS(PCIc23-(PCI23-PCI24)+TREY24):

$\mathrm{PCl} 24>=\mathrm{PClmin}:$

PCle 24 <-PClmax;

ICUMMULATIVE PCI AT SECTION 2 AT YEAR5:

PCIc25= @ABS(PClc24-(PCI24-PCI25)+TREY25):

PClc25 $>$ PClmin;

PClc25<=PCImax:

ICUMMULATIVE PCI AT SECTION 2 AT YEAR6;

PClc26 - @ABS(PClc25-(PCI25-PCI26)+TREY26):

PCIc26>=PCImin;

PCle26 $<=$ PCImax;

LCUMMUIATIVE PCI AT SECTION 2 AT YEAR7:

$\mathrm{PCI} 27=@ \mathrm{ABS}(\mathrm{PCl} 26-(\mathrm{PCI} 26-\mathrm{PCI} 27)+\mathrm{TREY} 27)$

PCIc27 s=PCImin:

PCle27 $\Leftarrow$ PClmax;

ICUMMULATIVE PCT AT SECTION 2 AT YEAR8;

PCl.28=@ABS(PCle27-(PCI27-PCI28)+TREY28);

PCIc28 > =PClmin;

PCI $28<=$ PCImax:

ICUMMULATIVE PCI AT SECTION 2 AT YEAR9;

PClc29=@ABS(PCle28-(PCI28-PCI29)+TREY29)

PCk:29>=PCImin;

PCIc29 $<=$ PCImax:

ICUMMULATIVE PCI AT SECTION 2 AT YEAR10;

PCIc210=@ABS(PCIc29-(PCI29-PCI210)+TREY210);

PClc210 $>=$ PCImin:

PCIc210<=PCImax:

IPRIDICTED PCI AT SECTION 3 FOR YEARS 0-10: 


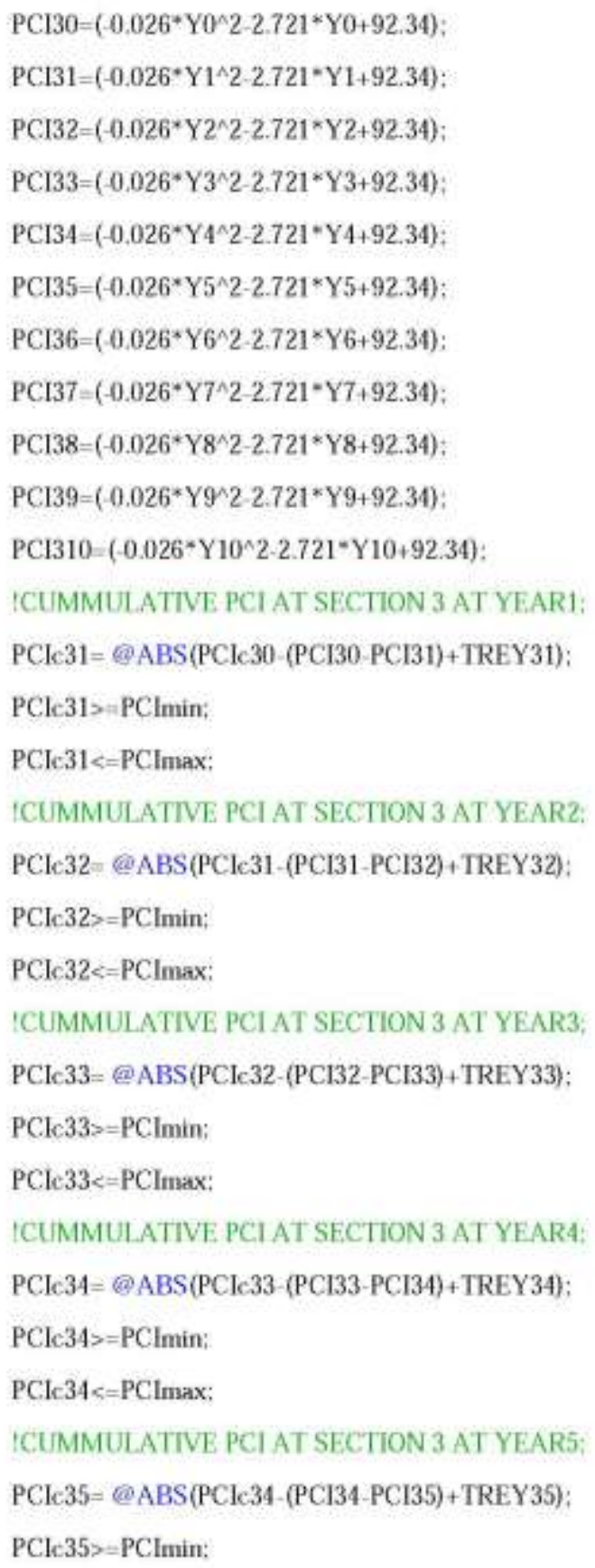


PCI $35<=$ PClmax;

ICUMMULATIVE PCI AT SECTION 3 AT YEAR6:

$\mathrm{PCI} 36=$ ABS(PCle35-(PCI35-PCI36) + TREY 36$)$;

PCle 36s $=$ PClmin:

PCle $36<=$ PClmax;

ICUMMULATIVE PCI AT SECTION 3 AT YEAR7:

$\mathrm{PCl} 37=$ ABS(PCle36-(PCI36-PCI37) $+\mathrm{TREY} 37)$ :

PClc 37 > PClmin;

PCI $37<=$ PCImax;

ICUMMULATIVE PCI AT SECTION 3 AT YEAR8;

PClc38:@ABS(PClc37-(PCI37-PCl38)+TREY38):

PCIc38 $>=$ PCImin;

PClc38<=PCImax;

ICUMMUIATTVE PCI AT SECTION 3 AT YEAR9:

PCIc39=@ABS(PCIc38-(PCI38-PCI39)+TREY39):

PCI 39>=PCImin:

PCle39<-PCImax;

ICUMMULATIVE PCI AT SECTION 3 AT YEAR10:

PCI $310=$ ABS $($ PClc 39-(PCI39-PCI310)+TREY310);

PCIc310s=-PClmin;

PCI $310<=$ PCImax:

END 